\title{
Clinical and therapeutic aspects of Cerebral Palsy
}

Citation for published version (APA):

Vles, G. (2012). Clinical and therapeutic aspects of Cerebral Palsy. [Doctoral Thesis, Maastricht University]. Datawyse / Universitaire Pers Maastricht. https://doi.org/10.26481/dis.20120622gv

Document status and date:

Published: 01/01/2012

DOI:

10.26481/dis.20120622gv

Document Version:

Publisher's PDF, also known as Version of record

\section{Please check the document version of this publication:}

- A submitted manuscript is the version of the article upon submission and before peer-review. There can be important differences between the submitted version and the official published version of record.

People interested in the research are advised to contact the author for the final version of the publication, or visit the DOI to the publisher's website.

- The final author version and the galley proof are versions of the publication after peer review.

- The final published version features the final layout of the paper including the volume, issue and page numbers.

Link to publication

\footnotetext{
General rights rights.

- You may freely distribute the URL identifying the publication in the public portal. please follow below link for the End User Agreement:

www.umlib.nl/taverne-license

Take down policy

If you believe that this document breaches copyright please contact us at:

repository@maastrichtuniversity.nl

providing details and we will investigate your claim.
}

Copyright and moral rights for the publications made accessible in the public portal are retained by the authors and/or other copyright owners and it is a condition of accessing publications that users recognise and abide by the legal requirements associated with these

- Users may download and print one copy of any publication from the public portal for the purpose of private study or research.

- You may not further distribute the material or use it for any profit-making activity or commercial gain

If the publication is distributed under the terms of Article $25 \mathrm{fa}$ of the Dutch Copyright Act, indicated by the "Taverne" license above, 


\section{Clinical and therapeutic aspects of Cerebral Palsy}


(c) Georges Vles, Maastricht 2012

The copyright of the articles that have been published or have been accepted for publication has been transferred to the respective journals.

ISBN 978-94-6159-144-9

Design: Georges Vles

Production: Datawyse | Universitaire Pers Maastricht 


\title{
Clinical and therapeutic aspects of Cerebral Palsy
}

\author{
PROEFSCHRIFT \\ ter verkrijging van de graad van doctor aan de Universiteit Maastricht, \\ op gezag van de Rector Magnificus Prof. Mr. G.P.M.F. Mols, \\ volgens het besluit van het College van Decanen in het openbaar te verdedigen \\ op vrijdag 22 juni 2012 om 10:00 uur \\ door \\ Georges Vles \\ Geboren in 1986 te Maastricht
}

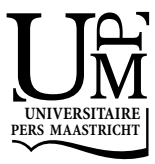




\section{Promotores}

Prof. dr. E.A.M. Beuls (Emeritus)

Prof. dr. R.J. van Oostenbrugge

\section{Copromotor}

Dr. J.G.M. Hendriksen

\section{Beoordelingscommissie}

Prof. dr. B.W. Kramer (Voorzitter)

Prof. dr. A.P. Aldenkamp

Prof. dr. E.U. Conrad (Seattle Children's Hospital, Seattle)

Prof. dr. A.J. Scherpbier

Prof. dr. L. Smit (V.U. Medisch Centrum, Amsterdam) 
To my parents 



\section{CONTENT}

Abbreviations

Chapter I General introduction 11

Chapter II Aim and outline of the thesis 27

Chapter III Psychosocial adjustment in a Dutch sample of children $\quad 31$ with Cerebral Palsy

European Journal of Paediatric Neurology. Accepted

Chapter IV Percutaneous radiofrequency lesions adjacent to the dorsal root ganglion alleviate spasticity and pain in children with Cerebral Palsy: pilot study in 17 patients BMC Neurology. 2010: 22; 10: 52

Chapter V Levetiracetam therapy for treatment of choreoathetosis in dyskinetic Cerebral Palsy Developmental Medicine \& Child Neurology. 2009; 51(6): 487-90

Chapter VI Visual Analogue Scale to score the effects of Botulinum Toxin A treatment in children with Cerebral Palsy in daily clinical practice European European Journal of Paediatric Neurology. 2008; 12(3): 231-8.

Chapter VII Constipation after Botulinum Toxin A injections in lower and upper limb muscles: a transitory systemic autonomic adverse effect Journal of Experimental and Clinical Medicine. 2009; 26: 47-51

Chapter VIII Long-term follow-up on intrathecal Baclofen therapy in children with intractable spastic Cerebral Palsy In preparation

Chapter IX Quality of Life of children with Cerebral Palsy: a crosssectional KIDSCREEN study in the Southern part of the Netherlands Submitted 
Chapter X General discussion and conclusion

English summary

127

Nederlandse samenvatting

137

Dankwoord

147

List of publications

151

Curriculum vitae 


\section{LIST OF ABBREVIATIONS}

\begin{tabular}{|c|c|}
\hline AOC & Angle Of Catch \\
\hline BBB & Blood Brain Barrier \\
\hline BMI & Body Mass Index \\
\hline BTX-A & Botulinum Toxin A \\
\hline BTX-B & Botulinum Toxin B \\
\hline CBCL & Child Behavior Checklist \\
\hline CFA & Confirmatory Factor Analysis \\
\hline CHQ & Child Health Questionnaire \\
\hline CITB & Continuous Intrathecal Baclofen \\
\hline CNS & Central Nervous System \\
\hline $\mathrm{CP}$ & Cerebral Palsy \\
\hline CS & Communication Skills \\
\hline $\mathrm{CT}$ & Computed Tomography \\
\hline DMD & Duchenne Muscular Dystrophy \\
\hline DTI & Diffusion Tensor Imaging \\
\hline EMG & Electromyography \\
\hline GABA & Gamma-Aminobutyric Acid \\
\hline GAS & Goal Attainment Scale \\
\hline GMFM & Gross Motor Function Measurement \\
\hline GMFCS & Gross Motor Function Classification System \\
\hline ICF & International Classification of Functioning, disability and health \\
\hline ITB & Intrathecal Baclofen \\
\hline IQ & Intellectual Quotient \\
\hline LAQ-CP & Lifestyle Assessment Questionnaire - CP \\
\hline LEV & Levetiracetam \\
\hline $\mathrm{LoH}$ & Level of Hand function \\
\hline MUMC & Maastricht University Medical Centre \\
\hline MAS & Modified Ashworth Scale \\
\hline MRI & Magnetic Resonance Imaging \\
\hline PARS-III & Psychosocial And Role Skill Scale - III \\
\hline PEDI & Pediatric Evaluation of Disability Inventory \\
\hline PPVT-III-NL & Peabody Picture Vocabulary Test - III - NL \\
\hline
\end{tabular}




$\begin{array}{ll}\text { PROM } & \text { Passive Range Of Motion } \\ \text { QoL } & \text { Quality of Life } \\ \text { RF-DRG } & \text { Radio Frequency lesion of the Dorsal Root Ganglion } \\ \text { ROC } & \text { Receiver Operating Characteristic } \\ \text { SCPE } & \text { Surveillance of Cerebral Palsy in Europe } \\ \text { SD } & \text { Standard Deviation } \\ \text { SDR } & \text { Selective Dorsal Rhizotomy } \\ \text { SDQ } & \text { Strengths and Difficulties Questionnaire } \\ \text { SEM } & \text { Standard Error of Means } \\ \text { SEV } & \text { Sociaal Emotionele Vragenlijst } \\ \text { SNAP-25 } & \text { Synaptosomal-Associated Protein - 25 } \\ \text { SPARCLE } & \text { Study of Participation of Children with Cerebral Palsy Living in } \\ & \text { Europe } \\ \text { SPASM } & \text { Support Programme for Assembly of a database for Spasticity } \\ \text { SV2A } & \text { Measurement } \\ \text { TS } & \text { Synaptic Vesicle glycoprotein 2A } \\ \text { UMN } & \text { Tardieu Scale } \\ \text { US } & \text { Upper Motor Neuron } \\ \text { VAS } & \text { Ultrasound } \\ \text { WHO } & \text { Visual Analogue Scale } \\ & \text { World Health Organization } \\ & \end{array}$


CHAPTER I

GENERAL INTRODUCTION 
CHAPTER I 


\section{CEREBRAL PALSY}

Cerebral palsy (CP) is defined as a static, but often changing disorder of movement and posture due to a defect or lesion to the developing fetal or infant brain. ${ }^{1}$ It is a major health problem as it affects 1 in 400 children making it the most common developmental disorder associated with lifelong disability. ${ }^{2}$ The disorder can result from various insults to different areas within the developing central nervous system (CNS), partially explaining the variety in its clinical presentation. ${ }^{3}$ Causes of $\mathrm{CP}$ differ to some degree according to their time of onset (in utero, during delivery, during the first two years of life) and their clinical subtype. Although CP can be caused by a single causative factor (e.g. intracranial bleeding, perinatal stroke, congenital malformations, intrauterine infection, extreme prematurity, traumatic brain injury), it is most often caused by the interaction of genetic values and multiple environmental stressors. ${ }^{4} \mathrm{~A}$ specific hypoxic event associated with immediate and irreversible cell death explains the etiology of CP in less than $50 \% .5,6$

Children usually present with slow motor development, abnormal muscle tone, muscle weakness, and disturbances in posture, although difficulties in swallowing and poor oromotor skills often precede these more noticeable abnormalities.7 Diagnosis is based on a complete history, thorough physical examination and additional investigations. ${ }^{3}$ Ultrasound (US), magnetic resonance imaging (MRI), computed tomography (CT), and diffusion tensor imaging (DTI) can be used to assess the extent of CNS damage as more than $80 \%$ of the children with $\mathrm{CP}$ have neuroimaging abnormalities, most often isolated whitematter damage. 8,9 The Surveillance of Cerebral Palsy in Europe (SCPE) has classified CP into three main groups: dyskinetic, ataxic, and spastic (table 1.1). ${ }^{10}$ The latter is the most common as $70-80 \%$ of the children with CP have spastic clinical features. ${ }^{11}$ The SCPE states that at least two of the following clinical signs have to be present in spastic CP: abnormal pattern of posture and/or movement, increased tone, and pathological reflexes. The spastic CP syndromes can be further classified according to their topographic distribution. In bilateral spastic $\mathrm{CP}$ both sides of the body are involved whereas in unilateral CP only one side of the body is involved. ${ }^{10}$ 
Table 1.1 Classifcation of CP subtypes according to the SCPE ${ }^{10}$

Spastic CP is characterized by at least two of the following:

- Abnormal pattern of posture and/or movement

- Increased tone (not necessarily constant)

- Pathological reflexes (increased reflexes: hyperreflexia and/or pyramidal signs e.g. Babinski response)

Spastic CP may be either bilateral or unilateral:

- Spastic bilateral CP: Limbs on both sides of the body are involved

- Spastic unilateral CP: Limbs on one side of the body are involved

Ataxic CP is characterized by both:

- Abnormal pattern of posture and/or movement

- Loss of orderly muscular coordination so that movements are performed with abnormal force, rhythm, and accuracy

Dyskinetic CP is dominated by both:

- Abnormal pattern of posture and/or movement

- Involuntary, uncontrolled, recurring, occasionally stereotyped movements

Dyskinetic CP may be either dystonic or choreo-athetotic:

- Dystonic CP is dominated by both: Hypokinesia (reduced activity, i.e. stiff movement) and hypertonia (tone usually increased)

- Choreo-athetotic CP is dominated by both: Hyperkinesia (increased activity, i.e. stormy movement) and hypotonia (tone usually decreased)

\section{SPASTICITY}

\section{Definition}

Before considering the definitions of spasticity the concept of the upper motor neuron (UMN) is discussed. An UMN is a neuron of any long descending tract that controls movement and muscle tone, i.e. the pyramidal and parapyramidal tracts. Damage to these tracts leads to a so called UMN syndrome, which can include both negative phenomena, like weakness, impaired fine-motor function, and difficulty in isolating individual movements and positive phenomena, like hyperreflexia, clonus, and spasticity.

The most often cited definition of spasticity is the one by Lance who defined spasticity in 1980 as a motor disorder characterized by a velocity dependent increase in the tonic stretch reflex (muscle tone) with exaggerated tendon jerks, resulting from hyper excitability of the stretch reflex, as one component of the upper motor neuron syndrome. ${ }^{12}$

However, in 2005 the Support Programme for Assembly of a database for Spasticity Measurement (SPASM) project came to the conclusion that the evidence generated since 1980 justified an update of the definition by Lance.13 Recent research suggests that spasticity is not a pure motor disorder and does 
not exclusively result from hyper excitability of the stretch reflex. Furthermore, the phenomenon of velocity dependence is not exclusive to stretch reflex hyper excitability. Therefore, the SPASM project proposed the following definition: a disordered sensori-motor control, resulting from an upper motor neuron lesion, presenting as intermittent of sustained involuntary activation of muscles.

However, several more definitions of spasticity are used and debate continues on which one is most correct. An important contributing factor to the lack of an universal and more precise definition of spasticity is the fact that its pathophysiology remains not fully elucidated.

\section{Etiology}

Again, an UMN is a neuron of any long descending tract that controls movement and muscle tone, i.e. the pyramidal and parapyramidal tracts. A lesion of the pyramidal tracts (the corticospinal tracts) results in clumsiness, modest weakness, some exaggeration of deep tendon reflexes, and a Babinksi sign, but does not result in spasticity. Lesions of the parapyramidal tracts however do result in spasticity. The parapyramidal tracts consist of the medial and dorsal reticulospinal, the rubrospinal, the vestibulospinal, and the tectospinal tracts. These descending pathways synapse upon interneural networks within the spinal cord that control spinal stretch, flexor, and extensor reflexes. Normally, the supraspinal inhibitory and excitatory inputs are balanced. However, in case of a lesion of these tracts a state of net disinhibtion of spinal reflexes develops, which can cause spasticity.

When studying the anatomy of the parapyramidal tracts, one very rapidly realizes that there are significant differences in localizations of these fiber tracts in the different atlases. ${ }^{14}$ This is mainly due to the fact that findings in animals (cats, macaques) were extrapolated to humans. Before the introduction of advanced MRI techniques, studying white matter anatomy was limited to the dissection of formalin-fixed parts of the CNS. Large fiber tracts, like the pyramidal tracts, are therefore well studied in man, but the smaller and not neatly organized tracts, like the parapyramidal tracts, are not. However, with the introduction of DTI the direction of white matter fibers can now be shown. Using this technique Mamata et al were able to provide us with a detailed map of these structures in man..$^{15}$ Studying small parapyramidal tract traumas in humans by means of DTI should provide further insight in the etiology of spasticity.

\section{Signs and symptoms}

Spasticity can cause pain, sleeping disorders, and increased energy requirements. ${ }^{16}$ Furthermore, ease of care is impeded as spasticity can interfere with positioning, transfers, dressing, and body hygiene. Additionally, spasticity can lead to contractures, subluxations, pressure sores, and heterotopic calcifica- 
tions. ${ }^{17}$ There is an implicit, but yet not fully established causal relationship between spasticity and activity limitations and participation restrictions. ${ }^{13,18}$

\section{MANAGEMENT OF SPASTICITY}

\section{Background}

Management of spasticity begins with the evaluation of the necessity to treat. This is done by a multidisciplinary management team, which includes the patient and the caregivers. There are two scenarios in which spasticity should not be treated. First, when there is no interference with function, comfort, or care. Second and perhaps seemingly illogical, when "useful spasticity" is adding function in stead of restricting it. However, when spasticity, along with other positive motor phenomena of the UMN syndrome, has a significant negative impact on the functioning of a child, it represents an important therapeutic target. Regardless of the selected management option, the goal is to optimize function, ease care giving, alleviate pain, and prevent secondary problems like contractures and subluxations. It is important to set realistic, attainable goals desired by both the child and his care-givers. At each stage of goal setting, treatment planning, and plan modification, it is necessary to obtain information not only about the clinical aspects of spasticity, but also about psychosocial factors, such as participation of the child in daily life, his coping strategies, and the stress handling capacity of his family. Only then will the chance of treating every unique case successfully be highest.

Common treatment options in the management of spasticity are orally administered drugs (Baclofen, Diazepam, Dantrolene, and Tizanidine), intramuscular chemodenervation agents (alcohol, phenol, and Botulinum Toxin A), intrathecally administered drugs (Baclofen), and neurosurgery (selective dorsal rhizotomy). ${ }^{3}$

\section{Orally administered drugs}

Several orally administered drugs with various mechanisms of action are available for the management of spasticity in children with CP, i.e. Diazepam, Baclofen, Dantrolene, and Tizanidine. Diazepam, a post-synaptic GABA-a receptor agonist, is considered the most useful oral anti-spasticity agent in CP. ${ }^{19,} 20$ It helps against muscle stiffness, flexor and extensor spasms, pain, and insomnia. Oral Baclofen, a pre-synaptic GABA-b receptor agonist, is more suited to treat spasticity related to spinal dysfunction and is therefore less useful in children with CP. ${ }^{21,} 22$ The evidence on the efficacy of these drugs remains scarce and weak, and adverse drug reactions (like drowsiness, sedation, and muscle weakness) are common. ${ }^{23-25}$ 


\section{Injectable chemodenervation agents}

Two strategies of injecting anti-spasticity agents are presently used, both causing temporary chemodenervation, i.e. the blockage of nerve-muscle transmission. Ethyl alcohol or phenol can be injected perineurally where they promote axonal degeneration. ${ }^{3,} 26$ Benefits can last for a few weeks up to over two years. $^{27-29}$ The main drawbacks of this method are the necessity to identify the nerve using electrical stimulating and the significant risk of permanent postprocedure pain or paresthesia. ${ }^{22}$ Botulinum toxine A and B (BTX-A and B) are injected intramuscularly. They disable the sensitive factor attachment protein25 (SNAP-25) and thereby prevent the release of acetycholine from the presynaptic vesicle at the neuromuscular junction. ${ }^{30}$ Clinical effects are usually observed after 2-5 days, last for 16-24 weeks, and are more noticeable in lower extremities than upper extremities. ${ }^{31-35}$ Although the functional improvements seen in randomized controlled trials are modest, this is most likely due to limitations of study design rather than by the effectiveness of the therapy itself. ${ }^{22} \mathrm{An}$ easily administrable outcome instrument capable of measuring change on domains of interest is still lacking. Furthermore, BTX-A therapy is not without risks. A recent and large study found that $6 \%$ of the children treated with BTX-A develop systemic adverse events, mainly respiratory complications and bowel and bladder incontinence. ${ }^{36}$

\section{Intrathecally administered drugs}

In case of intrathecal Baclofen (ITB) therapy a pump is implanted subcutaneously or subfacially in the abdomen which delivers Baclofen directly to the intrathecal space via a catheter. This has the large advantage of by-passing the blood-brain-barrier (BBB). Orally administered Baclofen passes the BBB poorly and results in high blood levels (hence side-effects) and almost undetectable cerebrospinal fluid levels of Baclofen (hence low treatment effects). ${ }^{37}$ In ITB, administration of a hundredth part of the dose of oral Baclofen is sufficient to relieve spasticity and therefore the side-effects seen when Baclofen is administered orally are prevented. ${ }^{38}$ Children with intractable lower extremity spasticity who show significant response to a test treatment are considered candidates. Nevertheless, criteria describing the ideal candidate are still lacking. ${ }^{39}$ Several large trials have shown that ITB is able to reduce spasticity. ${ }^{40-42}$ Furthermore, in a prospective, randomized controlled trial by the Dutch study group on spasticity functional benefits of ITB were shown. ${ }^{43-45}$ It was found that ITB reduces individually formulated problems, relieves pain, and improves ease of care and certain domains of health related quality of life. However, as recently stated by Miller, the follow-up on ITB treatment so far has been relatively short-term regarding that this is a treatment probably going to be continued for a 50-60 year period. ${ }^{46}$ It is not clear whether or not benefits of therapy are still present 
at the very long-term nor is the course over time. Also, the impact of accumulation of more and less severe complications, hospital visits, and hospitalizations on the enthusiasm of the caregivers for ITB treatment remains uncertain.

Furthermore, ITB caries a small but clinically significant risk of complications. Frequencies and severities of surgical complications, drug adverse events, and drug-delivery system-related complications vary significantly between studies. ${ }^{47}$ In general, ITB is generally considered a high risk/high gain treatment. ${ }^{48}$

\section{Neurosurgery}

Since its first description by Foerster in 1913, selective dorsal rhizotomy (SDR) has been modified by various surgeons and has become a standard neurosurgical procedure to treat spasticity in children with CP.49, 50 SDR is mainly performed at the lumbar level to reduce spasticity in patients with bilateral spasticy. A multilevel laminotomy/laminectomy exposes the dorsal roots (L2-S2) which are then separated into different rootlets. Those eliciting excessive EMG activity are incompletely transsected, hereby reducing the excitatory input to the spinal cord. SDR reduces spasticity and improves gait pattern, range of motion, and gross motor function. ${ }^{51}$ It must be noted that considerable cooperation of the patient is required to successfully complete the postoperative rehabilitation program. A recent review found a significant amount of spinal abnormalities and back-pain in children who have undergone SDR. ${ }^{52}$ However, the relationship between the two remains unclear.

In chronic pain medicine, a radiofrequency lesion of the dorsal root ganglion (RF-DRG) is considered an alternative to SDR. RF-DRG has been used to treat chronic pain for over 30 years. ${ }^{53}$ The RF-DRG is a simple and safe treatment option with little side-effects. ${ }^{54}$ In the 1980's several authors reported that the same procedure might be able to treat spasticity in adult patients. ${ }^{55,}{ }^{56}$ More recently, RF-DRG showed to alleviate hip flexor spasms in 2 children with CP. ${ }^{57}$ Further research with regard to the role of RF-DRG in the treatment of spasticity is required.

\section{EVALUATION OF SPASTICITY MANAGEMENT}

If you cannot measure it, you cannot control it. (John Grebe, 1990)

Evaluating interventions in children with $\mathrm{CP}$, poses somewhat of a challenge as many health-care disciplines are involved and effects can appear at physiological, functional, social, and / or behavioral levels. With regard to spasticity, we are not absolutely sure what we are dealing with, let alone how we should measure it. This is probably best illustrated by the plethora of scales developed 
to assess spasticity. A recent review found 37 clinical scales claiming to assess spasticity or spasticity associated functions. ${ }^{58}$ However, these scales have not been evaluated to a sufficient extent and for many scales reliability data is missing, especially concerning test-retest reliability. One can understand this to be a huge problem when using these scales as an outcome measure for spasticity management in children with CP.

In accordance with the currently often used WHO international classification of functioning, disability and health (ICF), the scales are classified into those assessing tone (ICF body functions and structure) and those assessing functioning (ICF activity and participation). Recently, a modified ICF model has been proposed which also incorporates quality of life (fig I.I). ${ }^{59}$ Quality of life of children with $\mathrm{CP}$ will be discussed later on.

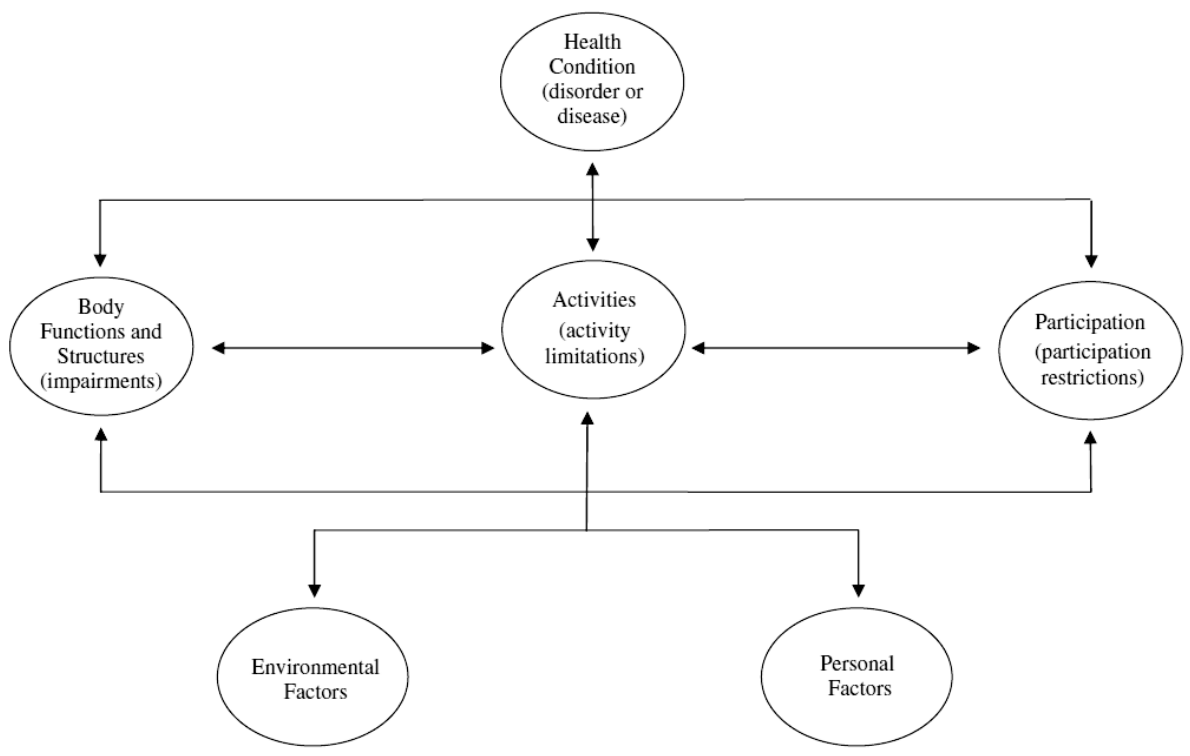

Figure 1.1 The WHO ICF including human development and QoL

\section{Assessment of tone}

The most often used scales concentrate on assessing tone, i.e. the Ashworth Scale, the Modified Ashworth Scale (MAS) and the Tardieu Scale (TS). The Ashworth Scale is a 5-point rating scale (0-4), which measures resistance to passive movement. Although the most commonly used, the methodological quality of the Ashworth Scale is doubtful. It does not measure spasticity exclusively, it has low interrater reliability, and it lacks precision and sensitivity for measuring smaller changes in spasticity.60-62 A recent study showed both the Ashworth Scale and the MAS to not be very reliable and therefore assessment of spasticity using these ordinal rating scales should be interpreted with great caution. ${ }^{63}$ The TS is 
a 6-point rating scale which describes the muscle reaction to passive stretch at different speeds. Recently, it has been shown to be more effective than the Ashworth scale in identifying the presence of spasticity, but again is not capable of measuring the severity of spasticity. ${ }^{64}$ Furthermore, it is a very time-consuming method and therefore its feasibility is questioned, especially when applied to children. ${ }^{62}$

\section{Assessment of functioning}

Several other scales focus on functioning after spasticity treatment. The ones most often used in children with CP are the Gross Motor Function Measurement (GMFM) and the Pediatric Evaluation of Disability Inventory (PEDI). The GMFM is widely accepted as the best available quantitative method. However, in infants with CP it was shown that spasticity is only marginally related to gross motor function development. 65 Especially in severely affected children the GMFM is of limited value. 66 The PEDI is a generic questionnaire which measures the functioning, health, and self care in chronically ill children with disabilities. It is administered through a structured interview with a parent. A recent review found the PEDI to be valid, reliable and responsive to change. ${ }^{67}$ The main drawback of the PEDI is that it takes over 45 minutes to complete, making it not very suitable in a busy outpatient clinic.

\section{Assessment of side-effects}

Besides evaluating the effect of treatment, the physician has to be aware of possible side-effects. These are not uncommon after routine treatments of spasticity as mentioned before.

\section{MORE THAN MOTOR PROBLEMS ALONE}

In addition to their motor problems, children with CP often have a spectrum of accompanying problems for which a multidisciplinary approach is needed. Epilepsy in children with CP is common (up to one third), has an early onset, and requires prolonged and intense pharmaceutical treatment. ${ }^{68}$ Recent studies have established the relationships between CP and impaired non-verbal intelligence, learning disabilities, impaired memory and language functioning, and disturbed executive functions. ${ }^{69}$ Feeding problems are widespread in children with CP; more than 1 out of 10 depends on gastrostomy tube feeding and around 40 percent has an abnormal body mass index (BMI). ${ }^{70}$ Orthopaedic problems are highly prevalent amongst children with CP. The most common deformity is the equinus, but hip deformities and spastic scoliosis are far from rare either. ${ }^{71}$ It is now recognized that 4 out of 10 children with $\mathrm{CP}$ have at least 
one clinically significant sleeping disorder. ${ }^{72}$ A recent Dutch study investigated sexuality in young adults with CP and found $80 \%$ to report physical problems with sex and $45 \%$ to report emotional inhibition to initiate sexual contact. ${ }^{73}$ There is increasing interest in the consequences of the combination of these accompanying problems and the previous discussed motor problems on the quality of life (QoL) of children with CP.

\section{QUALITY OF LIFE}

The WHO defines QoL as "an individual's perception of their position in life in the context of culture and value systems in which they live, and in relation to their goals, expectations, standards and concerns". ${ }^{74}$ Technically speaking QoL is not a definition; it is a concept, an invention of the human mind to construct a model of the world. As with all human inventions, it is not perfect and therefore QoL does not represent one single truth. Nevertheless, attempts should be made to capture and analyse this QoL in the best way possible as it may expose problem areas in chronically ill children and lead to treatment opportunities.

There are several instruments available to assess QoL of children with CP. Two well established and often used instruments are the Child Health Questionnaire (CHQ) and the KIDSCREEN. The CHQ is a generic QoL instrument which measures 14 unique physical and psychosocial concepts. ${ }^{75}$ All concepts are scored on a 0-100 scale with higher scores reflecting better QoL. Physical and psychosocial summary scores can be derived from the separate CHQ profile scores which have a mean of 50 and a standard deviation of 10 in the general population. The KIDSCREEN is a modern, generic QoL instrument, which uses questions based on focus-groups with children and adolescents held all over Europe. ${ }^{76-78}$ It focuses entirely on subjective perceptions, has shown to possess excellent psychometric properties, can be used for both disabled and nondisabled children, and can be reported by both the children themselves and their caregivers. ${ }^{76-79}$

Previous studies have assessed QoL of children with CP. Several smaller studies found contradicting results. ${ }^{80-83}$ The largest study so far (SPARCLE study, 7 European countries, KIDSCREEN-52) found that QoL of children with CP aged 8-12 years is, on average, similar to that of children in the general population on practically all domains. ${ }^{84}$ This study provided clues that children with $\mathrm{CP}$ might have a slightly better school environment, but experience lower autonomy. Specific factors were found to be associated with lower QoL in certain domains, e.g. pain is associated with less QoL in the physical and psychological well-being and self-perception domains. ${ }^{85}$ Greater limitations, on the other hand, lead to higher or lower QoL depending on the domain. However, impairment and pain can only explain a small amount of variance in QoL, which is therefore likely to be largely determined by social and environmental factors. 
Unfortunately social and environmental factors can differ significantly between countries and even regions and KIDSCREEN QoL results for Dutch children with $\mathrm{CP}$ are still lacking. 


\section{REFERENCES}

1. Bax MC. Terminology and Classification of Cerebral Palsy. Dev Med Child Neurol 1964. 6: p. 2957.

2. Bax MC, Flodmark 0, and Tydeman C. Definition and classification of cerebral palsy. From syndrome toward disease. Dev Med Child Neurol Suppl 2007. 109: p. 39-41.

3. Koman LA, Smith BP, and Shilt JS. Cerebral palsy. Lancet 2004. 363(9421): p. 1619-31.

4. Nelson KB. Causative factors in cerebral palsy. Clin Obstet Gynecol 2008. 51(4): p. 749-62.

5. Nelson KB and Grether JK. Causes of cerebral palsy. Curr Opin Pediatr 1999. 11(6): p. 487-91.

6. Nelson KB and Willoughby RE. Infection, inflammation and the risk of cerebral palsy. Curr Opin Neurol 2000. 13(2): p. 133-9.

7. Aisen ML, Kerkovich D, Mast J, et al. Cerebral palsy: clinical care and neurological rehabilitation. Lancet Neurol 2011. 10(9): p. 844-52.

8. Korzeniewski SJ, Birbeck G, DeLano MC, et al. A systematic review of neuroimaging for cerebral palsy. J Child Neurol 2008. 23(2): p. 216-27.

9. Prasad R, Verma N, Srivastava A, et al. Magnetic resonance imaging, risk factors and comorbidities in children with cerebral palsy. J Neurol 2011. 258(3): p. 471-8.

10. Surveillance of cerebral palsy in Europe: a collaboration of cerebral palsy surveys and registers. Surveillance of Cerebral Palsy in Europe (SCPE). Dev Med Child Neurol 2000. 42(12): p. 816-24.

11. Krigger KW. Cerebral palsy: an overview. Am Fam Physician 2006. 73(1): p. 91-100.

12. Lance JW. Disordered muscle tone and movement. Clin Exp Neurol 1981. 18: p. 27-35.

13. Pandyan AD, Gregoric M, Barnes MP, et al. Spasticity: clinical perceptions, neurological realities and meaningful measurement. Disabil Rehabil 2005. 27(1-2): p. 2-6.

14. Nathan PW, Smith M, and Deacon P. Vestibulospinal, reticulospinal and descending propriospinal nerve fibres in man. Brain 1996. 119 ( Pt 6): p. 1809-33.

15. Mamata H, Mamata Y, Westin CF, et al. High-resolution line scan diffusion tensor MR imaging of white matter fiber tract anatomy. AJNR Am J Neuroradiol 2002. 23(1): p. 67-75.

16. Hemingway C, McGrogan J, and Freeman JM. Energy requirements of spasticity. Dev Med Child Neurol 2001. 43(4): p. 277-8.

17. Flett PJ. Rehabilitation of spasticity and related problems in childhood cerebral palsy. J Paediatr Child Health 2003. 39(1): p. 6-14.

18. Young RR. Spasticity: a review. Neurology 1994. 44(11 Suppl 9): p. S12-20.

19. Papavasiliou AS. Management of motor problems in cerebral palsy: a critical update for the clinician. Eur J Paediatr Neurol 2009. 13(5): p. 387-96.

20. Mathew A, Mathew MC, Thomas M, et al. The efficacy of diazepam in enhancing motor function in children with spastic cerebral palsy. J Trop Pediatr 2005. 51(2): p. 109-13.

21. Scheinberg A, Hall K, Lam LT, et al. Oral baclofen in children with cerebral palsy: a double-blind cross-over pilot study. J Paediatr Child Health 2006. 42(11): p. 715-20.

22. Tilton A. Management of spasticity in children with cerebral palsy. Semin Pediatr Neurol 2009. 16(2): p. 82-9.

23. Krach LE. Pharmacotherapy of spasticity: oral medications and intrathecal baclofen. J Child Neurol 2001. 16(1): p. 31-6.

24. Montane E, Vallano A, and Laporte JR. Oral antispastic drugs in nonprogressive neurologic diseases: a systematic review. Neurology 2004. 63(8): p. 1357-63.

25. Verrotti A, Greco R, Spalice A, et al. Pharmacotherapy of spasticity in children with cerebral palsy. Pediatr Neurol 2006. 34(1): p. 1-6.

26. Chung CY, Chen CL, and Wong AM. Pharmacotherapy of spasticity in children with cerebral palsy. J Formos Med Assoc 2011. 110(4): p. 215-22.

27. Spira R. Management of spasticity in cerebral palsied children by peripheral nerve block with phenol. Dev Med Child Neurol 1971. 13(2): p. 164-73.

28. Tardieu G, Tardieu C, Hariga J, et al. Treatment of spasticity in injection of dilute alcohol at the motor point or by epidural route. Clinical extension of an experiment on the decerebrate cat. Dev Med Child Neurol 1968. 10(5): p. 555-68. 
29. Yadav SL, Singh U, Dureja GP, et al. Phenol block in the management of spastic cerebral palsy. Indian J Pediatr 1994. 61(3): p. 249-55.

30. Dolly JO and Aoki KR. The structure and mode of action of different botulinum toxins. Eur J Neurol 2006. 13 Suppl 4: p. 1-9.

31. Fehlings D, Rang M, Glazier J, et al. An evaluation of botulinum-A toxin injections to improve upper extremity function in children with hemiplegic cerebral palsy. J Pediatr 2000. 137(3): p. 331-7.

32. Fehlings D, Rang M, Glazier J, et al. Botulinum toxin type A injections in the spastic upper extremity of children with hemiplegia: child characteristics that predict a positive outcome. Eur J Neurol 2001. 8 Suppl 5: p. 145-9.

33. Love SC, Valentine JP, Blair EM, et al. The effect of botulinum toxin type A on the functional ability of the child with spastic hemiplegia a randomized controlled trial. Eur J Neurol 2001. 8 Suppl 5: p. 50-8.

34. Steenbeek D, Meester-Delver A, Becher JG, et al. The effect of botulinum toxin type A treatment of the lower extremity on the level of functional abilities in children with cerebral palsy: evaluation with goal attainment scaling. Clin Rehabil 2005. 19(3): p. 274-82.

35. Ubhi T, Bhakta BB, Ives HL, et al. Randomised double blind placebo controlled trial of the effect of botulinum toxin on walking in cerebral palsy. Arch Dis Child 2000. 83(6): p. 481-7.

36. Naidu K, Smith K, Sheedy M, et al. Systemic adverse events following botulinum toxin A therapy in children with cerebral palsy. Dev Med Child Neurol 2010. 52(2): p. 139-44.

37. Leisen C, Langguth P, Herbert B, et al. Lipophilicities of baclofen ester prodrugs correlate with affinities to the ATP-dependent efflux pump P-glycoprotein: relevance for their permeation across the blood-brain barrier? Pharm Res 2003. 20(5): p. 772-8.

38. Kroin JS. Intrathecal drug administration. Present use and future trends. Clin Pharmacokinet 1992. 22(5): p. 319-26.

39. Murphy NA, Irwin MC, and Hoff C. Intrathecal baclofen therapy in children with cerebral palsy: efficacy and complications. Arch Phys Med Rehabil 2002. 83(12): p. 1721-5.

40. Awaad Y, Tayem H, Munoz S, et al. Functional assessment following intrathecal baclofen therapy in children with spastic cerebral palsy. J Child Neurol 2003. 18(1): p. 26-34.

41. Morton RE, Gray N, and Vloeberghs M. Controlled study of the effects of continuous intrathecal baclofen infusion in non-ambulant children with cerebral palsy. Dev Med Child Neurol 2011. 53(8): p. 736-41.

42. Van Schaeybroeck P, Nuttin B, Lagae L, et al. Intrathecal baclofen for intractable cerebral spasticity: a prospective placebo-controlled, double-blind study. Neurosurgery 2000. 46(3): p. 603-9; discussion 609-12.

43. Hoving MA, van Raak EP, Spincemaille GH, et al. Efficacy of intrathecal baclofen therapy in children with intractable spastic cerebral palsy: a randomised controlled trial. Eur J Paediatr Neurol 2009. 13(3): p. 240-6.

44. Hoving MA, van Raak EP, Spincemaille GH, et al. Safety and one-year efficacy of intrathecal baclofen therapy in children with intractable spastic cerebral palsy. Eur J Paediatr Neurol 2009. 13(3): p. 247-56.

45. Hoving MA, van Raak EP, Spincemaille GH, et al. Intrathecal baclofen in children with spastic cerebral palsy: a double-blind, randomized, placebo-controlled, dose-finding study. Dev Med Child Neurol 2007. 49(9): p. 654-9.

46. Miller F. The effects of continuous intrathecal baclofen infusion in non-ambulant children with cerebral palsy. Dev Med Child Neurol 2011. 53(8): p. 679-80.

47. Kolaski $\mathrm{K}$ and Logan LR. A review of the complications of intrathecal baclofen in patients with cerebral palsy. NeuroRehabilitation 2007. 22(5): p. 383-95.

48. Coffey RJ, Edgar TS, Francisco GE, et al. Abrupt withdrawal from intrathecal baclofen: recognition and management of a potentially life-threatening syndrome. Arch Phys Med Rehabil 2002. 83(6): p. 735-41.

49. Farmer JP and Sabbagh AJ. Selective dorsal rhizotomies in the treatment of spasticity related to cerebral palsy. Childs Nerv Syst 2007. 23(9): p. 991-1002. 
50. Langerak NG, Lamberts RP, Fieggen AG, et al. A prospective gait analysis study in patients with diplegic cerebral palsy 20 years after selective dorsal rhizotomy. J Neurosurg Pediatr 2008. 1(3): p. 180-6.

51. Steinbok P. Outcomes after selective dorsal rhizotomy for spastic cerebral palsy. Childs Nerv Syst 2001. 17(1-2): p. 1-18.

52. Grunt S, Becher JG, and Vermeulen RJ. Long-term outcome and adverse effects of selective dorsal rhizotomy in children with cerebral palsy: a systematic review. Dev Med Child Neurol 2011. 53(6): p. 490-8.

53. Uematsu S, Udvarhelyi GB, Benson DW, et al. Percutaneous radiofrequency rhizotomy. Surg Neurol 1974. 2(5): p. 319-25.

54. van Kleef M. Radiofrequency lesions of the dorsal root ganglion in the treatment of spinal pain, ed. Maastricht. 1996, Maastricht: Maastricht University.

55. Herz DA, Parsons KC, and Pearl L. Percutaneous radiofrequency foramenal rhizotomies. Spine (Phila Pa 1976) 1983. 8(7): p. 729-32.

56. Kasdon DL and Lathi ES. A prospective study of radiofrequency rhizotomy in the treatment of posttraumatic spasticity. Neurosurgery 1984. 15(4): p. 526-9.

57. Vles J, van Kleef M, Sleypen F, et al. Radiofrequency lesions of the dorsal root ganglion in the treatment of hip flexor spasm: a report of two cases. Eur J Paediatr Neurol 1997. 1(4): p. 123-6.

58. Platz T, Eickhof C, Nuyens G, et al. Clinical scales for the assessment of spasticity, associated phenomena, and function: a systematic review of the literature. Disabil Rehabil 2005. 27(1-2): p. 7-18.

59. McDougall J, Wright $V$, and Rosenbaum P. The ICF model of functioning and disability: incorporating quality of life and human development. Dev Neurorehabil 2010. 13(3): p. 204-11.

60. Biering-Sorensen F, Nielsen JB, and Klinge K. Spasticity-assessment: a review. Spinal Cord 2006. 44(12): p. 708-22.

61. Damiano DL, Quinlivan JM, Owen BF, et al. What does the Ashworth scale really measure and are instrumented measures more valid and precise? Dev Med Child Neurol 2002. 44(2): p. 112-8.

62. Scholtes VA, Becher JG, Beelen A, et al. Clinical assessment of spasticity in children with cerebral palsy: a critical review of available instruments. Dev Med Child Neurol 2006. 48(1): p. 64-73.

63. Mutlu A, Livanelioglu A, and Gunel MK. Reliability of Ashworth and Modified Ashworth scales in children with spastic cerebral palsy. BMC Musculoskelet Disord 2008. 9: p. 44.

64. Alhusaini AA, Dean CM, Crosbie J, et al. Evaluation of spasticity in children with cerebral palsy using Ashworth and Tardieu Scales compared with laboratory measures. J Child Neurol 2010. 25(10): p. 1242-7.

65. Gorter JW, Verschuren 0 , van Riel L, et al. The relationship between spasticity in young children (18 months of age) with cerebral palsy and their gross motor function development. BMC Musculoskelet Disord 2009. 10: p. 108.

66. Mall V, Heinen F, Kirschner J, et al. Evaluation of botulinum toxin A therapy in children with adductor spasm by gross motor function measure. J Child Neurol 2000. 15(4): p. 214-7.

67. Debuse D and Brace H. Outcome measures of activity for children with cerebral palsy: a systematic review. Pediatr Phys Ther 2011. 23(3): p. 221-31.

68. Gururaj AK, Sztriha L, Bener A, et al. Epilepsy in children with cerebral palsy. Seizure 2003. 12(2): p. 110-4.

69. Pirila S, van der Meere JJ, Rantanen K, et al. Executive functions in youth with spastic cerebral palsy. J Child Neurol 2011. 26(7): p. 817-21.

70. Dahlseng MO, Finbraten AK, Juliusson PB, et al. Feeding problems, growth and nutritional status in children with cerebral palsy. Acta Paediatr 2011.

71. Jozwiak M, Harasymczuk P, Koch A, et al. Incidence and risk factors of hip joint pain in children with severe cerebral palsy. Disabil Rehabil 2011.33(15-16): p. 1367-72.

72. Newman CJ, O'Regan M, and Hensey O. Sleep disorders in children with cerebral palsy. Dev Med Child Neurol 2006. 48(7): p. 564-8.

73. Wiegerink D, Roebroeck M, Bender J, et al. Sexuality of Young Adults with Cerebral Palsy: Experienced Limitations and Needs. Sex Disabil 2011. 29(2): p. 119-128. 


\section{CHAPTER I}

74. The World Health Organization Quality of Life assessment (WHOQOL): position paper from the World Health Organization. Soc Sci Med 1995. 41(10): p. 1403-9.

75. Landgraf J, Abetz L, and Ware J. The CHQ user's manual, ed. T.H. institute. 1996, Boston: New England Medical Center.

76. Detmar SB, Bruil J, Ravens-Sieberer U, et al. The use of focus groups in the development of the KIDSCREEN HRQL questionnaire. Qual Life Res 2006. 15(8): p. 1345-53.

77. KIDSCREEN GROUP EUROPE. The KIDSCREEN questionnaires. Quality of life questionnaires for children and adolescents - handbook, ed. Lengerich. 2006: Pabst Science Publisher.

78. Ravens-Sieberer U, Gosch A, Rajmil L, et al. KIDSCREEN-52 quality-of-life measure for children and adolescents. Expert Rev Pharmacoecon Outcomes Res 2005. 5(3): p. 353-64.

79. Robitail S, Simeoni MC, Ravens-Sieberer U, et al. Children proxies' quality-of-life agreement depended on the country using the European KIDSCREEN-52 questionnaire. J Clin Epidemiol 2007. 60(5): p. 469-78.

80. Varni JW, Burwinkle TM, Sherman SA, et al. Health-related quality of life of children and adolescents with cerebral palsy: hearing the voices of the children. Dev Med Child Neurol 2005. 47(9): p. 592-7.

81. Vargus-Adams J. Health-related quality of life in childhood cerebral palsy. Arch Phys Med Rehabil 2005. 86(5): p. 940-5.

82. Kennes J, Rosenbaum P, Hanna SE, et al. Health status of school-aged children with cerebral palsy: information from a population-based sample. Dev Med Child Neurol 2002. 44(4): p. 240 7.

83. Liptak GS, O'Donnell M, Conaway M, et al. Health status of children with moderate to severe cerebral palsy. Dev Med Child Neurol 2001. 43(6): p. 364-70.

84. Dickinson HO, Parkinson KN, Ravens-Sieberer U, et al. Self-reported quality of life of 8-12-yearold children with cerebral palsy: a cross-sectional European study. Lancet 2007. 369(9580): p. 2171-8.

85. Arnaud C, White-Koning M, Michelsen SI, et al. Parent-reported quality of life of children with cerebral palsy in Europe. Pediatrics 2008. 121(1): p. 54-64. 
CHAPTER II

AIM AND OUTLINE OF THE THESIS 
CHAPTER II 


\section{AIM AND OUTLINE OF THE THESIS}

In the general introduction a brief overview of clinical and therapeutic aspects of CP has been provided. Furthermore, gaps, concerns, and controversies in current knowledge were highlighted. The aim of this thesis was to address and study some of these issues in the population of approximately 100 children with $\mathrm{CP}$ who are seen at the outpatient clinic of the Maastricht University Medical Centre (MUMC).

As a first step of this thesis the basic characteristics of these children were collected, which was followed by a study to see how these children cope with their often severe disabilities and limitations. Therefore, in chapter II1 the psychosocial adjustment of the Dutch sample of children with CP is described.

Chapter IV and $V$ concentrate on the management of spasticity in CP. In chapter $I V$ the effects of a percutaneous radiofrequency lesion adjacent to the dorsal root ganglion on spasticity and pain is investigated as it was hypothesized that this could serve as an alternative to the conventional SDR. The results of a pilot study in 17 children with CP are described. In chapter $V$ two cases of dyskinetic $\mathrm{CP}$ are reported on in which an anti-convulsant drug (Levetiracetam) led to an impressive improvement of balance control and fine motor skills.

Chapter VI to VIII focus on the evaluation of spasticity management. In chapter VI the usefulness of a simple visual analogue scale to evaluate the effects of BTX-A treatment on spasticity is demonstrated. In chapter VII three cases of a never before reported side-effect of BTX-A treatment are described. Chapter VIII reports on the long-term follow-up on the beneficial effects of ITB treatment in children with intractable spastic CP.

In chapter IX the QoL of children with CP living in the Southern part of the Netherlands is described, as the Netherlands did not participate in the SPARCLE study. 



\section{CHAPTER III}

\section{PSYCHOSOCIAL ADJUSTMENT IN A DUTCH SAMPLE OF CHILDREN WITH CEREBRAL PALSY}

Vles GF, Hendriksen RGF, Vles JSH, Kessels AG, Hendriksen JGM

Accepted for publication in the European Journal of Paediatric Neurology 


\section{ABSTRACT}

\section{Background}

Over the last couple of years, there has been increasing interest for QoL of children with CP. Psychosocial adjustment in these children remains underrepresented in current literature.

\section{Aims}

To describe psychosocial adjustment in children with CP by means of the Psychosocial Adjustment and Role Skills Scale - III (PARS-III), to describe the psychometric properties of this questionnaire, to identify a cut-off score for psychosocial maladjustment, and to investigate the relationship between patient characteristics (i.e. predictive factors) and psychosocial adjustment.

\section{Methods}

The parents of 93 children with CP (59 boys, 34 girls; mean age 12.3 years, SD 3.8, 4-18; GMFCS 1: 28, 2: 5, 3: 19, 4: 18, 5: 23) completed the PARS-III and the Child Behavior Checklist (CBCL) concerning the psychosocial and behavioral functioning of their child.

\section{Results}

Cronbachs alpha-coefficient for the PARS-III was 0.89 indicating good internal consistency. High correlation with the CBCL was found. Confirmatory factor analysis confirmed the 6 domain structure of the PARS-III. Overall, children with $\mathrm{CP}$ achieved lower psychosocial adjustment scores compared to healthy children. A cut-off score (1 SD below the mean) of 78 was found. When predicting psychosocial maladjustment in children with $\mathrm{CP}$, less gross motor function, hand function, communication skills, and bilateral involvement of CP are the most important factors, but these can only explain $36 \%$ of variation in psychosocial adjustment.

\section{Conclusion}

Using the by-proxy version of the PARS-III it was found that children with CP are reported to achieve lower psychosocial adjustment scores than healthy children. 


\section{INTRODUCTION}

Over the last couple of years, there has been increasing interest for health outcomes in children with cerebral palsy (CP). ${ }^{1}$ More and more, treatments are evaluated in terms of health, Quality of Life (QoL) and health related QoL. The World Health Organization (WHO) defines QoL as "an individual's perception of their position in life in the context of culture and value systems in which they live, and in relation to their goals, expectations, standards and concerns". ${ }^{2}$ Extensive research concerning QoL of children with $\mathrm{CP}$ has been done. The largest study so far (SPARCLE study, 7 European countries, KIDSCREEN-52) found that QoL of children with CP aged 8-12 years is, on average, similar to that of children in the general population on practically all domains. ${ }^{3}$

Another important concept is psychosocial adjustment, defined as the adaptive task of coping with upsetting feelings and frustrations aroused by the illness. ${ }^{4}$ Contrary to QoL, psychosocial adjustment remains underrepresented in current literature. Although strongly related, psychosocial adjustment and QoL are distinct entities, which will hopefully be illustrated by the following example. Children with CP frequently have hip deformities which may cause pain. ${ }^{5}$ The way of coping with this pain is different for every child. Some children with little hip deformity will become very anxious when they have to put weight on their hip joint and will therefore not participate in playing outdoors, while others with severe hip deformity will ignore the pain, play outside and establish new friendships (the so called "disability paradox"). ${ }^{6}$ Hence, psychosocial adjustment determines whether and to what extent pain influences QoL. It is the result of a complex process in which children attempt to meet the demands of their illness with their emotional/social resources and coping strategies. In other words, better coping strategies will lead to higher QoL. Thus, in order to understand a child's QoL and to eventually be able to improve it, one must understand why and when children will apply appropriate psychosocial adjustment.

The main problem in this research area is that there are few standardized instruments specifically developed for these children with a chronic illness. Using the Child Behavior Checklist (CBCL) Sigurdardottir et al found a prevalence of 40 to $50 \%$ of substantial behavioural or emotional difficulties in preschool children with CP. ${ }^{7}$ However, the primary aim of the CBCL is to identify and diagnose psychopathological behaviour. ${ }^{8}$ It does not take into account the stress and emotional reactions part of normal adjustment to a chronic illness. ${ }^{9,10}$ As such, the CBCL is prone to over identify pathological behaviour. Using the Strengths and Difficulties Questionnaire (SDQ) Parkes et al found that over a quarter of children with CP aged 8-12 years experience significant psychological problems, mainly peer problems, hyperactivity, and emotional problems. ${ }^{11}$ The major drawback of the SDQ is that it measures general behaviour problems without special consideration of illness-related factors. ${ }^{12}$ As the CBCL, it may over identify pathological behaviour. 
A questionnaire specifically developed to measure psychosocial adjustment in children with a chronic illness is the Psychosocial Adjustment and Role Skills Scale - III (PARS-III). ${ }^{13}$ Its main strength is that it includes domains important to the psychosocial adjustment of children with a chronic illness and leaves out items based on physical symptoms like pain, fatigue, and headaches. ${ }^{14}$

Recently, Hendriksen et al found the PARS-III to be a reliable and valid index of psychosocial adjustment in boys with Duchenne Muscular Dystrophy (DMD), a fatal, X-linked, muscle disorder, which affects approximately 1 in 3,500 children, almost all boys. ${ }^{15}$ On the basis of this result the current study was conducted with the following aims. The first aim is to describe psychosocial adjustment in a Dutch sample of children with CP using the PARS-III questionnaire and to describe its psychometric properties. Secondly, in order to provide a first step towards identifying psychosocial adjustment profiles in different patient populations, a brief comparison to boys with DMD will be made. Thirdly, a clinical useful cut-off score for psychosocial maladjustment in children with CP will be identified. Finally, the relationship between patient charateristics (i.e. predictive factors) and psychosocial adjustment will be investigated.

\section{METHODS}

\section{Design}

This cross-sectional study was approved by the Medical Ethics Committee (MEC) of the Maastricht University Medical Centre (MUMC) according to Dutch governmental guidelines.

The parents of all 94 children with CP (aged 4-18 years) seen at the outpatient clinic of the MUMC were informed about the study and asked to participate. All except one agreed and were sent the PARS-III and the CBCL questionnaires.

Data concerning the psychosocial adjustment of 63 Dutch boys with DMD and 95 healthy children were collected at an earlier stage. ${ }^{15}$

\section{Measures}

Psychosocial Adjustment and Role Skills Scale - III

The PARS-III was specifically developed to measure psychosocial adjustment in children (aged 5 to 18 years) with a variety of chronic physical illnesses. ${ }^{13,14}$ It is a brief - 28-item - parent-completed questionnaire of which all items use a fourpoint ordinal rating scale: "never or rarely", "sometimes", "often", or "always or almost always". The total score is the summation of the scores assigned (from 1 to 4 ) to each item with higher scores indicating more adjusted functioning. 
Summation of specific items also yields six factor-derived psychosocial subscales: peer relations, dependency, hostility, productivity, anxiety/depression, and withdrawal. Reliability and validity are described as adequate to good, e.g. alpha coefficient for the total score is $0.88(n=449) .{ }^{13,14}$

\section{Child Behaviour Checklist}

The Achenbach CBCL is one of the most widely used measures for the assessment of behavioral problems and domains of competence. ${ }^{8}$ Based on a 113-item questionnaire, a total problem scale, two broadband scales (internalising and externalising behaviour problems) and eight narrowband scales (anxiety/depression, withdrawal, physical complaints, social problems, thought problems, attention problems, rule breaking behaviour, aggressive behaviour) can be derived. For the purpose of this study only the narrowband scales were used. Resulting standardised T-scores are defined as "borderline" (67 to 70) and "clinical" (larger than 70, that is, above the $98^{\text {th }}$ percentile).

\section{Participants}

\section{Children with $C P$}

The major patient characteristics were collected from the medical files of the children and are displayed in Table 3.1. The 93 children with CP consisted of 59 boys and 34 girls with a mean age of 12.3 years (SD 3.8; 4-18). Forty-four per cent of the children with $\mathrm{CP}$ were wheelchair dependent and $52 \%$ had a cognitive level below 70 . The percentages of children scoring in the clinical range on the eight narrowband scales of the CBCL (above the $98^{\text {th }}$ percentile) are displayed in Table 3.2. It can be seen that for the areas of physical complaints (14\%), social problems (8\%) and attention problems (5\%) larger proportions of children with CP scored above the $98^{\text {th }}$ percentile than would be expected.

\section{Boys with DMD and healthy children}

The parents of 63 boys with DMD were recruited from the Dutch Parent Project Muscular Dystrophy, which is a parent advocacy group. The mean age of the 63 boys with DMD was 10.8 years (SD 4.1; 3-23); 65\% were wheelchair dependent. The parents of 100 healthy children were recruited at random from three different schools in the Southern part of the Netherlands; 95 agreed to participate. The mean age of the 48 healthy boys and 47 healthy girls was 7.7 years (SD 2.8; 4-13). 
Table 3.1 Characteristics of the children with CP

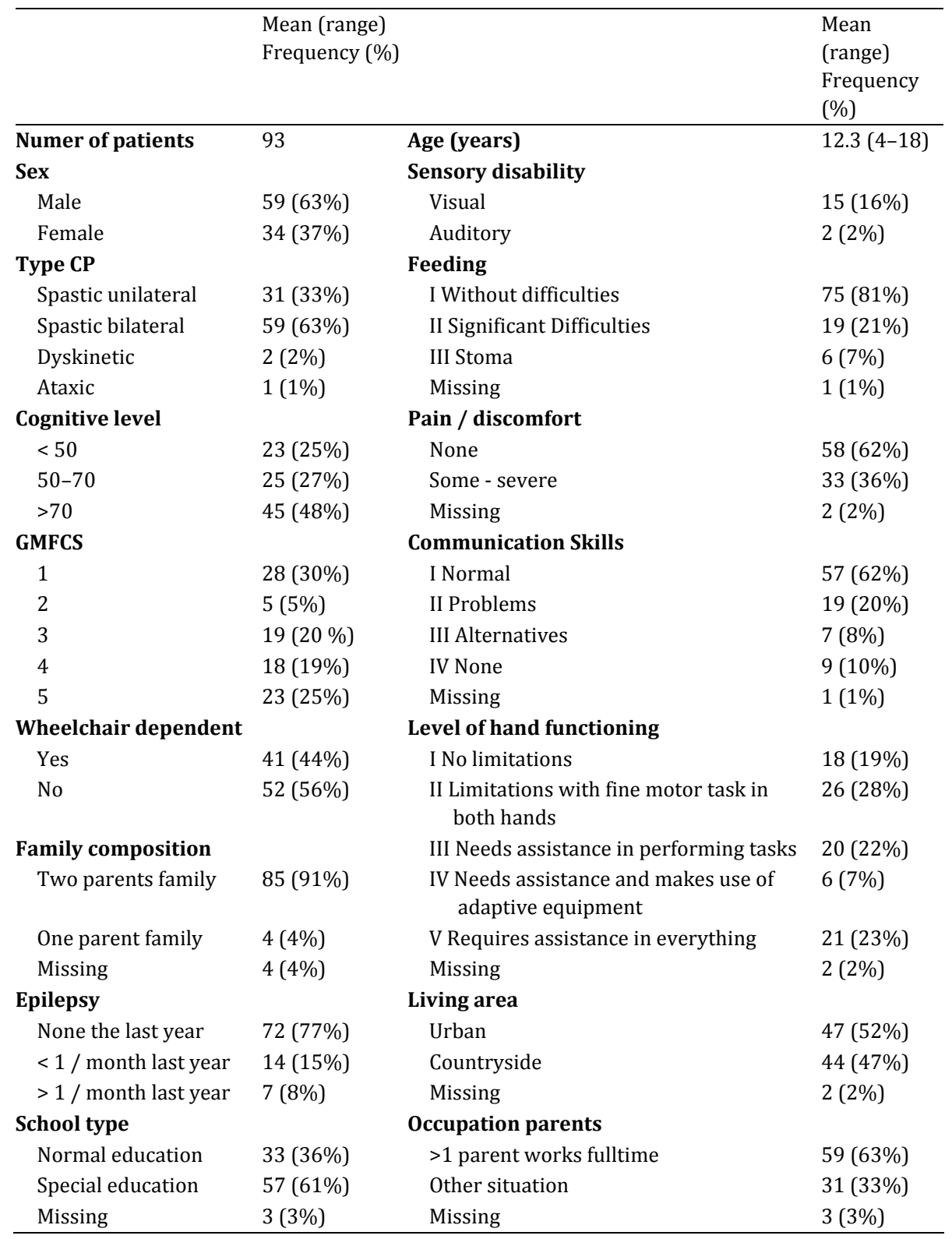


Table 3.2 Percentages of children with $\mathrm{CP}(\mathrm{N}=86)$ scoring in the clinical range of the CBCL narrowband scales (above the $98^{\text {th }}$ percentile)

\begin{tabular}{llll}
\hline Scale & $\%$ & Scale & $\%$ \\
\hline Anxiety / depression & $1 \%$ & Thought problems & $1 \%$ \\
Withdrawal & $3 \%$ & Attention problems & $5 \%$ \\
Physical complaints & $14 \%$ & Rule breaking behavior & $0 \%$ \\
Social problems & $8 \%$ & Aggressive behavior & $2 \%$ \\
\hline
\end{tabular}

\section{Statistical analysis}

All data were entered into SPSS 18.0 for statistical analysis (RH). The accuracy of data entry was randomly checked and found correct by a different researcher $(\mathrm{JH})$. Cronbach's alpha was used to calculate the internal consistency of the PARS-III. Confirmatory factor analysis (CFA, AMOS 17) was performed to confirm the six domains of psychosocial functioning on the PARS-III questionnaire. Factor loadings above 0.6 were considered high and factor loadings below 0.4 were considerd low. As an indication for criterion validity of the PARS-III bivariate correlations with the eight narrowband scales of the CBCL were calculated.

Subsequently, independent sample $T$ tests were used to assess differences between PARS-III scores of children with CP, boys with DMD and healthy children. P-values below 0.05 were considered significant.

In order to establish a cut-off score, the same method as Witt et al, Pless et al and Hendriksen et al was used, meaning that 1 SD below the group mean is used as a cut-off score for poor psychosocial adjustment. ${ }^{15-17}$

Finally, univariate and multivariate (forward entry, dummy variables) model testing was used to identify patient characteristics (Table 3.1) predictive for poor psychosocial adjustment in children with CP. 


\section{RESULTS}

\section{Psychometric properties of the PARS-III when used for children with CP}

Good internal consistency for the total PARS-III score was found: a Cronbach's alpha of 0.89 . For the six subscales the alpha coefficient was 0.81 for peer relations; 0.56 for dependency; 0.83 for hostility; 0.80 for productivity; 0.76 for anxiety/depression and 0.76 for withdrawal.

CFA confirmed the six domains of psychosocial functioning on the PARS-III questionnaire (Figure 3.1). Except for questions 6, 13 and 20, all factor loadings were adequate (8) and high (18). Exploratory factor analysis showed that question 6 did load on the domain withdrawal. Questions 13 and 20 did not load on any.

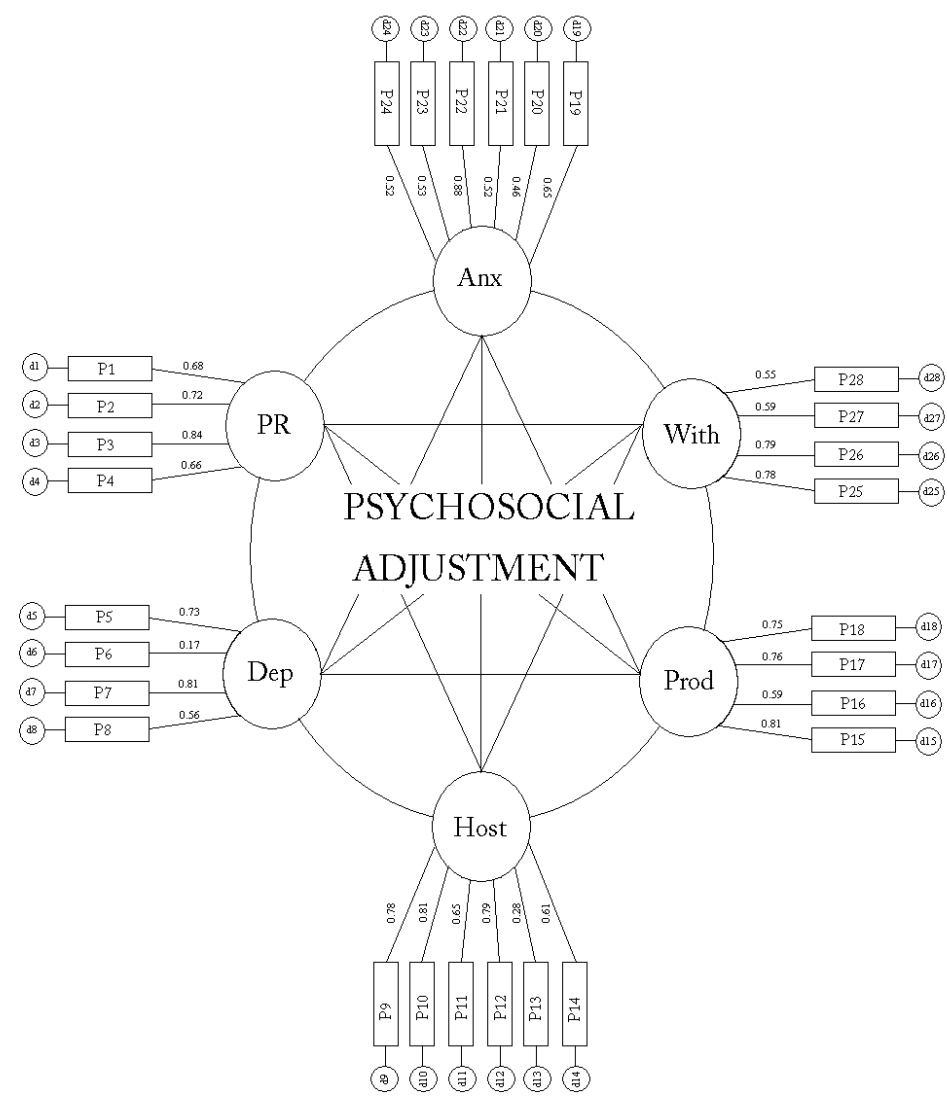

Figure 3.1 Confirmatory factor analysis of the structure of the PARS-III questionnaire P1-P28: questions on the PARS-III questionnaire; PR = peer relations; Dep = dependency; Host = hostility; Prod = productivity; With = withdrawal; Anx = anxiety and depression. Numbers indicate factor loadings. 
As an indication for criterion validity of the PARS-III bivariate correlations with the eight narrowband scales of the CBCL were calculated (Table 3.3). It can be seen that all correlations are in the expected directions (low adjustment scores on the PARS-III correlate with high problem scores on the CBCL). The PARS-III total score correlates significantly $(r=-0.29$ to $r=-0.59)$ with all narrowband scales of the CBCL. Furthermore, it can be seen that the CBCL scale for social problems correlates highest with the PARS-III domain peer relations $(\mathrm{r}=-0.50)$. Also, as can be expected, the CBCL scale for aggression correlates highest with the PARS-III domain hostility $(r=-0.68)$, the CBCL scale for anxiety/depression with the PARS-III domain anxiety $(\mathrm{r}=-0.58)$, and the CBCL scale for withdrawal with the PARS-III domain withdrawal $(r=-0.43)$.

Table 3.3 Bivariate correlations (r) between the PARS-III and the CBCL in children with CP

\begin{tabular}{|c|c|c|c|c|c|c|c|c|}
\hline & \multicolumn{8}{|c|}{ P A R S - I I I } \\
\hline & & Peer & Dep & Host & Prod & Anx/Depr & Withd & Total \\
\hline & Anx/Depr & $-0.23^{*}$ & $-0.29^{* *}$ & -0.12 & -0.03 & $-0.58^{* * *}$ & $-0.35^{* * *}$ & $-0.39^{* * * *}$ \\
\hline & Withd & $-0.39^{* * *}$ & $-0.45^{* * *}$ & -0.16 & $-0.24^{*}$ & $-0.40^{* * *}$ & $-0.43^{* * *}$ & $-0.52^{* * *}$ \\
\hline $\mathrm{C}$ & Somatic & $-0.40^{* * *}$ & -0.04 & -0.16 & $-0.37^{* * *}$ & -0.21 & $-0.27^{*}$ & $-0.37^{* * *}$ \\
\hline B & Social & $-0.50^{* * *}$ & $-0.38^{* * *}$ & $-0.42^{* * *}$ & $-0.24^{*}$ & $-0.49^{* * *}$ & $-0.37^{* * *}$ & $-0.59^{* * *}$ \\
\hline $\mathrm{C}$ & Thought & -0.03 & $-0.32^{* * *}$ & -0.21 & -0.13 & -0.15 & $-0.35^{* * *}$ & $-0.29^{*}$ \\
\hline $\mathrm{L}$ & Attention & -0.22 & $-0.54^{* * *}$ & $-0.46^{* * *}$ & $-0.32^{* * * *}$ & $-0.27^{*}$ & $-0.34^{* * *}$ & $-0.52^{* * *}$ \\
\hline & Rule & -0.13 & $-0.57^{* * *}$ & $-0.39^{* * *}$ & -0.07 & $-0.34^{* * *}$ & $-0.28^{* *}$ & $-0.43^{* * *}$ \\
\hline & Aggress & -0.07 & $-0.52^{* * *}$ & $-0.68^{* * *}$ & $-0.24 *$ & $-0.40^{* * *}$ & $-0.29^{* *}$ & $-0.56^{* * *}$ \\
\hline
\end{tabular}

All correlations are in the expected directions (low adjustment scores on the PARS-III correlate with high problem scores on the CBCL). ${ }^{*}=\mathrm{p}<.05 ;^{* *}=\mathrm{p}<.01 ;{ }^{* * *}=\mathrm{p}<.001$; Peer = Peer Relations; Dep = Dependency; Host = Hostility; Prod = Productivity; Anx/Depr = Anxiety $/$ Depression; Withd = Withdrawal; Somatic $=$ Somatic Complaints; Social $=$ Social Problems; Thought $=$ Thought Problems; Attention = Attention Problems; Rule $=$ Rule-breaking Behavior; Aggress $=$ Aggressive Behavior

\section{Psychosocial adjustment profiles of children with CP, boys with DMD, and healthy children}

Children with CP achieve significantly lower psychosocial adjustment scores when compared to healthy children $(\mathrm{p}<0.001)$, especially in the domains peer relations ( $p<0.001)$, anxiety/depression ( $<0.01)$, withdrawal $(p<0.001)$, and productivity $(\mathrm{p}=0.02)$ (Table 3.4$)$. In general, boys with DMD do not differ significantly from children with CP ( $p=0.93)$. However, when looking at the domains of psychosocial adjustment, children with CP score significantly lower than boys with DMD on peer relations $(\mathrm{p}=0.03)$. 
Table 3.4 Comparison of psychosocial adjustment scores in healthy children, children with CP and boys with DMD

\begin{tabular}{|c|c|c|c|c|c|c|c|c|c|c|c|c|}
\hline & \multicolumn{3}{|c|}{ Healthy Children } & \multicolumn{3}{|c|}{ Children with CP } & \multirow[b]{2}{*}{ Sign1 } & \multicolumn{3}{|c|}{ Boys with DMD } & \multirow[b]{2}{*}{ Sign1 } & \multirow[b]{2}{*}{ Sign2 } \\
\hline & $\mathrm{N}$ & Mean & SD & $\mathrm{N}$ & Mean & SD & & $\mathrm{N}$ & Mean & $\mathrm{SD}$ & & \\
\hline Peer relations & 93 & 11.9 & 2.4 & 87 & 8.6 & 2.9 & $* * *$ & 62 & 9.6 & 2,8 & $* * *$ & * \\
\hline Dependency & 93 & 13.5 & 2.0 & 85 & 12.9 & 2.1 & ns & 60 & 12.4 & 2,1 & $* *$ & ns \\
\hline Hostility & 93 & 21.4 & 2.9 & 85 & 21.3 & 3.0 & ns & 63 & 20.6 & 3,4 & ns & ns \\
\hline Productivity & 91 & 11.0 & 2.3 & 87 & 10.0 & 2.9 & $*$ & 60 & 10.7 & 2,5 & ns & ns \\
\hline Anxiety & 93 & 22.5 & 1.7 & 87 & 21.6 & 2.4 & $* *$ & 63 & 21.9 & 1,9 & ns & ns \\
\hline Withdrawal & 91 & 15.6 & 1.0 & 91 & 14.2 & 2.0 & $* * *$ & 60 & 14.4 & 1,9 & $* * *$ & ns \\
\hline Total & 88 & 95.7 & 7.1 & 77 & 88.6 & 10.4 & $* * *$ & 55 & 88.5 & 9,9 & $* * *$ & ns \\
\hline
\end{tabular}

$\mathrm{N}=$ number of cases, ${ }^{*} \mathrm{p}<0.05,{ }^{* *} \mathrm{p}<0.01,{ }^{* * *} \mathrm{p}<0.001$, ns $=$ not significant

Sign 1 = significance compared to healthy children

Sign2 = significance compared to children with $\mathrm{CP}$

\section{Establishing a cut-off score}

Both Witt et al, Pless et al, and Hendriksen et al calculated 1 SD below the group mean and used this number as a cut-off score for psychosocial maladjustment.1517 They found cut-off scores of respectively 73.1 and 72.3. In this current study this method would result in a cut-off score of 78 (88.6 - 10.4) identifying the 16 $\%(1 \mathrm{SD})$ of the children with CP showing the worst psychosocial maladjustment.

\section{Factors predictive for less psychosocial adjustment in children with CP}

Using univariate and multivariate (forward entry, dummy variables) model testing it was found that the patient characteristics most predictive for lower PARS-III sub and total scores were gross motor function, level of hand function (LoH), communication skills (CS) and bilateral involvement of CP (Table 3.5). Put together in a model, these four patient characteristics could explain a significant proportion (36\%) of the variation in PARS-III total scores. 
Table 3.5 Patient characteristics explaining differences in PARS-III domain scores (multivariate regression analysis)

\begin{tabular}{|c|c|c|c|c|c|c|}
\hline & Patient characteristic & B & SE & $\mathrm{p}$ & $\mathrm{R}^{2}$ & F-ratio \\
\hline \multirow[t]{3}{*}{ Peer relations } & Bilateral & -2.54 & 0.70 & 0.00 & & \\
\hline & GMFCS5 & -1.33 & 0.59 & 0.03 & & \\
\hline & & & & & 0.23 & 12.24 \\
\hline \multirow[t]{2}{*}{ Dependency } & LoH-IV & -3.17 & 0.90 & 0.00 & & \\
\hline & & & & & 0.14 & 12.31 \\
\hline \multirow[t]{5}{*}{ Hostility } & CS-III & -4.20 & 0.96 & 0.00 & & \\
\hline & LoH-IV & -3.29 & 1.01 & 0.00 & & \\
\hline & Age & 0.22 & 0.07 & 0.00 & & \\
\hline & GMFCS5 & -1.59 & 0.64 & 0.02 & & \\
\hline & & & & & 0.38 & 12.36 \\
\hline \multirow[t]{4}{*}{ Productivity } & GMFCS5 & -1.62 & 0.76 & 0.04 & & \\
\hline & Bilateral & -1.38 & 0.58 & 0.02 & & \\
\hline & CS-IV & -2.88 & 1.29 & 0.03 & & \\
\hline & & & & & 0.28 & 10.20 \\
\hline Anxiety / depression & - & - & - & - & - & - \\
\hline \multirow[t]{2}{*}{ Withdrawal } & $\mathrm{CL}<50$ & -1.43 & 0.48 & 0.00 & & \\
\hline & & & & & 0.10 & 8.99 \\
\hline \multirow{4}{*}{ Total } & GMFCS5 & -7.32 & 2.63 & 0.00 & & \\
\hline & $\begin{array}{l}\text { Sign. feeding difficulties } \\
\text { Bilateral }\end{array}$ & -9.47 & 3.30 & 0.00 & & \\
\hline & LoH-IV & -5.63 & 2.16 & 0.00 & & \\
\hline & & -8.81 & 4.08 & 0.00 & 0.36 & 9.72 \\
\hline
\end{tabular}

Bilateral $=$ Bilateral spastic CP, LoH-IV = Level of Hand function level IV: needs assistance and makes use of adaptive equipment, CS-III = Communication Skills level III: having to use alternative methods to communicate, $\mathrm{CS}-\mathrm{IV}=$ Communication Skills level IV: no ways of communication, $\mathrm{CL}=$ Cognitive level, GMFCS = Gross Motor Function Classification System, B = beta, SE = Standard Error

\section{DISCUSSION}

\section{Psychosocial adjustment of children with CP}

To the best of our knowledge this is the first study describing psychosocial adjustment in children with CP using the PARS-III questionnaire for parents. It shows that children with $\mathrm{CP}$ are reported to achieve less psychosocial adjustment when compared to healthy children (Table 3.4). The first domain of significantly lower psychosocial adjustment is peer relations, with lower gross motor function being an important predictive factor (Table 3.5). This can be explained by the fact that participation in daily life and leisure activities, key to developing peer relations, is less in children with more physical restriction. ${ }^{18,19}$

The second domain of lower scores in children with CP was anxiety/depression. Sigurdardottir et al found lower IQ to be a risk factor for more anxiety. ${ }^{7}$ In the current study cognitive level was not found to be related to anxiety $\left(\mathrm{R}^{2}=0.012\right)$. In fact, none of the patient characteristics were. Possible expla- 
nations might be that Sigurdardottir et al studied preschool children and used the CBCL questionnaire, which is not specifically developed to assess psychosocial adjustment.

The third domain, in which children with CP show significantly lower psychosocial adjustment scores, was withdrawal. Low cognitive level (IQ below 50) turned out to be the only predictor $\left(B=-1.42 ; R^{2}=0.10\right)$, which this time is in agreement with the study by Sigurdardottir et al. ${ }^{7}$

\section{Comparison to boys with DMD}

Overall, children with CP do not differ significantly from boys with DMD on the PARS-III total score $(p=0.92)$. However, children with CP score significantly lower than boys with DMD on the domain peer relations $(p=0.03)$. This could be due to the fact that during the initial phases of their disease boys with DMD are able to participate almost normally in life and therefore establish more and better peer relations. Furthermore, children with $\mathrm{CP}$ showed a trend towards lower scores on the domain of dependency $(p=0.09)$, reflecting higher independence in boys with DMD as they are more able to live independent lives.

\section{The cut-off score}

A cut-off score (1 SD below the mean) of 78 was identified in this study. This means that children with CP scoring below 78 are at risk for psychosocial maladjustment and merit further assessment. Even though the identified cut-off score can be helpful in clinical practice, the development of clinical norms based on a demographically representative sample would be highly useful.

\section{Predictive factors of psychosocial adjustment in children with CP}

The most important predictive factor for lower psychosocial adjustment was a higher restriction in gross motor function, i.e. higher GMFCS level, bilateral involvement and worse hand function. This is a common observation in the literature. $3,20 \mathrm{~A}$ regression analysis model could explain $36 \%$ of variation in PARS-III adjustment scores, highlighting the complexity of both CP and psychosocial adjustment.

Although pain is common in children with CP (35\% of studied population had moderate to severe pain complaints), it was found that pain was not a significant predictive factor for psychosocial adjustment on any of the 6 domains of the PARS-III. This is in contrast with previous studies in which pain resulted in lower QoL and more behavioral problems (measured by means of the KIDSCREEN and SDQ respectively). ${ }^{3,11}$ This discrepancy between our findings and literature may be due to the fact that dichotomous pain data was used, but also due to the fact that psychosocial adjustment and QoL are different concepts. For 
example, in a study by Engel et al it was shown that in adults with CP it is not the pain itself that influences psychological functioning, but the coping strategies in reaction to the pain. ${ }^{21}$

As already stated above, differences in psychosocial adjustment could only partially be explained using patient characteristics previously reported in literature. It is suggested that future studies should also include basic neurological substrates when investigating psychosocial adjustment. For example, for both $\mathrm{CP}$ and DMD it is known that the cerebellum can be involved in the pathogenesis. It has recently been shown that cerebellar injury in premature infants is associated with a high prevalence of cognitive, learning and behavioral disabilities.22 Sophisticated MRI analyses (e.g. Diffusion Tensor Imaging and connectivity analyses) would aid investigating such a relationship between the cerebellum and psychosocial functioning in children with CP. Future research should compare PARS-III scores in children with $\mathrm{CP}$ with and without cerebellar involvement.

\section{Limitations of this study}

This study has several limitations, some of which are almost inevitable in this field of research.

The first limitation is that the data are cross-sectional and therefore no conclusions about causal relationships can be made. Consequently, the developmental profile of psychosocial adjustment in children with CP remains unclear. A longitudinal - follow-up - study using the PARS-III questionnaire is advised in order to elucidate this developmental profile and find out whether different age periods (moving to another town, older brother going to college, hitting puberty, etc) are characterized by different psychosocial adjustment problems.

The second limitation is the sole reliance on proxy reports. The literature on the best source to evaluate QoL and psychosocial adjustment is inconsistent at best. The WHO and the International Association for Child Psychology and Psychiatry recommend that children should report their own QoL. ${ }^{23}$ However Le Coq et al found that in 8 to 11 year old pediatric asthma patients parents were more responsive and reliable reporters on a QoL measure. ${ }^{24}$ Then there is the limitation that some children might not be capable to self-report because of their age, cognitive impairments or disabilities. ${ }^{25}$ In this case, proxy-reports are the only way to evaluate QoL with their parents / caregivers being the most logical source of information as they are assumed to have intimate knowledge of the child. It is now becoming more and more accepted that there is no one single truth concerning concepts like QoL and psychosocial adjustment and therefore self-reports and proxy reports are complementary. ${ }^{26}$ With regard to the current study, self-reports would have been extremely difficult to obtain and interpret given the severity of disability of the majority of the children with CP. 
Finally, in the absence of a golden standard for psychosocial maladjustment ROC curves cannot be produced and therefore identifying a cut-off score is arbitrary. In accordance with Witt et al, Pless et al and Hendriksen et al this study used 1 SD below the mean as a cut-off score. ${ }^{15-17}$ This inevitably means that $16 \%$ of the children with CP will receive further assessment. Experience will tell whether this method over-, under- or appropriately identifies psychosocial maladjustment.

\section{CONCLUSION}

This study showed the PARS-III to possess good internal consistency and criterion validity when applied to children with $\mathrm{CP}$ and can therefore be used for both clinical screening and research purposes. Using this by-proxy questionnaire, it was found that children with CP achieve lower psychosocial adjustment scores when compared to healthy children, especially in the subdomains peer relations, anxiety/depression, withdrawal, and productivity. Future studies should aim at unraveling the developmental profile and risk factors for psychosocial maladjustment. 


\section{REFERENCES}

1. Ronen GM, Fayed N, and Rosenbaum PL. Outcomes in pediatric neurology: a review of conceptual issues and recommendationsThe 2010 Ronnie Mac Keith Lecture. Dev Med Child Neurol 2011. 53(4): p. 305-12.

2. World Health Organization. The World Health Organization Quality of Life assessment (WHOQOL): position paper from the World Health organization. Soc Sci Med 1995. 41: p. 1403-1409.

3. Dickinson HO, Parkinson KN, Ravens-Sieberer U, et al. Self-reported quality of life of 8-12-yearold children with cerebral palsy: a cross-sectional European study. Lancet 2007. 369(9580): p. 2171-8.

4. Moos R, Tsu, VD, Coping with Physical ilness, in The crisis of physical ilness: an overview, R. Moos, Editor. 1977, Plenium Medical Book Company: London. p. 3-21.

5. Jozwiak M, Harasymczuk P, Koch A, et al. Incidence and risk factors of hip joint pain in children with severe cerebral palsy. Disabil Rehabil 2010: p. 1-6.

6. Albrecht GL and Devlieger PJ. The disability paradox: high quality of life against all odds. Soc Sci Med 1999. 48(8): p. 977-88.

7. Sigurdardottir S, Indredavik MS, Eiriksdottir A, et al. Behavioural and emotional symptoms of preschool children with cerebral palsy: a population-based study. Dev Med Child Neurol 2010. 52(11): p. 1056-61.

8. Achenbach TM and Ruffle TM. The Child Behavior Checklist and related forms for assessing behavioral/emotional problems and competencies. Pediatr Rev 2000. 21(8): p. 265-71.

9. Eiser C. Chronic childhood disease: and introduction to psychological theory and research. 1990, Cambridge, UK: Cambridge University Press.

10. Perrin EC, Stein RE, and Drotar D. Cautions in using the Child Behavior Checklist: observations based on research about children with a chronic illness. J Pediatr Psychol 1991. 16(4): p. 41121.

11. Parkes J, White-Koning M, Dickinson HO, et al. Psychological problems in children with cerebral palsy: a cross-sectional European study. J Child Psychol Psychiatry 2008. 49(4): p. 405-13.

12. Goodman R. The Strengths and Difficulties Questionnaire: a research note. J Child Psychol Psychiatry 1997. 38(5): p. 581-6.

13. Stein REK, Jessop D, Manual for Personal Adjustment and Role Skills Scale III (PARS III). 1990: Bronx, New York.

14. Walker DK, Stein RE, Perrin EC, et al. Assessing psychosocial adjustment of children with chronic illnesses: a review of the technical properties of PARS III. J Dev Behav Pediatr 1990. 11(3): p. 116-21.

15. Hendriksen JG, Poysky JT, Schrans DG, et al. Psychosocial adjustment in males with Duchenne muscular dystrophy: psychometric properties and clinical utility of a parent-report questionnaire. J Pediatr Psychol 2009. 34(1): p. 69-78.

16. Pless IB, Feeley N, Gottlieb L, et al. A randomized trial of a nursing intervention to promote the adjustment of children with chronic physical disorders. Pediatrics 1994. 94(1): p. 70-5.

17. Witt WP, Riley AW, and Coiro MJ. Childhood functional status, family stressors, and psychosocial adjustment among school-aged children with disabilities in the United States. Arch Pediatr Adolesc Med 2003. 157(7): p. 687-95.

18. Majnemer A, Shikako-Thomas K, Chokron N, et al. Leisure activity preferences for 6- to 12-yearold children with cerebral palsy. Dev Med Child Neurol. 52(2): p. 167-73.

19. Michelsen SI, Flachs EM, Uldall P, et al. Frequency of participation of 8-12-year-old children with cerebral palsy: a multi-centre cross-sectional European study. Eur J Paediatr Neurol 2009. 13(2): p. 165-77.

20. Chiarello LA, Almasri N, and Palisano RJ. Factors related to adaptive behavior in children with cerebral palsy. J Dev Behav Pediatr 2009. 30(5): p. 435-41.

21. Engel JM, Jensen MP, and Schwartz L. Coping with chronic pain associated with cerebral palsy. Occup Ther Int 2006. 13(4): p. 224-33. 


\section{CHAPTER II I}

22. Limperopoulos C, Bassan H, Gauvreau K, et al. Does cerebellar injury in premature infants contribute to the high prevalence of long-term cognitive, learning, and behavioral disability in survivors? Pediatrics 2007. 120(3): p. 584-93.

23. World Health Organization, Measurement of Quality of Life in children, World Health Organization, Editor. 1993, World Health Organization: Geneva, Switzerland.

24. le Coq EM, Boeke AJ, Bezemer PD, et al. Which source should we use to measure quality of life in children with asthma: the children themselves or their parents? Qual Life Res 2000. 9(6): p. 625-36.

25. White-Koning M, Arnaud C, Dickinson HO, et al. Determinants of child-parent agreement in quality-of-life reports: a European study of children with cerebral palsy. Pediatrics 2007. 120(4): p. e804-14.

26. Eiser C and Morse R. Can parents rate their child's health-related quality of life? Results of a systematic review. Qual Life Res 2001. 10(4): p. 347-57. 


\section{CHAPTER IV \\ PERCUTANEOUS RADIOFREQUENCY LESIONS ADJACENT TO THE DORSAL ROOT GANGLION ALLEVIATE SPASTICITY AND PAIN IN CHILDREN WITH CP}

pilot study in 17 patients

Vles GF, Vles JSH, van Kleef M, van Zundert J, Staal HM, Weber WE, van Rhijn LW, Soudant D, Graham HK, de Louw AJ

BMC Neurol. 2010: 22; 10: 52. 


\section{ABSTRACT}

\section{Background}

Cerebral palsy (CP) may cause severe spasticity, requiring neurosurgical procedures. The most common neurosurgical procedures are continuous infusion of intrathecal baclofen and selective dorsal rhizotomy. Both are invasive and complex procedures. We hypothesized that a percutaneous radiofrequency lesion of the dorsal root ganglion (RF-DRG) could be a simple and safe alternative treatment. We undertook a pilot study to test this hypothesis.

\section{Methods}

We performed an RF-DRG procedure in 17 consecutive patients with CP with severe hip flexor / adductor spasms accompanied by pain or care-giving difficulties. Six children were systematically evaluated at baseline, and 1 month and 6 months after treatment by means of the Modified Ashworth Scale (MAS), Gross Motor Function Measure (GMFM), and a self-made caregiver's questionnaire. Eleven subsequent children were evaluated using a Visual Analogue Scale (VAS) for spasticity, pain, and ease of care.

\section{Results}

A total of 19 RF-DRG treatments were performed in 17 patients. We found a small improvement in muscle tone measured by MAS, but no effect on the GMFM scale. Despite this, the caregivers of these six treated children unanimously stated that the quality of life of their children had indeed improved after the RFDRG. In the subsequent 11 children we found improvements in all VAS scores, in a range comparable to the conventional treatment options.

\section{Conclusion}

RF-DRG is a promising new treatment option for severe spasticity in patients with CP. Its definitive effectiveness remains to be defined in a randomized controlled trial. 


\section{BACKGROUND}

Cerebral palsy (CP) is a central nervous system deficit resulting from a nonprogressive lesion in the developing brain. Although these brain lesions are static, the movement disorders that arise are not unchanging and are characterised by atypical muscle tone, posture, and movement. ${ }^{1}$ The spastic motor type is the most common form of $\mathrm{CP}$ and its conventional therapeutic management may include splinting / casting, physiotherapy, occupational therapy, oral spasmolytics and anti-dystonic drugs, Botulinum Toxin-A (BTX-A) injections, orthopaedic procedures, and neurosurgical procedures. The most common neurosurgical procedures are continuous infusion of intrathecal Baclofen (ITB) and selective dorsal rhizotomy (SDR). Since its first description by Foerster in 1913, SDR has been modified by various researchers and has become a standard neurosurgical procedure to treat spasticity in patients with CP. ${ }^{2-5}$ However, as multi-level laminectomies at the L1-S1 level are often required, the procedure is invasive and can lead to complications as transient urinary incontinence, chronic low back pain, and spinal deformity. ${ }^{6-9}$ Furthermore, considerable cooperation of the patient is required to successfully complete the postoperative rehabilitation program.

An alternative for the SDR is a radiofrequency lesion of the dorsal root ganglion (RF-DRG), which has been used to treat chronic pain for over 30 years. ${ }^{10}$ The RF-DRG is a simple and safe treatment with little side-effects. ${ }^{11,}{ }^{12}$ In the 1980 's several authors reported that the same procedure might be used to treat adult patients with spasticity. ${ }^{13,14}$ More recently, we were able to show that an RF-DRG alleviates hip flexor spasms in 2 patients with CP. ${ }^{15}$ Patients with CP can also suffer from severe pain through spasticity, bone deformities or joint subluxation, especially hip displacement and dislocation ${ }^{16,17}$, which may lead, through an enhanced processing of afferent information within the spinal cord, to secondary pain. ${ }^{18}$

We thus hypothesized that an RF-DRG may alleviate spasticity and pain in patients with $\mathrm{CP}$, and we tested this hypothesis in a pilot study of 17 patients.

\section{METHODS}

Children with spastic CP were seen by a multi-disciplinary spasticity management team (child neurologist, orthopaedic surgeon, and physician assistant child neurology) of the Maastricht University Medical Centre (MUMC). Individual treatment goals were determined after a careful assessment of the aetiology, functional ability, and associated impairments as a result of the spasticity. The RF-DRG treatment was considered in children with severe hip flexor / adductor spasms accompanied by pain or care giving difficulties. The procedure was ap- 
proved by the Institutional Review Board of the MUMC, according to Dutch governmental regulations and informed consent from the caregivers was obtained for each patient.

A total of 17 children were treated with RF-DRG (tables 4.1, 4.2). The severity of CP was based on the Gross Motor Function Classification System (GMFCS) for CP.19, $20 \mathrm{Hip}(\mathrm{sub})$ luxation was classified according to the morphological hip classification system proposed by Robin et al. ${ }^{21}$

Table 4.1 Summary of 6 patients (Group A) treated with RF-DRG and systematically evaluated.

\begin{tabular}{|c|c|c|c|c|c|c|c|c|c|c|c|c|c|c|c|c|c|c|}
\hline \multirow{2}{*}{\multicolumn{2}{|c|}{$\begin{array}{r}\mathrm{m} / \mathrm{f} \text { Age } \\
(\mathrm{yr})\end{array}$}} & \multirow[t]{2}{*}{ Aet } & \multirow[t]{2}{*}{$\begin{array}{l}\text { GMFCS } \\
\text { score }\end{array}$} & \multicolumn{2}{|c|}{ RF-DRG } & \multicolumn{3}{|c|}{ Indication } & \multicolumn{3}{|c|}{ Improv 4w } & \multirow[t]{2}{*}{ SE 4w } & \multicolumn{3}{|c|}{ Improv $6 \mathrm{~m}$} & \multirow[t]{2}{*}{ SE $6 \mathrm{~m}$} & \multicolumn{2}{|c|}{$\begin{array}{l}\text { Hip } \\
\text { morphology }\end{array}$} \\
\hline & & & & Left & Right & Spas & sPain & nCare & Spas & Pain & Care & & Spas & Pain & Care & & Left & Right \\
\hline $1 \mathrm{f}$ & 6 & Asph & V & L1-2 & L1-2 & - & & घ & + & & & no & + & & & no & IV & III \\
\hline $2 \mathrm{f}$ & 12 & $\operatorname{Tr}$ & V & L1-4 & L1-4 & - & घ & ! & + & + & + & no & + & + & + & no & III & I \\
\hline $3 \mathrm{f}$ & 16 & Prem & V & - & L1-3 & & 匹 & घ & & + & + & no & & + & + & no & II & V \\
\hline $4 \mathrm{f}$ & 11 & Asph & V & $\mathrm{L} 2-4$ & $\mathrm{~L} 2-4$ & घ & & & + & & & no & + & & & no & II & IV \\
\hline $5 \mathrm{~m}$ & 7 & Prem & V & L1-2 & - & & घ & & & - & & yes & & + & & no & V & III \\
\hline $6 \mathrm{f}$ & 14 & Asph & $\mathrm{V}$ & - & $\mathrm{L} 1-3$ & - & $\square$ & - & + & + & + & no & + & + & + & no & III & $\mathrm{V}$ \\
\hline
\end{tabular}

m: male; f: female; yr: years; spast: spasticity; Aet: Aetiology: Asph: Asphyxia; Tr: Trauma; Prem:

Premature; SE: Side-effects; Improv: Improvement; 4w: 4 weeks; 6m: 6 months

a: indication

Improvement: +/-: summary of improvement/worsening measured by the self-made questionnaire

Table 4.2 Summary of 11 patients (Group B) treated with RF-DRG and evaluated by VAS.

\begin{tabular}{|c|c|c|c|c|c|c|c|c|c|c|c|c|c|c|c|}
\hline \multicolumn{2}{|c|}{$\begin{array}{r}\text { m/f Age } \\
\text { (yr) }\end{array}$} & \multirow{2}{*}{\multicolumn{2}{|c|}{$\begin{array}{c}\text { SCPE GMFCS } \\
\text { Score }\end{array}$}} & \multirow[t]{2}{*}{$\begin{array}{l}\text { RF-DRG- } \\
\text { left }\end{array}$} & \multirow[t]{2}{*}{$\begin{array}{l}\text { RF-DRG- } \\
\text { right }\end{array}$} & \multicolumn{2}{|c|}{ Indication } & \multirow[t]{2}{*}{$\begin{array}{l}\text { VAS } \\
\text { pre }\end{array}$} & \multicolumn{3}{|c|}{$\begin{array}{r}\text { Improvement VAS } \\
\text { post } \\
\end{array}$} & \multirow[t]{2}{*}{$\Delta$-VAS } & \multirow[t]{2}{*}{$\overline{S E}$} & \multicolumn{2}{|c|}{ Hip morphology } \\
\hline & & & & & & Spas & Pain Care & & SpasPa & nCare & & & & Left & Right \\
\hline $1 \mathrm{f}$ & 18 & 2 & V & L1-3 & - & & - & 8 & + & & 2 & 6 & no & III & V \\
\hline $2 \mathrm{f}$ & 22 & 2 & V & L1-4 & - & - & - & 10 & + & & 1.5 & 8.5 & no & ns & ns \\
\hline $3 \mathrm{f}$ & 10 & 2 & V & L1-2 & L1-2 & - & - & 10 & + & & 8 & 2 & no & $\mathrm{V}$ & III \\
\hline $4 \mathrm{~m}$ & 16 & 2 & V & L1-3 & - & & - & 7 & + & & 3 & 4 & no & II & V \\
\hline $5 \mathrm{~m}$ & 16 & 2 & V & L1-4 & - & - & - & 8.2 & + & & 1.6 & 6.6 & no & IV & V \\
\hline $6 \mathrm{~m}$ & 7 & 2 & V & - & L1-3 & - & & ns & & & ns & & yes & 0 & III \\
\hline $7 \mathrm{~m}$ & 5 & 2 & V & L1-3 & L1-3 & - & - & ns & & + & ns & & no & IV & IV \\
\hline $8 \mathrm{f}$ & 11 & 2 & V & L1-2 & - & & - & 6 & + & & 2 & 4 & no & * & II \\
\hline \multirow[t]{3}{*}{$9 \mathrm{f}$} & 10 & 2 & V & L1-2 & - & - & - & 8 & + & + & 5.5 & 2.5 & no & I & I \\
\hline & 12 & 2 & V & L1-2 & - & - & - & 8 & + & + & 5 & 3 & no & I & I \\
\hline & 14 & 2 & V & L1-2 & - & - & - & 10 & & & 10 & 0 & no & I & I \\
\hline $10 \mathrm{~m}$ & 5 & 2 & V & L1-4 & L1-4 & - & - & ns & + & & ns & & no & II & V \\
\hline $11 \mathrm{f}$ & 16 & 2 & V & L1-4 & L1-4 & - & - & 8.7 & + & + & 3.1 & 5.6 & no & ns & ns \\
\hline
\end{tabular}

m: male; f: female; yr: years; SCPE: surveillance for cerebral palsy in Europe classification: (1) unilateral; (2) bilateral * Osteomyelitis; ns: not scored; SE: Side-effects

m: indication

+: domain in which the improvement measured by VAS was noted 
Six children (group A) were systematically evaluated at baseline, and 1 month and 6 months after treatment (table 4.1, table 4.3). In this group all assessments were performed by a physical therapist. The Modified Ashworth Scale (MAS) was used for the assessment of changes in muscle tone..$^{22}$ In the MAS muscle tone is scored on a 6 point scale, in which " 0 " represents no hypertonia or no increase of muscle tone and " 4 " represents severe hypertonia and severe stiffness of the extremities. In each patient hip flexion and adduction, knee flexion and extension, and dorsal and plantar flexion in the ankle were tested bilaterally. Functional improvement was assessed using the Gross Motor Function Measure (GMFM), a widely used scale consisting of 5 different locomotor domains to evaluate treatment of spasticity in children with CP.23-25 Furthermore, we developed a more extensive questionnaire for caregivers. Besides items on pain, several items of daily activities of life, like dressing, undressing, and bathing, were investigated. Data of the 6 systematically evaluated children were statistically analyzed using a students T-test and a Wilcoxon signed rank test. A $\mathrm{p}$ value of $<0.05$ was considered to be statistically significant. All data are represented as means and standard error of means (SEM).

Tabel 4.3 Ashworth scores of the first 6 patients: pre-operative, post-operative 4 weeks and 6 months

\begin{tabular}{|c|c|c|c|c|c|c|c|c|c|c|c|c|c|}
\hline \multirow[b]{2}{*}{$\mathrm{Pt}$} & & \multicolumn{2}{|c|}{ Hipflexion } & \multicolumn{2}{|c|}{ Hip adduction } & \multicolumn{2}{|c|}{$\begin{array}{l}\text { Knee } \\
\text { flexion }\end{array}$} & \multicolumn{2}{|c|}{$\begin{array}{l}\text { Knee } \\
\text { extension }\end{array}$} & \multicolumn{2}{|c|}{$\begin{array}{l}\text { Ankle dorsal } \\
\text { flexion }\end{array}$} & \multicolumn{2}{|c|}{$\begin{array}{l}\text { Ankle plantar } \\
\text { flexion }\end{array}$} \\
\hline & & $\mathrm{L}$ & $\mathrm{R}$ & $\mathrm{L}$ & $\mathrm{R}$ & $\mathrm{L}$ & $\mathrm{R}$ & $\mathrm{L}$ & $\mathrm{R}$ & $\mathrm{L}$ & $\mathrm{R}$ & $\mathrm{L}$ & $\mathrm{R}$ \\
\hline \multirow[t]{3}{*}{1} & Pre & $1+$ & $1+$ & 1 & 2 & 1 & 2 & 0 & 0 & 3 & 3 & 0 & 0 \\
\hline & Post4w & 1 & 1 & 0 & 0 & 1 & 1 & 0 & 0 & 2 & 2 & 0 & 0 \\
\hline & Post6m & 1 & 0 & 1 & 1 & 1 & 0 & 0 & 0 & 3 & 2 & 0 & 0 \\
\hline \multirow[t]{3}{*}{2} & Pre & 0 & 0 & 1 & 3 & 0 & 0 & 1 & 1 & 3 & 3 & 0 & 0 \\
\hline & Post4w & 0 & 0 & 1 & 1 & 0 & 0 & 1 & 1 & 1 & 1 & 0 & 0 \\
\hline & Post6m & 0 & 0 & 1 & 1 & 0 & 0 & 0 & 0 & 1 & 1 & 0 & 0 \\
\hline \multirow[t]{3}{*}{3} & Pre & 0 & 1 & $1+$ & 2 & 1 & 1 & 2 & 2 & 3 & 3 & 0 & 1 \\
\hline & Post4w & 0 & $1+$ & $1+$ & 1 & $1+$ & 1 & 2 & $1+$ & 2 & 2 & 0 & 0 \\
\hline & Post6m & 2 & 1 & 2 & 1 & 2 & 1 & 0 & 0 & 2 & 2 & 0 & 0 \\
\hline \multirow[t]{3}{*}{4} & Pre & 0 & 0 & 1 & 1 & $1+$ & $1+$ & 3 & 3 & 0 & 0 & 1 & 1 \\
\hline & Post4w & 0 & 0 & 0 & 0 & 2 & 2 & 0 & 0 & 1 & 0 & 0 & 0 \\
\hline & Post6m & 1 & 1 & 0 & 0 & 2 & 2 & 0 & 0 & 1 & 1 & 0 & 0 \\
\hline \multirow[t]{3}{*}{5} & Pre & 2 & 0 & 0 & 1 & 0 & $1+$ & 2 & 2 & 2 & 2 & $1+$ & $1+$ \\
\hline & Post4w & 1 & 1 & 0 & 1 & 1 & 2 & 1 & 4 & 1 & 1 & 2 & 3 \\
\hline & Post6m & 2 & 0 & 0 & 0 & 2 & 4 & 0 & 0 & 2 & 3 & 0 & 0 \\
\hline \multirow[t]{3}{*}{6} & Pre & 3 & 3 & 4 & 4 & 4 & 4 & 4 & 4 & 4 & 3 & 4 & 3 \\
\hline & Post4w & 0 & 0 & 1 & 0 & 3 & 1 & 2 & 3 & 2 & $1+$ & 2 & 2 \\
\hline & Post6m & 3 & 3 & 4 & 3 & 3 & 3 & 0 & 0 & 4 & 4 & 4 & 4 \\
\hline \multirow[t]{3}{*}{ Mean } & Pre & 1 & 0.83 & 1.33 & 2.17 & 1.17 & 1.5 & 2 & 2 & 2.5 & 2.33 & 1 & 1 \\
\hline & Post4w & 0.33 & 0.5 & 0.75 & 0.5 & 1.33 & 1.17 & 1 & 1.5 & 1.5 & 1.17 & 1.67 & 0.83 \\
\hline & Post6m & 1.5 & 0.83 & 1.33 & 1.0 & 1.67 & 1.67 & 0.17 & 0 & 2.17 & 2.17 & 0.67 & 0.67 \\
\hline
\end{tabular}


The subsequent 11 children (group B) were evaluated at 6 weeks and 3 months using a Visual Analogue Scale (VAS; figure 4.1), which was used to measure the severity of the individually formulated problems. We changed the evaluation methods, as we were not able to detect the kind of change that the caregivers unanimously did notice. Furthermore, literature had become available which showed that the MAS and the GMFM are not indicated to measure changes in these severely handicapped children. ${ }^{26-28}$ Instead we used a VAS, which is a valid pain-rating instrument. ${ }^{29}$ The VAS used in pain assessment is a straight 10 $\mathrm{cm}$ horizontal line with anchor points of no pain (score 0 ) and unbearable pain (score 10). For our study we changed the anchor points into very satisfied (score 0 ) and very dissatisfied (score 10) to use the VAS uniformly for individually defined problems. ${ }^{30,31}$ A VAS score for spasticity, pain, and ease of care was given by the caregivers, since the majority of the patients with $\mathrm{CP}$ were severely mentally handicapped. Usually the patient and his/her caregiver(s) are the best judges of the severity of the impairments accompanying spasticity, as they are the only people who can assess its impact on the daily life of the patient. ${ }^{32}$ Caregivers of children with profound impairments note changes in function far more accurately than staff workers. ${ }^{33}$

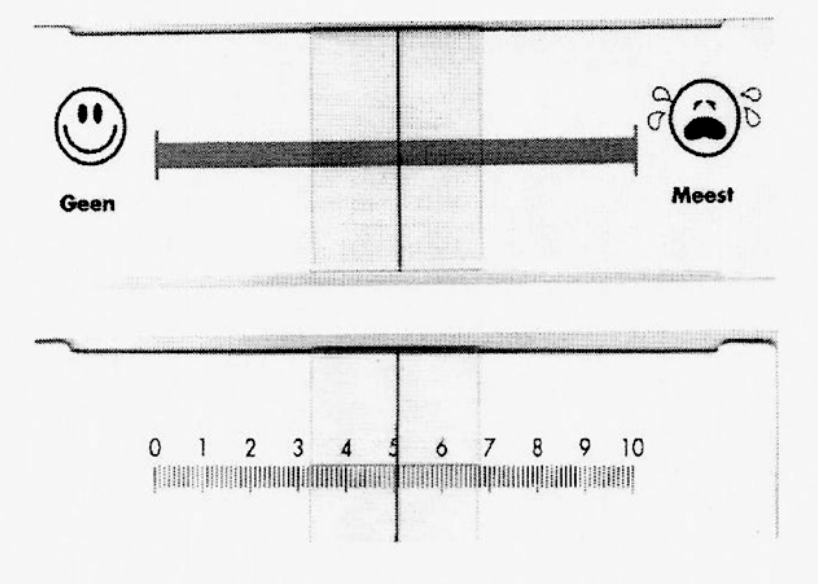

Figure 4.1 The VAS device

Score 0 / "geen": Very satisfied

Score 10 / "meest": Very dissatisfied

\section{RF-DRG procedure}

All patients were treated in our outpatient clinic, and RF-DRG was performed as described. ${ }^{12,}{ }^{34}$ Under general anaesthesia, the patients were placed in prone position on an operating table. The level to be treated was based on clinical symptoms; afterwards stimulation was used to verify these levels. 
The procedure was performed in tunnel vision, a technique for entering the electrode in the direct vision of the X-rays. Therefore, the C-arm (Ziehm electronics) was adjusted in such a way that the X-rays ran parallel to the end plates of the relevant level. Thereafter, the $\mathrm{C}$-arm was rotated until the processus spinosus projected over the contralateral facet column. With the $\mathrm{C}$-arm in this projection, the injection point was found by projecting a metal ruler over the lateral part of the foramen intervertebrale.

A 10-cm long, 22-G needle SMK-5 mm tip was inserted locally in the direction of the X-rays. Thereafter, the direction was corrected in such a way that the needle was being projected as a point on the screen. The direction of the radiation beam was now modified to a profile (lateral) view, and the needle was inserted until the point was located in the craniodorsal part of the foramen intervertebrale (Figure 4.2a).
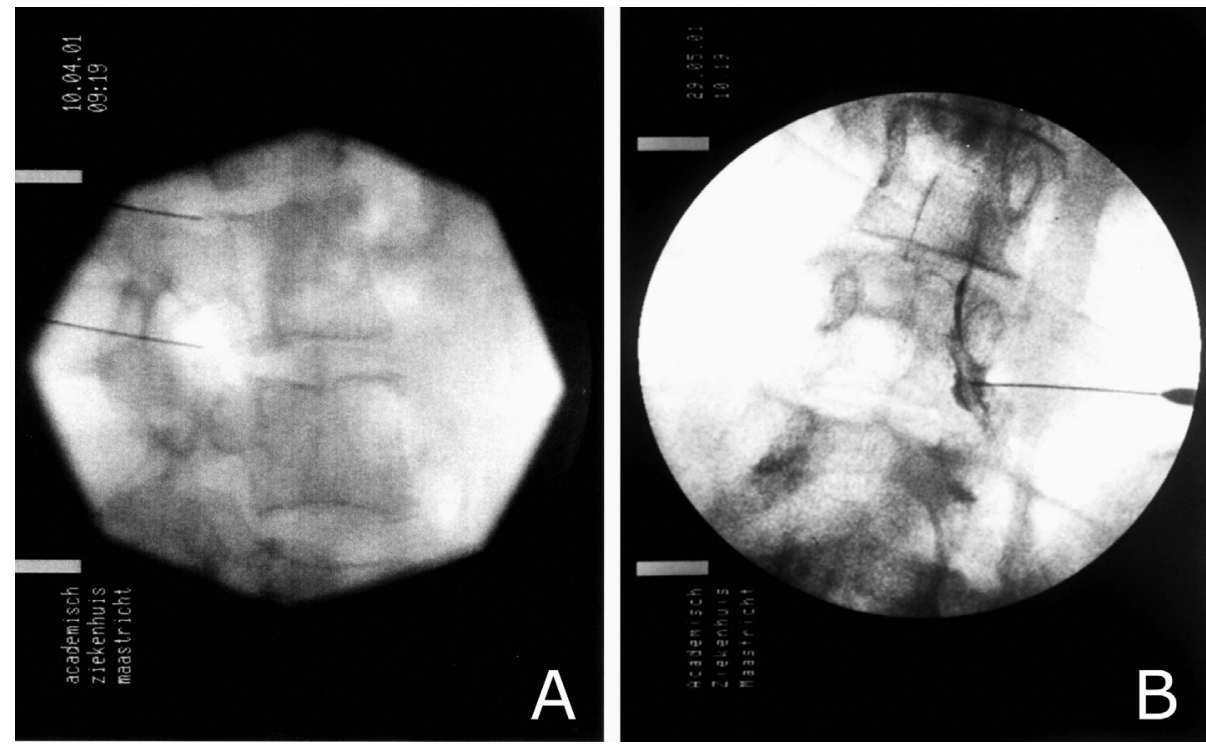

Figure 4.2 Photomicrograph showing the position of a RF electrode a: lateral view and b: anteriorposterior view after injection of Omnipaque.

In an AP view, the course of a small amount of contrast agent was followed with "real-time imaging"; it should spread out laterocaudally along the spinal nerve (Figure 4.2b). The stylet was removed and exchanged for the radio frequent probe. After checking the impedance (an indicator for the type of tissue next to the cannula tip), electrical stimulation was started at a rate of $2 \mathrm{~Hz}$ and the corresponding muscles were observed for contractions. At $2 \mathrm{~Hz}$ stimulation motor contractions should be observed in the area of the relevant muscles at a threshold between 0.4 -0.8 Volts. $1 \mathrm{ml}$ local anaesthetic solution (bupivacain 0.5\%) was injected and radio frequent current was then led through the electrode in 
order to increase the temperature to $67^{\circ} \mathrm{C}$ for 60 seconds. Total operating time, including anaesthesia, was about 45 minutes. All patients were discharged from the clinic the same day after full recovery from the anaesthesia.

\section{RESULTS}

A total of 19 RF-DRG treatments were performed in 17 patients. One patient received three interventions, as the effects gradually wore off. A summary of the clinical data, including treated levels and outcome measures, are given in table 4.1 (group A: 6 patients) and table 4.2 (group B: 11 patients). In 2 patients a transient increase in pain after the RF-DRG procedure was noted, and 1 patient was successfully treated with Gabapentine for 4 weeks. No further side-effects (e.g. dysaesthesia or excessive weakness in the treated limbs) were reported. No significant differences were observed between the different lumbar levels for both the impedance and the stimulation threshold.

Group A: In the first six systematically evaluated children (table 4.1) an improvement in muscle tone after RF-DRG was detected on both the short (4 weeks) and long ( 6 months) term using the MAS. Especially the right hip adductors showed improvement on the MAS which went from $2.2+/-0.5$ before RFDRG to $0.5+/-0.2$ four weeks after RF-DRG and $1.0+/-0.4$ six months after RFDRG (table 4.3). Due to the small sample size, no comment on the lack of significance of a null result can be given.

Using the GMFM no improvement was observed after RF-DRG treatment. At baseline a mean total score including all 5 domains of $17.2 \%+/-6$ was found. After 4 weeks the score was $17.3 \%+/-7$ and after 6 months the score was 16.2 $\%+/-6$.

Using the caregiver's questionnaire, an improvement in ease and quality of care and pain was detected. Although statistically not significant, in four patients pain in the lower extremities decreased, at both 4 weeks and 6 months. In one patient there was no change in pain and in another patient pain increased at 4 weeks but decreased at 6 months when compared to the baseline.

Group B: Because of the abovementioned results we switched to a VAS to evaluate the initiated treatment in the subsequent patients. This score was available in 8 out of the 11 patients. The missing values are due to the fact that some caregivers did not feel comfortable judging their own child in a numerical way. During outpatient follow up, the evaluation of the VAS scores showed improvement in most of the defined treatment goals in most children (table 4.2). Most parents reported that the positive effects of the RF-DRG lasted at least 6-9 months.

In one patient (no. 9), the VAS score showed no change after the third procedure. Her flexor spasms were then successfully treated with Botulinum ToxinA injections in the iliopsoas and adductor muscles (Dysport, Ipsen). 


\section{DISCUSSION}

To test our hypothesis that RF-DRG may be a serious treatment option for severe spasticity in children with $\mathrm{CP}$, we undertook a pilot study in 17 patients. Our primary treatment goal was improvement of well-being and ease of care of patients with CP with severe hip flexor/adductor spasms and pain. Our first 6 consecutively treated patients (Group A) were evaluated at baseline, 1 month after treatment, and 6 months after treatment using the GMFM and the MAS. We found a small improvement in muscle tone on the MAS, but no effect on the GMFM scale. Despite this, the caregivers of these six treated children unanimously stated that the quality of life of their children had indeed improved after the RF-DRG (data not shown, summary represented by +/- in table 4.1). This disagreement between the MAS and the judgement of the caregivers highlights the difficulties measuring change in these severely handicapped children. The MAS as a method for the evaluation of the treatment of spasticity in children with $\mathrm{CP}$ has been disputed before, although in adult populations the reliability of the MAS has been demonstrated. ${ }^{28}$ In a study in children with moderate to severe spasticity, a wide variability in test-retest results was reported for the MAS. ${ }^{27}$ The assumption that the MAS exclusively measures spasticity is not entirely right. The MAS measures a broader set of neural and musculoskeletal factors of non-velocity-dependent hypertonia in addition to spasticity itself. ${ }^{26}$

Furthermore, we added up the MAS scores of different muscles to produce a summed Ashworth score, in order to compare with most previous studies. However, this might be methodologically incorrect as the Ashworth score is an ordinal level measure. ${ }^{35}$

For the next 11 patients we thus changed our evaluating system: instead of the MAS and the GMFM, we asked the caregivers to give a VAS score for spasticity, pain, and ease of care at different time points. Using this outcome measure we were able to show a significant improvement in spasticity, pain, and ease of care after an RF-DRG procedure, lasting up to 9 months. In two patients we found a transient increase in pain, for which 1 patient received Gabapentine for 4 weeks. This is a known transient procedure related event. ${ }^{36}$ Although this was not a controlled study, the amount of improvement in VAS scores is in the same range as in conventional treatments, e.g. ITB and SDR. ${ }^{30,}{ }^{37}$ RF-DRG is thus a promising new treatment option for severe spasticity in patients with $\mathrm{CP}$, and its definitive effectiveness remains to be defined in a randomized controlled trial. It is less invasive and probably has less side-effects than ITB and SDR, but its main disadvantage in this patient population is, of course, the temporary character of its effects. In this regard RF-DRG resembles BTX-A treatment, but its main advantage over this therapeutic option is its strong pain-reducing effect. Theoretically, repetitive RF-DRGs may lead to dysesthesias and causalgias, but we have not seen this in the one patient we treated three times. ${ }^{34}$ To prevent this possi- 
ble side-effect, more definitive effects of RF-DRG might perhaps be achieved with higher radiofrequency currents and temperatures during the procedure.

Our pilot study does highlight the methodological problem of evaluating treatment effects in children with CP. As we were not able to conduct an extensive battery of clinical tests in our pilot study, we had to select a few outcome measures. Using the MAS and the GMFM, we were not able to detect any beneficial effects, which is in line with other studies. ${ }^{32}$ We had to resort to a VAS to find improvements in the condition of treated patients. In retrospect we should also have included the Pediatric Evaluation of Disability Inventory (PEDI), which is a generic standardized instrument used by the multidisciplinary team for evaluating functional performance, programme monitoring, documentation of functional development, and clinical decision-making. ${ }^{30,37,38}$

The exact mechanism of action of an RF-DRG remains unknown. We recently reported an increase of proliferation inside the dorsal root ganglion after RFDRG adjacent to the ganglion without signs of neural tissue damage (e.g. necrosis) inside the ganglion. ${ }^{39}$ For years, the only mode of action of a radiofrequency lesion was thought to be through nerve damage due to thermocoagulation. ${ }^{40}$ Recent experiments with pulsed radiofrequency treatment (a high-frequency current delivered in bursts of $20 \mathrm{~ms}$ followed by a silent period of $480 \mathrm{~ms}$, during which the generated heat is washed out) suggest that thermocoagulation is not the only mode of action. ${ }^{40,41} \mathrm{~A}$ late and temperature-independent increase in the expression of the immediate early $c$-fos gene within the rat spinal cord was found after exposure of the cervical dorsal root ganglion to continuous radiofrequency $\left(67^{\circ} \mathrm{C}\right)$ and pulsed radiofrequency current. ${ }^{42}$ In one model of spasticity, the locomotor abnormalities are thought to be the result of hyperexcitability of spinal interneurons involved in the spinal stretch reflex. ${ }^{43}$ Reduction of spinal input through de-afferentation is then the basic mechanism of RF-DRG.

\section{CONCLUSION}

Our pilot study on RF-DRG in 17 patients with CP with severe hip flexor/adductor spasms and pain shows that it may improve spasticity, pain, and ease of care, with a duration of up to 9 months. As the amount of improvement is in the same range as in conventional treatments, RF-DRG is thus a promising new treatment option for severe spasticity in patients with $\mathrm{CP}$, and its definitive effectiveness remains to be defined in a randomized controlled trial. The main advantages are the less invasive character of RF-DRG compared to the SDR with the potential benefit of a shorter hospitalization period, and its clear painreducing effect. 


\section{REFERENCES}

1. Krigger KW. Cerebral palsy: an overview. Am Fam Physician 2006. 73(1): p. 91-100.

2. Farmer JP and Sabbagh AJ. Selective dorsal rhizotomies in the treatment of spasticity related to cerebral palsy. Childs Nerv Syst 2007. 23(9): p. 991-1002.

3. Foerster 0. On the indications and results of the excision of posterior spinal roots in men. Surg Gynecal Obstet 1913.16: p. 463-474.

4. Langerak NG, Lamberts RP, Fieggen AG, et al. A prospective gait analysis study in patients with diplegic cerebral palsy 20 years after selective dorsal rhizotomy. J Neurosurg Pediatr 2008. 1(3): p. 180-6.

5. Steinbok P. Selective dorsal rhizotomy for spastic cerebral palsy: a review. Childs Nerv Syst 2007. 23(9): p. 981-90.

6. Johnson MB, Goldstein L, Thomas SS, et al. Spinal deformity after selective dorsal rhizotomy in ambulatory patients with cerebral palsy. J Pediatr Orthop 2004. 24(5): p. 529-36.

7. Spiegel DA, Loder RT, Alley KA, et al. Spinal deformity following selective dorsal rhizotomy. J Pediatr Orthop 2004. 24(1): p. 30-6.

8. Steinbok P, Hicdonmez T, Sawatzky B, et al. Spinal deformities after selective dorsal rhizotomy for spastic cerebral palsy. J Neurosurg 2005. 102(4 Suppl): p. 363-73.

9. Turi $\mathrm{M}$ and Kalen V. The risk of spinal deformity after selective dorsal rhizotomy. J Pediatr Orthop 2000. 20(1): p. 104-7.

10. Uematsu S, Udvarhelyi GB, Benson DW, et al. Percutaneous radiofrequency rhizotomy. Surg Neurol 1974. 2(5): p. 319-25.

11. Segnarbieux F and Frerebeau P. Neurosurgery for spasticity: a multidisciplinary approach. The different (open surgical, percutanous hermal, and intrathecal chemical) rhizotomies for the treatment of spasticity, ed. A.R.Y.K. M S. 1991, New York: Springer Verlag.

12. van Kleef M. Radiofrequency lesions of the dorsal root ganglion in the treatment of spinal pain, ed. M. University. 1996, Maastricht: Maastricht University.

13. Herz DA, Parsons KC, and Pearl L. Percutaneous radiofrequency foramenal rhizotomies. Spine (Phila Pa 1976) 1983. 8(7): p. 729-32.

14. Kasdon DL and Lathi ES. A prospective study of radiofrequency rhizotomy in the treatment of posttraumatic spasticity. Neurosurgery 1984. 15(4): p. 526-9.

15. Vles J, van Kleef M, Sleypen F, et al. Radiofrequency lesions of the dorsal root ganglion in the treatment of hip flexor spasm: a report of two cases. Eur J Paediatr Neurol 1997. 1(4): p. 123-6.

16. Bagg MR, Farber J, and Miller F. Long-term follow-up of hip subluxation in cerebral palsy patients. J Pediatr Orthop 1993. 13(1): p. 32-6.

17. Schwartz L, Engel JM, and Jensen MP. Pain in persons with cerebral palsy. Arch Phys Med Rehabil 1999. 80(10): p. 1243-6.

18. Mayer NH. Clinicophysiologic concepts of spasticity and motor dysfunction in adults with an upper motoneuron lesion. Muscle Nerve Suppl 1997. 6: p. S1-13.

19. Palisano R, Rosenbaum P, Walter S, et al. Development and reliability of a system to classify gross motor function in children with cerebral palsy. Dev Med Child Neurol 1997. 39(4): p. 21423.

20. Wood E and Rosenbaum P. The gross motor function classification system for cerebral palsy: a study of reliability and stability over time. Dev Med Child Neurol 2000. 42(5): p. 292-6.

21. Robin J, Graham HK, Baker R, et al. A classification system for hip disease in cerebral palsy. Dev Med Child Neurol 2009. 51(3): p. 183-92.

22. Bohannon RW and Smith MB. Interrater reliability of a modified Ashworth scale of muscle spasticity. Phys Ther 1987. 67(2): p. 206-7.

23. Kirschner J HF, Mall F, Linder M, Stein S, Michaels U, Korinthenberg R. Gross Motor Function Measure for therapy evaluation in children treated with botulinum toxin A. Dev Med Child Neurol. 1199878 (Suppl:I1.).

24. Russell D, Rosenbaum P, Gowland C, et al. Manual for the Gross Motor Function Measure. 1993, Hamilton ON, Canada: McMaster University. 
25. Russell DJ, Rosenbaum PL, Cadman DT, et al. The gross motor function measure: a means to evaluate the effects of physical therapy. Dev Med Child Neurol 1989. 31(3): p. 341-52.

26. Delgado MR, Hirtz D, Aisen M, et al. Practice parameter: pharmacologic treatment of spasticity in children and adolescents with cerebral palsy (an evidence-based review): report of the Quality Standards Subcommittee of the American Academy of Neurology and the Practice Committee of the Child Neurology Society. Neurology 2010. 74(4): p. 336-43.

27. Fosang AL, Galea MP, McCoy AT, et al. Measures of muscle and joint performance in the lower limb of children with cerebral palsy. Dev Med Child Neurol 2003. 45(10): p. 664-70.

28. Gregson JM, Leathley M, Moore AP, et al. Reliability of the Tone Assessment Scale and the modified Ashworth scale as clinical tools for assessing poststroke spasticity. Arch Phys Med Rehabil 1999. 80(9): p. 1013-6.

29. Stinson JN, Kavanagh T, Yamada J, et al. Systematic review of the psychometric properties, interpretability and feasibility of self-report pain intensity measures for use in clinical trials in children and adolescents. Pain 2006. 125(1-2): p. 143-57.

30. Hoving MA, van Raak EP, Spincemaille GH, et al. Efficacy of intrathecal baclofen therapy in children with intractable spastic cerebral palsy: a randomised controlled trial. Eur J Paediatr Neurol 2009. 13(3): p. 240-6.

31. Vles GF, de Louw AJ, Speth LA, et al. Visual Analogue Scale to score the effects of Botulinum Toxin A treatment in children with cerebral palsy in daily clinical practice. Eur J Paediatr Neurol 2008. 12(3): p. 231-8.

32. Hanna $\mathrm{K}$ and Rodger $\mathrm{S}$. Towards family-centered practice in paediatric occupational therapy: a review of the literature on parent-therapist collaboration. Aust Occup Ther J 2002. 49: p. 4-24.

33. White-Koning M, Arnaud C, Bourdet-Loubere S, et al. Subjective quality of life in children with intellectual impairment--how can it be assessed? Dev Med Child Neurol 2005. 47(4): p. 281-5.

34. van Kleef M, Barendse GA, Dingemans WA, et al. Effects of producing a radiofrequency lesion adjacent to the dorsal root ganglion in patients with thoracic segmental pain. Clin J Pain 1995. 11(4): p. 325-32.

35. Pandyan AD, Johnson GR, Price CI, et al. A review of the properties and limitations of the Ashworth and modified Ashworth Scales as measures of spasticity. Clin Rehabil 1999. 13(5): p. 373-83.

36. van Kleef M, Liem L, Lousberg R, et al. Radiofrequency lesion adjacent to the dorsal root ganglion for cervicobrachial pain: a prospective double blind randomized study. Neurosurgery 1996. 38(6): p. 1127-31; discussion 1131-2.

37. Nordmark E, Josenby AL, Lagergren J, et al. Long-term outcomes five years after selective dorsal rhizotomy. BMC Pediatr 2008. 8: p. 54.

38. Haley S, Coster W, Ludlow L, et al. Peadiatric Evaluation Disability Inventory (PEDI), Version 1,0. 1992, Boston, MA, USA: New England Medical Centre Hospitals, Inc.

39. de Louw AJ, Vles HS, Freling G, et al. The morphological effects of a radio frequency lesion adjacent to the dorsal root ganglion (RF-DRG)--an experimental study in the goat. Eur J Pain 2001. 5(2): p. 169-74.

40. Sluijter M and Racz G. Technical aspects of radiofrequency. Pain Pract 2002. 2(3): p. 195-200.

41. van Zundert J LI, de Louw AJA, Jansen J, Kessels F, Patijn J, van Kleef M. . Percutaneous pulsed radiofrequency treatment of the cervical dorsal root ganglion in the treatment of chronic cervical pain syndromes: a clinical audit. Neuromodulation. 2003. 6(1): p. 6-14.

42. Van Zundert J, de Louw AJ, Joosten EA, et al. Pulsed and continuous radiofrequency current adjacent to the cervical dorsal root ganglion of the rat induces late cellular activity in the dorsal horn. Anesthesiology 2005. 102(1): p. 125-31.

43. Young RR. Spasticity: a review. Neurology 1994. 44(11 Suppl 9): p. S12-20. 
CHAPTER V

\section{LEVETIRACETAM THERAPY FOR TREATMENT OF CHOREOATHETOSIS IN DYSKINETIC CEREBRAL PALSY}

Vles GF, Hendriksen JG, Visschers A, Speth LA, Nicolai J, Vles JSH

Dev Med Child Neurol. 2009; 51(6): 487-90. 


\section{ABSTRACT}

Dyskinetic cerebral palsy (CP) is a movement disorder that is difficult to treat and which causes major disability. We report on two female patients (aged 5 and 8 years) who experienced severe perinatal asphyxia and developed dyskinetic $\mathrm{CP}$, clinically characterized by choreoathetosis.

Neuropsychological testing of these children showed a low average developmental quotient and no attentional deficits. Monotherapy with Levetiracetam (LEV) was initiated to improve balance control and fine motor skills. Treatment was evaluated by means of video analysis and the Visual Analogue Scale. In both children an impressive improvement of balance control and fine motor skills was observed. No side-effects occurred. Furthermore, both patients showed more interest for and pleasure during activities according to their parents. In a recent multidisciplinary evaluation of the initiated therapy, the parents, the therapist, and the rehabilitation doctor all confirmed that the effect initially observed was still present at 14 respectively 26 months after commencement of treatment. To our knowledge, this report on two patients with dyskinetic CP is the first suggesting that LEV may offer an alternative to the standard therapy of involuntary, uncontrolled movements in this group of patients. 


\section{BACKGROUND}

Cerebral palsy (CP) is a non-progressive disorder of posture or movement caused by a lesion of the developing brain. The Surveillance of Cerebral Palsy in Europe (SCPE) has classified CP into three main groups (spastic, dyskinetic, and ataxic), which are based on clear neurological signs indicating pathology of the cerebral motor systems (table 1.1). ${ }^{1}$ Dyskinetic CP presents with involuntary, uncontrolled, recurring, and, occasionally, stereotyped movements. The SCPE distinguishes between dystonic and choreoathetotic subtypes for dyskinetic CP. The pathophysiology of dyskinesia in $\mathrm{CP}$ is not fully elucidated, but existing evidence suggests that disorders of the basal ganglia (BG) play a role in this entity.

The symptomatic treatment of this movement disorder is still very difficult. In a retrospective survey of 22 children with extrapyramidal $\mathrm{CP}$, only a minority showed a functional improvement using trihexyphenidyl, which is a centrally active muscarinic antagonist. ${ }^{2}$

Several anticonvulsants seem to be efficacious for the treatment of (paroxysmal) involuntary movement disorders. On the basis of a recent report about Levetiracetam (LEV) efficacy in the treatment of movement disorders, we started LEV in two patients with dyskinetic CP unresponsive to conventional drugs mostly used in such cases. ${ }^{3}$

To our knowledge, this report on two patients with dyskinetic $\mathrm{CP}$, is the first suggesting that LEV may offer an alternative to standard therapy of involuntary, uncontrolled movements in this group of patients.

\section{METHODS}

Informed consent of the parents was obtained for both patients. LEV was only started after the other available drugs usually prescribed had failed. Baclofen (GABA-agonist) and Artane (Muscarine-antagonist) were tried but did not show the desired effect. The initial dose of LEV was $2.5 \mathrm{mg} / \mathrm{kg} /$ day. The dosage was titrated over weeks to months, based on response as well as tolerability.

Cognitive functioning of both children was described using standardized instruments which could be used in children with serious disabilities, as formal testing with, for instance, the Wechsler Intelligence Scale for Children-III is not possible because of motor disabilities. ${ }^{4}$ We used the Peabody Picture Vocabulary Test - Third Edition (PPVT-III-NL) ${ }^{5}$ to describe receptive vocabulary, which is a commonly used screening test for verbal ability. Furthermore, a subtest from a standardized Dutch nonverbal intelligence test (subtest matrix analogies from the Snijders Oomen Nonverbal Intelligence Test) ${ }^{6}$ for which no motor response is necessary, was used. Using the Child Behavior Checklist (CBCL), which is a by- 
proxy instrument, general behavioural functioning, especially the existence of attentional problems, was assessed. ${ }^{7}$

The patients were re-evaluated on a regular basis by an occupational therapist, using video analysis. The parents regularly used the Visual Analogue Scale (VAS), an ordinal scale that ranges from 0 to 10 , to score improvements on goals defined before treatment with LEV was started. The VAS is known as a valid and reliable measure for rating pain intensity in adults and children of more than 6 years of age and has recently been found useful for evaluating therapy in children with CP.8, 9 When clinicians are raters, the VAS validly identifies the minimal clinically important difference on the Pediatric Evaluation of Disability Inventory. ${ }^{10}$

Based on these two parameters combined with regular visits at our outpatient department (LS and JSHV) a decision was made with the parents either to continue the drug or taper it off.

\section{Case 1}

A 5-year-old female experienced severe perinatal asphyxia (umbilical artery $\mathrm{pH}$ 6.8). Pregnancy had been complicated by pre-eclampsia. Neurological examination was compatible with Sarnat II encephalopathy. During the first hours of life the infant experienced severe neonatal seizures, for which she was treated with midazolam. The electroencephalogram showed a burst suppression image with severe epileptic activity. MRI showed abnormal signal intensity within the basal ganglia and thalami. Furthermore, focal signal abnormalities in the posterior limb of the internal capsules were observed.

From the beginning, she showed developmental delay and hypotonia. As time went by she developed a severe movement disorder characterized by involuntary, uncontrolled, and occasional stereotyped movements, which can be classified as dyskinetic CP. Psychological examination showed that her vocabulary quotient on the PPVT-III-NL was low average (quotient score 82). Matrix reasoning was in accordance with this level of verbal abilities (standard-score 85). Her behaviour (reported by the parents using the CBCL) did not reveal significant attentional problems.

At the age of 5 years she was presented to the outpatient clinic for further treatment. The following goals were formulated: to improve sitting independently (balance control) and to improve grasping for and pointing towards objects (fine motor skills). Monotherapy with LEV was initiated, reaching a final dose of $5 \mathrm{mg} / \mathrm{kg} /$ day. Raising this dose was suggested, but parents were satisfied since all the treatment goals were achieved.

Evaluation of therapy and obtainment of VAS scores were carried out on a regular basis. After 3 months the child's parents rated her balance control limitations as 0 (before treatment: 8.2) and her limitations concerning grasping and fine motor skills as 3 (before treatment: 8.2). The patient is, for the first time in 
her life, able to drink independently from a cup with two handles. Also, she is now able to bring a fork to her mouth after being handed the fork and she needs less assistance when colouring. The patient shows more initiative and pleasure during activities has increased according to her parents. At 6, 9, and 14 months after commencement of treatment VAS scores confirmed these improvements.

Comparing videos before LEV treatment and 3 months after initiating medication, fewer fidgety movements of the trunk, less overextension of arms and hands during actions, and less (dystonic) co-movements of arms and mouth were seen. To our surprise she also showed marked improvement of speech and was now easier to understand. This was confirmed by a speech therapist. No side-effects were noted.

In a recent multidisciplinary evaluation of the initiated therapy, the parents, the therapist, and the rehabilitation doctor all confirmed that the effect initially observed was still present 14 months later.

\section{Case 2}

An 8-year-old female was born by means of Ventouse delivery after normal pregnancy. She was suffering from severe peripartal asphyxia (pH 7.12) and had to be resucitated.

From the beginning she showed developmental delay, axial hypotonia, constant abnormal tongue protrusion, and abnormal spontaneous motor activity. At the age of 7 years she was re-evaluated. Neurological examination showed a cooperative child with good social contact, but with a severe dyskinetic movement disorder, which, for example, made reaching for objects impossible. Furthermore, an MRI was performed and showed abnormal signal intensity within the lateral thalami and in the dorsal putamen on both sides.

Psychological examination showed that her vocabulary quotient on the PPVT-III-NL was in the low average range (quotient score 80). Her matrix reasoning was also low average (standard-score 78). CBCL behaviour report by the parents and teachers did not reveal significant attentional problems.

Therapy with LEV was initiated to improve trunk balance and fine motor skills. The starting dose was $2.5 \mathrm{mg} / \mathrm{kg} /$ day and was titrated to a final dose of $10 \mathrm{mg} / \mathrm{kg} /$ day. No side-effects were noted.

Evaluation of therapy and obtainment of VAS scores were carried out on a regular basis. After 6 months, parents rated her balance control limitations as 5 (before treatment: 7) and her fine motor skills limitations as 6 (before treatment: 10). Again, the patient showed more interest in and pleasure during activities according to her parents.

Comparing videos before medication and 3 months after initiating medication one can see that she is now able to independently cut pieces of paper whereas before much assistance was needed. Both the number of uncontrolled movements and their ranges of motion decreased. 
The child is now capable of holding a pencil with just three fingers and staying between the lines while previously she used her whole hand just to draw several uncontrolled crude lines. While working on her computer she used to be able to click on a $5 \mathrm{~cm}$ square, but this has now decreased to a $2 \mathrm{~cm}$ square.

In a recent multidisciplinary evaluation of the initiated LEV therapy, the parents, the therapist, and the rehabilitation doctor all confirmed that the effect initially observed was still present 26 months later.

\section{DISCUSSION}

The main difficulties for patients with choreoathetoid CP relate to their involuntary movements, which can be very powerful and extremely difficult to interrupt, making purposeful movement impossible. ${ }^{11}$ In patients with Huntington disease, it was found that chorea, when moderate to severe, can cause major disability and have a significant negative impact on daily life. ${ }^{12}$ In Parkinson patients, it was found that dyskinesias are associated with a reduction of Quality of Life and with an increase in total health-related-costs. ${ }^{13}$ In children with choreoathetoid encephalopathy after cardiac surgery, it was found that restrictions in the range of activities in which children participated (e.g. hobbies, clubs, sports) and difficulties in peer and sibling relationships led to poor total adaptive competence. ${ }^{14}$

So one may conclude that choreoathetosis is a very disabling disease. Various drugs have been tried but with no great success. We did not try the recommended presynaptic and postsynaptic dopamine antagonists because of lack of experience. Furthermore, tetrabenazine is not available for the treatment of children in the Netherlands.

To our knowledge, this is the first description of two patients with a nonprogressive, non-paroxysmal, dyskinetic movement disorder who have been treated with LEV to diminish choreoathetosis.

Evaluation of LEV treatment was done both objectively, by video analysis, and subjectively, by VAS. After 6 months both video analysis and VAS showed that (limitations by) choreoathetosis had decreased while no side-effects had occurred. It is very unlikely that these positive effects are due to maturation or to training given the course over time. Reasons for not increasing the dose of medication any further were that parents felt that all the goals were accomplished and that adverse affects, like somnolence, obtundation, and Parkinsonism, of which they were informed beforehand, should be avoided. ${ }^{15,16}$

Based on the results achieved with these two patients we may conclude that LEV may be used as an alternative to treat unmanageable choreoathetosis of a non-progressive kind, e.g. in children with dyskinetic CP. This is important because choreoathetosis appears to be a very severe and disabling condition which is difficult to treat. This could partly be due to the differences in patho- 
physiology between the two aspects of the condition, i.e. athetosis can be treated by increasing dopaminergic activity in the BG, while chorea can be treated by decreasing dopaminergic activity. ${ }^{2}$

These findings and our results suggest that LEV might reduce choreoathetosis by means of another pathway. So far, the synaptic vesicle protein SV2A has been identified as the binding site for LEV, but the molecular action of SV2A is still unknown. ${ }^{17}$

Further and larger studies are needed to confirm the positive effects of LEV on choreo-athetosis in patients with a non-progressive, non-paroxysmal, dyskinetic movement disorder. 


\section{REFERENCES}

1. Surveillance of cerebral palsy in Europe (SCPE). Surveillance of cerebral palsy in Europe: a collaboration of cerebral palsy surveys and registers. Surveillance of Cerebral Palsy in Europe (SCPE). Dev Med Child Neurol 2000. 42(12): p. 816-24.

2. Hoon AH, Jr., Freese PO, Reinhardt EM, et al. Age-dependent effects of trihexyphenidyl in extrapyramidal cerebral palsy. Pediatr Neurol 2001. 25(1): p. 55-8.

3. D'Amelio M, Callari G, Gammino M, et al. Levetiracetam in the treatment of vascular chorea: a case report. Eur J Clin Pharmacol 2005. 60(11): p. 835-6.

4. Wechsler D. Wechsler Intelligence Scale for Children - Third edition (WISC-III-NL). . Dutch version, ed. W. Kort, et al. 2005, Amsterdam: Harcourt Test Publishers.

5. Dunn L and Dunn LM. Peabody Picture Vocabulary Test-Third Edition (PPVT-III-NL). Dutch version, ed. L. Schlichting. 2004, Amsterdam: Harcourt Test Publishers.

6. Tellegen P, Winkel M, Wijnber-Williams B, et al. Snijders-Oomen Nonverbal Intelligence Test. Manual and Research report. 1998, Lisse: Swets Test Publishers.

7. Achenbach $\mathrm{T}$ and Edelbrock C. Manual for the Child Behavior Checklist and revised Child behavior profile. Dutch version, ed. F. Verhulst, J. Koot, and J. van der Ende. 1996, Rotterdam.

8. Stinson JN, Kavanagh T, Yamada J, et al. Systematic review of the psychometric properties, interpretability and feasibility of self-report pain intensity measures for use in clinical trials in children and adolescents. Pain 2006. 125(1-2): p. 143-57.

9. Vles GF, de Louw AJ, Speth LA, et al. Visual Analogue Scale to score the effects of Botulinum Toxin A treatment in children with cerebral palsy in daily clinical practice. Eur J Paediatr Neurol 2008. 12(3): p. 231-8.

10. Iyer LV, Haley SM, Watkins MP, et al. Establishing minimal clinically important differences for scores on the pediatric evaluation of disability inventory for inpatient rehabilitation. Phys Ther 2003. 83(10): p. 888-98.

11. Aicardi J and Bax M, Cerebral palsy, in Disease of the nervous system in childhood, J. Aicardi, Editor. 1998, Mac Keith Press: London. p. 210-239.

12. Caine ED and Shoulson I. Psychiatric syndromes in Huntington's disease. Am J Psychiatry 1983. 140(6): p. 728-33.

13. Pechevis M, Clarke CE, Vieregge $P$, et al. Effects of dyskinesias in Parkinson's disease on quality of life and health-related costs: a prospective European study. Eur J Neurol 2005. 12(12): p. 956-63.

14. du Plessis AJ, Bellinger DC, Gauvreau K, et al. Neurologic outcome of choreoathetoid encephalopathy after cardiac surgery. Pediatr Neurol 2002.27(1): p. 9-17.

15. Zesiewicz TA, Sullivan KL, Hauser RA, et al. Open-label pilot study of levetiracetam (Keppra) for the treatment of chorea in Huntington's disease. Mov Disord 2006. 21(11): p. 1998-2001.

16. Zesiewicz TA, Sullivan KL, Maldonado JL, et al. Open-label pilot study of levetiracetam (Keppra) for the treatment of levodopa-induced dyskinesias in Parkinson's disease. Mov Disord 2005. 20(9): p. 1205-9.

17. Lynch BA, Lambeng N, Nocka K, et al. The synaptic vesicle protein SV2A is the binding site for the antiepileptic drug levetiracetam. Proc Natl Acad Sci U S A 2004. 101(26): p. 9861-6. 


\section{CHAPTER VI}

\section{VISUAL ANALOGUE SCALE TO SCORE THE EFFECTS OF BOTULINUM TOXIN A TREATMENT IN CHILDREN WITH CEREBRAL PALSY IN DAILY CLINICAL PRACTICE}

Vles GF, de Louw AJA, Speth LA, van Rhijn LW, Janssen-Potten YJM, Hendriksen JG, Vles JSH

Eur J Paediatr Neurol. 2008; 12(3): 231-8. 


\section{ABSTRACT}

\section{Objective}

This study examined the validity and efficacy of the Visual Analogue Scale (VAS) when evaluating spasticity treatment in an outpatient setting.

\section{Patients and methods}

We used a parent-reported VAS device to evaluate the effects of Botulinum Toxin A (BTX-A) treatment. Data were collected on 55 children with cerebral palsy (CP). Individual goals of treatment were formulated in close consultation with the caregivers. The categories of treatment options were improvement of pain, problems with nursing, sitting position, standing, and walking.

\section{Results}

Seventy-four interventions were performed in 55 children with CP. A statistically significant effect was found for improvement of nursing, standing, and walking. No statistically significant effect for pain was found, probably because of small numbers. In seven children there was no effect at all. Side-effects were observed in five children. A positive (not significant) correlation was found between the VAS and the Modified Tardieu for those children who also underwent gait analysis.

\section{Conclusion}

Using a VAS device, beneficial effects were found for nursing, standing, and walking after BTX-A treatment. Evaluating spasticity treatment by use of the VAS has important advantages as it is a quick and easy method for evaluating individually defined treatment goals in an outpatient setting, in which timeconsuming evaluations are not an option. 


\section{INTRODUCTION}

Cerebral palsy (CP) is the most common cause of childhood physical disability. Its clinical presentation can be very diverse, although $70-80 \%$ of the patients have spastic clinical features. ${ }^{1}$

Spasticity is a motor disorder characterized by a velocity-dependent increase in muscle tone with exaggerated tendon jerks. ${ }^{2}$ Several studies have shown the benefits of intramuscular Botulinum Toxin Type A (BTX-A) injections for the management of spasticity in children with $\mathrm{CP}^{3-5}$ Studies indicate that parents of children with CP consider BTX-A treatment to be an acceptable form of therapy. ${ }^{6}$

BTX-A inhibits cholinergic transmission at neuromuscular synapses and relaxes muscles. Clinical effects are usually observed after 2-5 days and last for 16-24 weeks. ${ }^{7-9}$ Although evaluation of therapy is essential, there is no quick and easy to use outcome measure available to evaluate the effects of BTX-A injections in spastic children in daily clinical practice. In spite of its clear limitations, the standard clinical scale for measuring spasticity at function level of the International Classification of Functioning, Disability, and Health (ICF, WHO 2001) is the Ashworth Scale. ${ }^{10}$ However, the Ashworth Scale does not measure spasticity exclusively, it has low inter-rater reliability, and it lacks precision and sensitivity for measuring smaller changes in spasticity. ${ }^{11-13}$

Although the Gross Motor Function Measurement (GMFM) is widely accepted as the best available quantitative measure for gross motor function in $\mathrm{CP}$ at activity level of the ICF, it is of limited value when determining functional benefits in severely affected children. ${ }^{14}$

In our outpatient clinic patients with different degrees of severity of $\mathrm{CP}$ are seen. Goals for BTX-A treatment are defined together with parents or caregivers and the children themselves. To quantify their satisfaction in functioning within these goals, a Visual Analogue Scale (VAS) is used. This is a subjective measure in which caregivers or children themselves are able to assess their level of functioning with regard to sitting, standing, and walking (activity level of the ICF). In more severely affected patients pain or ease of caregiving can be rated with the VAS. In ICF terms, this will influence participation and quality of life.

In this article, the results of BTX-A injections on nursing, sitting, standing, walking, and pain in a group of children with $\mathrm{CP}$ as evaluated by means of the VAS are presented. Furthermore, correlations will be made between the VAS, a subjective measure, and more objective measures at function level of the ICF in patients able to walk. 


\section{PATIENTS AND METHODS}

In order to evaluate our daily clinical practice, we prospectively collected data on 55 children with CP (25 males; 30 females) with a mean age of 8.3 years (SD 3.3 ) at the moment of the first intervention (table 6.1). Patients were carefully selected for BTX-A treatment by a multidisciplinary team of specialists (LR, LS, $\mathrm{JV}$, and physiotherapists). Depending on the individually formulated goals the target muscle groups for treatment were defined. The treatment goals are shown in table 6.2. Children were included for treatment only after informed consent of the caregivers.

Table 6.2 Defined intervention goals

\begin{tabular}{cccccc}
\hline & GMFCS & Walking & Pain & Nursing & Standing \\
\hline Diagnosis & & & & & \\
Unilateral & 1 & 12 & 1 & - & 2 \\
Bilateral & 3 & 1 & - & - & - \\
& 1 & 6 & 1 & - & - \\
& 2 & 11 & - & - & - \\
& 3 & 14 & - & 5 & 4 \\
& 4 & $11^{*}$ & 1 & 6 & 4 \\
\hline
\end{tabular}

* Indoor walking and transfer

\section{Intervention}

The children received BTX-A injections (Dysport, Ipsen) under general anaesthesia in the day-care department of the Maastricht University Medical Centre (LR, LS, and JV). Each patient was given an individual clinical examination in order to determine which muscles to inject. Spastic hypertonia of a specific muscle disturbing strength and/or function or causing pain or difficulty in caregiving was a criterion to inject. The target muscles were located with the help of electrical stimulation.

Maximum dosage: $23 \mathrm{MU} / \mathrm{kg}$ bodyweight, limited to no more than 400 units per limb, within an overall maximum dose of $1200 \mathrm{MU}$ per session. After treatment, all children were discharged on the same day and they continued with their physical therapy. They were followed up at the outpatient clinic 6 and 12 weeks after intervention.

\section{Outcome measures}

Individual goals of treatment were formulated in close consultation with the caregivers. The categories of treatment goals were improvement of pain, problems with nursing, sitting position, standing, and walking. 
The VAS was used to measure the severity of the individually formulated problems. The VAS is a valid and reliable measure in rating pain intensity. ${ }^{15}$ The VAS used in pain assessment is a straight $10 \mathrm{~cm}$ horizontal line with anchor points of no pain (score 0) and unbearable pain (score 10). We changed the anchor points into very satisfied (score 0 ) and very dissatisfied (score 10) in order to use the VAS uniformly for the individually defined problems. On the day of the intervention, one of the authors (LS or JV) asked the caregivers to define their goal of the treatment and to assess their VAS score. The instrument used to rate the VAS score is shown in figure 6.1.

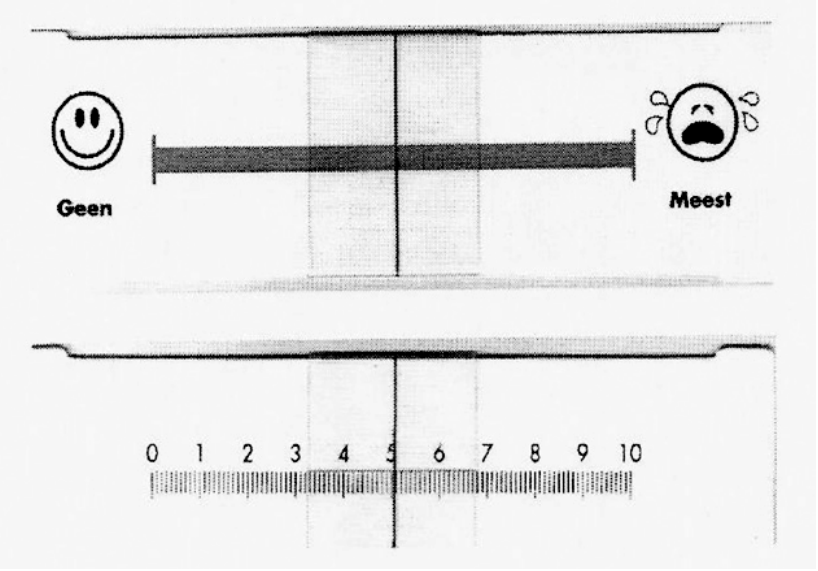

Figure 6.1 The VAS device

'Geen' 1/4 very satisfied (score 0 ), 'Meest' $1 / 4$ very dissatisfied (score 10).

We correlated the VAS with a Passive Range Of Motion (PROM), Angle Of Catch (AOC) and the Modified Tardieu for children who were able to walk.

Follow-up of each child took place at 6 and 12 weeks after intervention and a VAS score was rated. For statistical analysis the most improved post-treatment VAS score was used.

The caregivers were not informed about their pre-treatment score. Furthermore, information about side-effects and complications was collected.

\section{Statistical analysis}

The data were analyzed using SPSS 11.0.l. We used a paired sample t-test to compare the pre- and post-treatment VAS scores. One-way Anova was used to analyze sex differences affecting the dependent measures caregiving, standing, walking, and pain perception. One-way Anova was also used to test differences in aetiology and type of CP related to the effect of intervention on dependent measures. In order to calculate the correlations between the VAS and the PROM, AOC, and Modified Tardieu, we used the Spearman's rho. 


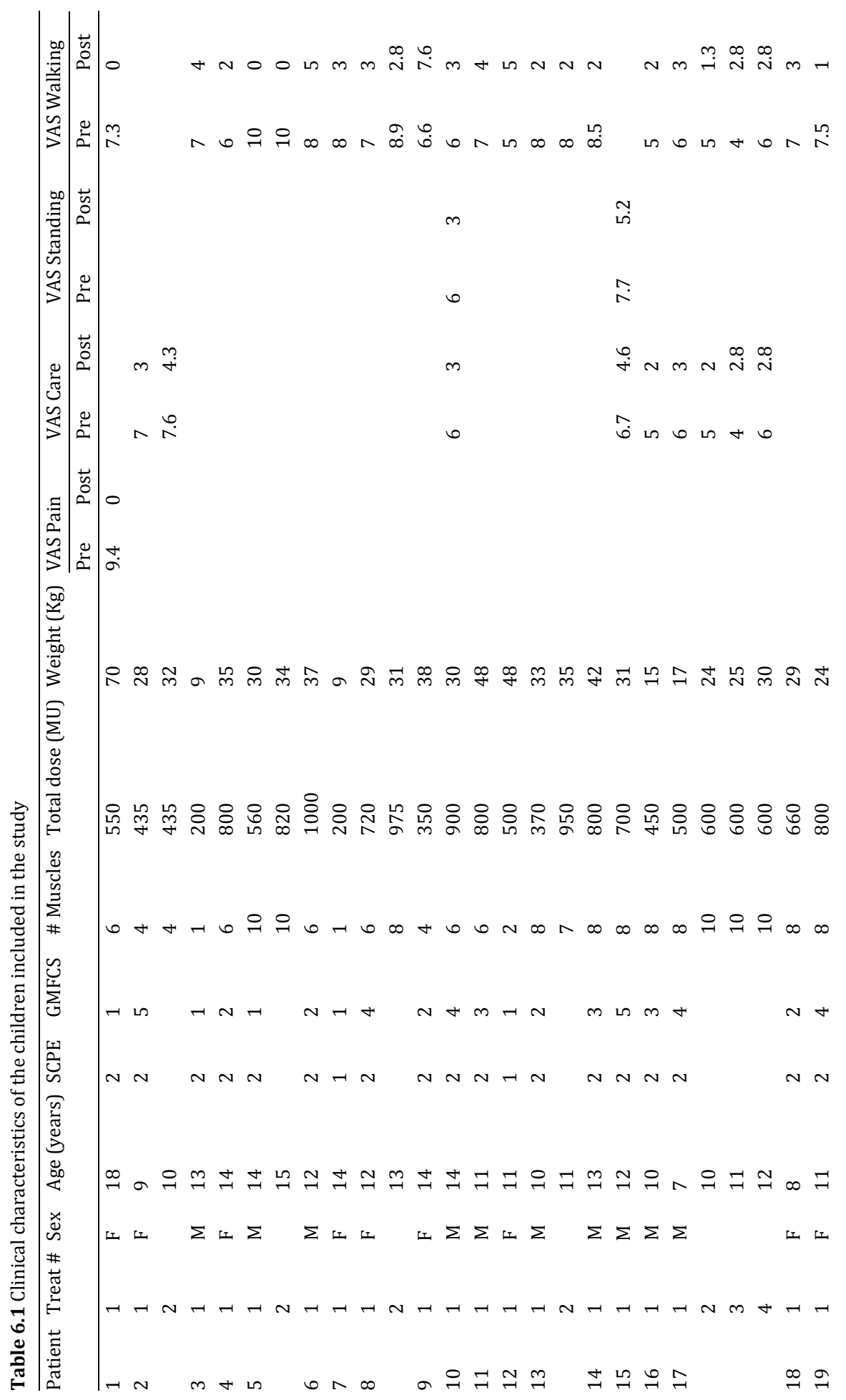




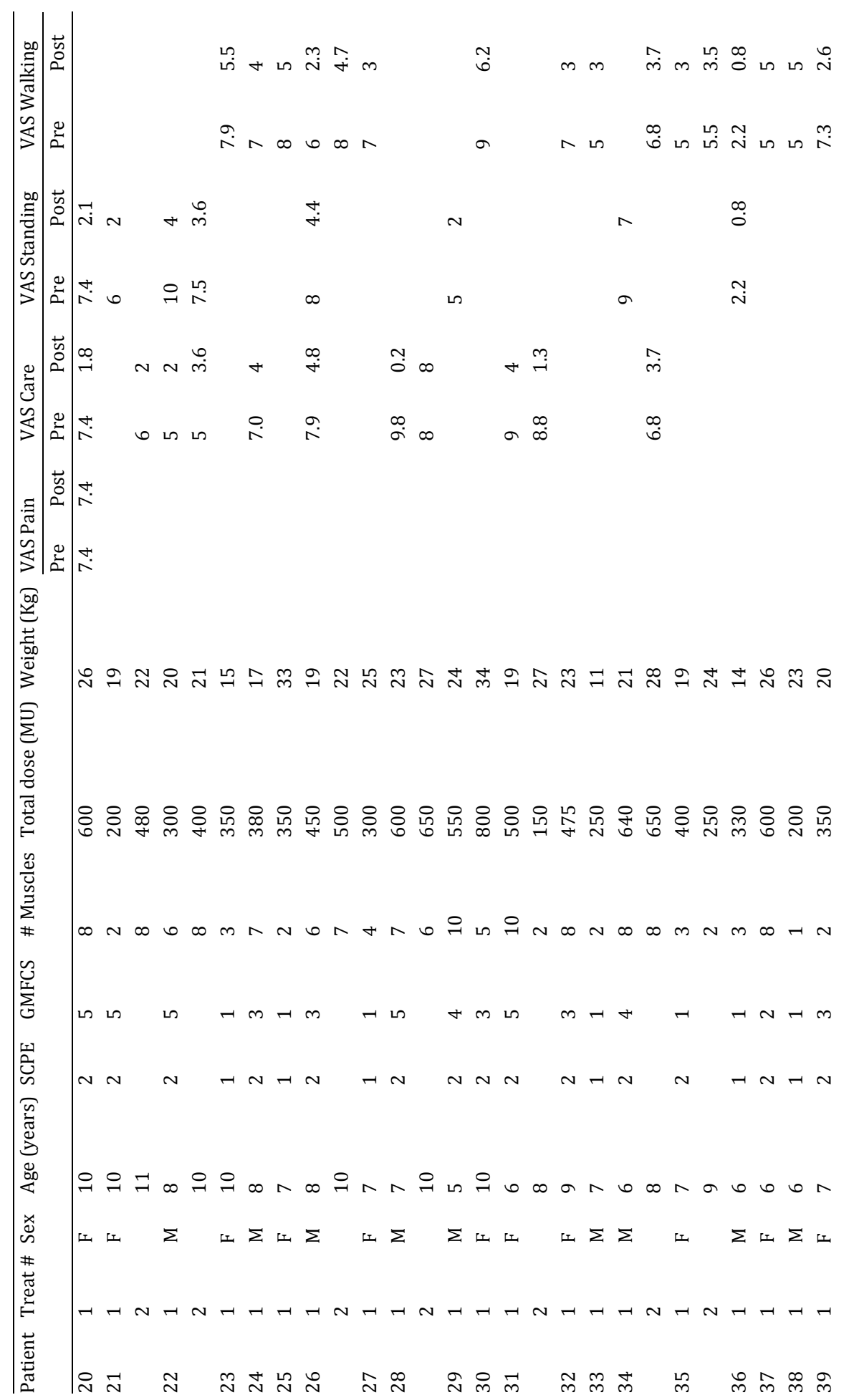




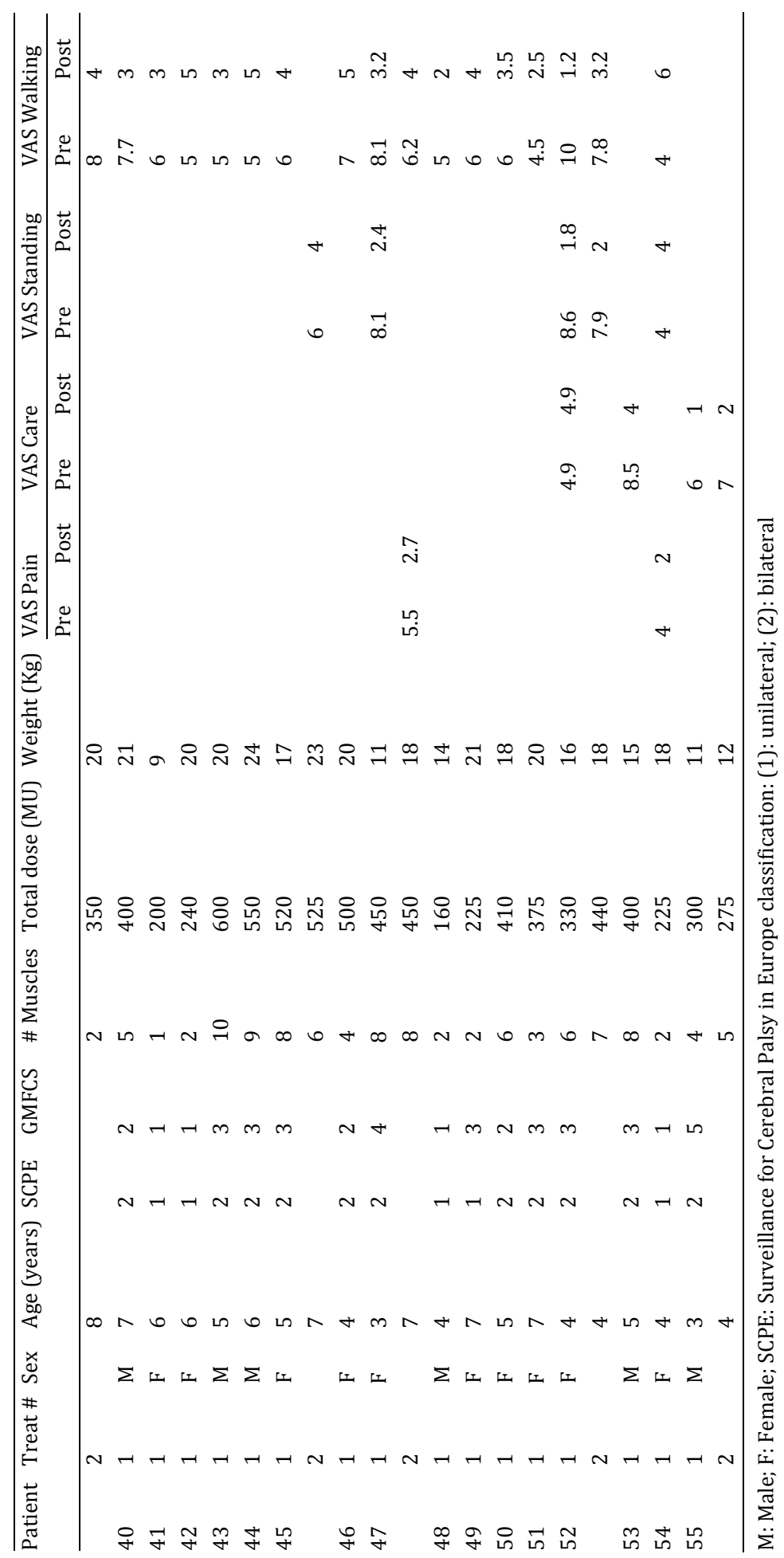




\section{RESULTS}

Seventy-four interventions were performed in 55 children. In tables 6.1 and 6.3, the main clinical characteristics of the children included are shown. The mean age at the first intervention was for both girls and boys 8.3 years. Most of the children treated were premature born children (32 out of 55) with bilateral spastic CP (29 out of 32).

Table 6.3 Diagnosis, GMFCS, aetiology and sex of the treated population

\begin{tabular}{|c|c|c|c|c|c|c|c|c|}
\hline & \multirow{3}{*}{ GMFCS } & \multicolumn{7}{|c|}{ Aetiology } \\
\hline & & \multicolumn{2}{|c|}{ Premature } & \multicolumn{2}{|c|}{ Asphyxia } & \multicolumn{2}{|l|}{ Other } & \multirow[t]{2}{*}{ Total } \\
\hline & & Male & Female & Male & Female & Male & Female & \\
\hline \multicolumn{9}{|l|}{ Diagnosis } \\
\hline \multirow[t]{2}{*}{ Unilateral } & 1 & 1 & 2 & & 1 & 3 & 5 & 12 \\
\hline & 3 & & & & & & 1 & 1 \\
\hline \multirow[t]{6}{*}{ Bilateral } & 1 & 2 & 1 & & & & 1 & 4 \\
\hline & 2 & 2 & 4 & 1 & 1 & & 1 & 9 \\
\hline & 3 & 7 & 6 & & & 1 & & 14 \\
\hline & 4 & 3 & 3 & & & 1 & & 7 \\
\hline & 5 & 1 & & 2 & 3 & 1 & 1 & 8 \\
\hline & Total & 16 & 16 & 3 & 5 & 6 & 9 & 55 \\
\hline
\end{tabular}

The number of interventions, the number of muscles treated, and the total dose of BTX-A used are shown in table 6.1.

Most interventions were bilateral (60 out of 74) and multilevel (50 out of 74). In some children, more than one goal was formulated by the caregivers. The most frequently formulated goal was improvement of walking (56 times), followed by nursing (24 times) and standing (15 times). Improvement of pain as an initial goal was formulated only 4 times.

In table 6.4 the results of a paired sample t-test are shown, comparing preand post-treatment related to the outcome variables. A statistically significant effect is found for improvement of care $(p \leq 0.000)$, standing $(p \leq 0.000)$, and walking $(p \leq 0.000)$. No statistically significant effect is found for pain $(p=0.180)$ probably because of small numbers. 
Table 6.4 Mean, standard deviation and significance comparing pre- and post treatment VAS scores on the variables caregiving, standing, walking and pain

\begin{tabular}{|c|c|c|c|c|c|c|c|c|}
\hline \multirow[t]{2}{*}{ Variable } & \multirow[t]{2}{*}{$\mathrm{N}$} & \multicolumn{2}{|c|}{ Pre-treatment } & \multicolumn{2}{|c|}{ Post-treatment } & \multicolumn{2}{|c|}{ Difference } & \multirow[t]{2}{*}{ t-value } \\
\hline & & Mean & SD & Mean & SD & Mean & SD & \\
\hline Walking & 56 & 6.62 & 1.61 & 3.27 & 1.56 & 3.35 & 2.41 & $10.40^{* * *}$ \\
\hline Pain & 4 & 6.58 & 2.34 & 3.03 & 3.13 & 3.55 & 4.07 & $1.74^{\text {n.s. }}$ \\
\hline Care & 24 & 6.68 & 1.50 & 3.12 & 1.63 & 3.57 & 2.13 & $8.22^{* * *}$ \\
\hline Standing & 15 & 6.89 & 2.04 & 3.22 & 1.60 & 3.67 & 1.96 & $7.27^{* * * *}$ \\
\hline
\end{tabular}

n.s. not significant; ${ }^{*} \mathrm{p}<0.05 ;{ }^{* *} \mathrm{P}<0.01 ;{ }^{* * *} \mathrm{p}<0.001$

Using an one-way Anova no statistically significant sex differences were found in treatment effect: boys reacted the same as girls to the outcome variables. Furthermore, no significant differences were observed between aetiology (preterm birth versus term asphyxia). Statistical analysis comparing diagnostic groups (unilateral versus bilateral spastic $\mathrm{CP}$ ) on the outcome variables could not be performed because of the small number of cases.

In table 6.5, the Spearman correlations between VAS scores (walking) and three clinical examinations of tone (PROM, AOC, and the Modified Tardieu) are presented. The following muscles were tested: quadriceps femoris, hamstrings, soleus, and gastrocnemius. In most cases, interventions were mainly restricted to gastrocnemius and hamstrings. Therefore, only these data could be analyzed. As we expected a positive relationship, an one-tailed test was used. Both PROM and AOC are not significantly correlated to the VAS. The VAS was positively correlated to the PROM for both muscle groups and to the AOC for the hamstrings. There was a negative correlation between the VAS and the AOC of the gastrocnemius. The Modified Tardieu was positively related to the VAS for all muscles investigated and significant for the left gastrocnemius.

Table 6.5 Spearman non-parametric correlation coefficient between VAS and PROM, AOC and Tardieu for walkers wit a gait analysis

\begin{tabular}{lllll}
\hline & $\mathrm{N}$ & $\Delta$ PROM & $\Delta \mathrm{AOC}$ & $\Delta$ Tardieu \\
\hline Gastrocnemius & & & & \\
$\quad$ Left & 19 & $0.15^{\text {n.s. }}$ & $-0.03^{\text {n.s. }}$ & $0.39^{*}$ \\
$\quad$ Right & 22 & $0.03^{\text {n.s. }}$ & $-0.14^{\text {n.s. }}$ & $0.20^{\text {n.s. }}$ \\
Hamstring & & & & \\
Left & 15 & $0.22^{\text {n.s. }}$ & $0.12^{\text {n.s. }}$ & $0.18^{\text {n.s. }}$ \\
Right & 18 & $0.24^{\text {n.s. }}$ & $0.13^{\text {n.s. }}$ & $0.07^{\text {n.s. }}$ \\
\hline
\end{tabular}

$\Delta$ : difference PROM, AOC and Tardieu (before and after treatment); PROM: passive range of motion; AOC: angle of catch; n.s. : not significant; ${ }^{*} \mathrm{p}<0.05 ;{ }^{* *} \mathrm{P}<0.01 ;{ }^{* * *} \mathrm{p}<0.001$

In seven children $(12.7 \%)$ there was no effect at all. Side-effects were observed 7 times in five children. One infant suffered from a flu-like illness and three had gastro-intestinal complaints: diarrhea (2) and constipation (1). In two children walking worsened and one child showed more instability during standing. In 36 
of the 74 (48.6\%), interventions a positive effect was observed for more than 12 weeks.

\section{DISCUSSION}

We evaluated the effect of BTX-A treatment on spasticity in children with CP in our outpatient clinic. Using a VAS device we found a beneficial effect on nursing, standing, and walking after BTX-A treatment. In previous studies, the beneficial effect of BTX-A treatment on pain and function has been demonstrated. ${ }^{3-5}$ The effect of BTX-A on walking is not clear. In the Cochrane review of Ade-Hall no significant effect was found. ${ }^{16}$ In articles in which parental satisfaction with functional ability was measured, positive effects are reported. ${ }^{17,18}$ The results in our study concur with the above mentioned studies.

The main problem in studies evaluating spasticity treatment is the assessment of spasticity.

In a recent Cochrane review of anti-spastic agents for multiple sclerosis, the reviewers describe both the understanding of the pathophysiology and the ability to measure spasticity as seriously deficient. ${ }^{19}$

The Ashworth Scale still is the golden standard for evaluating spasticity treatment today. ${ }^{10}$ The Ashworth Scale as a method for the evaluation of spasticity has been disputed before, although in adult populations the reliability of the Ashworth Scale has been demonstrated. ${ }^{20}$ In a study in children with moderate to severe spasticity, a wide variability in test-retest results was reported for the Ashworth Scale. ${ }^{21}$ Furthermore, the Ashworth Scale does not comply with the concept of spasticity, i.e. a velocity-dependent increase in muscle tone. ${ }^{13}$

In our study, we did not routinely use the Ashworth Scale for the assessment of the treated children because of the above mentioned reasons.

For measuring gross motor function in CP, the GMFM is widely accepted as the best available quantitative method. However, it is of limited value when determining functional benefits in severely affected children. ${ }^{14}$

The Tardieu Scale (TS) is a very comprehensive, but very time-consuming method to assess patients. Therefore its feasibility is questioned, especially for use in children. ${ }^{13}$ The 'dynamic component' is a measure derived from the TS and is a clinical measure of spasticity according to the literature. ${ }^{17}$ It can be calculated as the difference between the PROM at a very slow passive stretch and the AOC at a fast velocity stretch. However, it has been shown that the calculated difference adds together the variances of both joint angles, resulting in very wide inter-sessional variations. ${ }^{22}$ Therefore, it is probably better to compare the PROM and the AOC separately before and after treatment. ${ }^{13}$

Table 6.5 shows the correlations of the differences found with PROM, AOC, and the dynamic component with the differences found with the VAS. Although a positive correlation was found most of the time, it is clear that there is a sub- 
stantial difference between the currently used standards for evaluating spasticity and the VAS which measures the impact of the treatment on the daily life of the patient and caregiver.

The VAS is a valid and reliable measure for rating pain intensity in adults and children over 6 years of age. ${ }^{15}$ In adults it has also been used for measuring satisfaction, feelings, quality of sleep, dyspnea, emotional function, fatigue and appeared to be responsive and valid. ${ }^{23-26}$ In pediatric patients, aged 5-17 years, the VAS has also been applied to measure anxiety, sadness, anger, worry, happiness, and fatigue. ${ }^{27,} 28$ The VAS showed preliminary reliability and validity for both child self-report and parent-proxy report. ${ }^{28}$ When clinicians are raters, the VAS validly identifies the minimal clinically important difference on the Pediatric Evaluation of Disability Inventory. ${ }^{29}$

Evaluating spasticity treatment with the use of the VAS has several important advantages. First, it is a quick and easy method for evaluating treatment in an outpatient setting, in which time-consuming evaluations are not an option and where there is a need for such an instrument. ${ }^{11}$ Secondly, it is a subjective measure of the effects that BTX-A treatment has had on individually chosen goals. Usually the patient and his/her caregiver(s) are the best judges of the severity of the spasticity, as they are the only people who can assess its impact on the daily life of the patient. ${ }^{30}$ It is known that caregivers of children with profound impairments note changes in function far more accurately than staff workers. ${ }^{31}$

In spasticity after a spinal cord injury, it has been recommended to use both the VAS and other clinical evaluation methods (Modified Ashworth Scale) before starting therapeutically interventions. ${ }^{32}$ Another method for outcome measurement is Goal Attainment Scaling (GAS), introduced in the late 60's by Kiresuk and Sherman. ${ }^{33} \mathrm{An}$ individual goal scale for each patient is developed during an interview. Outcome is measured on a 5-point scale. The GAS can be administered by unqualified persons, nevertheless some training is advocated. Although the GAS is found to be an appropriate scale for the evaluation of outcome after intervention, the scale development time (first goal setting) is estimated at 45 minutes. ${ }^{34,35}$ In a busy outpatient clinic the scale development time of the GAS is at a clear disadvantage compared to the quick assessment with the VAS used in our study. Possibly, a further study could be set up to correlate the VAS with the GAS.

Our study results show that the VAS, although subjective, is a valid, easy, and quick method for evaluating spasticity treatment in an outpatient setting. 


\section{REFERENCES}

1. Krigger KW. Cerebral palsy: an overview. Am Fam Physician 2006. 73(1): p. 91-100.

2. Lance JW. Disordered muscle tone and movement. Clin Exp Neurol 1981. 18: p. 27-35.

3. Koman LA, Mooney JF, 3rd, Smith BP, et al. Botulinum toxin type A neuromuscular blockade in the treatment of lower extremity spasticity in cerebral palsy: a randomized, double-blind, placebo-controlled trial. BOTOX Study Group. J Pediatr Orthop 2000. 20(1): p. 108-15.

4. Mall V, Heinen F, Siebel A, et al. Treatment of adductor spasticity with BTX-A in children with CP: a randomized, double-blind, placebo-controlled study. Dev Med Child Neurol 2006. 48(1): p. 103.

5. Wissel J, Muller J, Dressnandt J, et al. Management of spasticity associated pain with botulinum toxin A. J Pain Symptom Manage 2000. 20(1): p. 44-9.

6. Symons FJ, Rivard PF, Nugent AC, et al. Parent evaluation of spasticity treatment in cerebral palsy using botulinum toxin type A. Arch Phys Med Rehabil 2006. 87(12): p. 1658-60.

7. Cosgrove AP, Corry IS, and Graham HK. Botulinum toxin in the management of the lower limb in cerebral palsy. Dev Med Child Neurol 1994. 36(5): p. 386-96.

8. Denislic M and Meh D. Botulinum toxin in the treatment of cerebral palsy. Neuropediatrics 1995. 26(5): p. 249-52.

9. Koman LA, Mooney JF, 3rd, Smith B, et al. Management of cerebral palsy with botulinum-A toxin: preliminary investigation. J Pediatr Orthop 1993. 13(4): p. 489-95.

10. Levin MF. On the nature and measurement of spasticity. Clin Neurophysiol 2005. 116(8): p. 1754-5.

11. Biering-Sorensen F, Nielsen JB, and Klinge K. Spasticity-assessment: a review. Spinal Cord 2006. 44(12): p. 708-22.

12. Damiano DL, Quinlivan JM, Owen BF, et al. What does the Ashworth scale really measure and are instrumented measures more valid and precise? Dev Med Child Neurol 2002.44(2): p. 112-8.

13. Scholtes VA, Becher JG, Beelen A, et al. Clinical assessment of spasticity in children with cerebral palsy: a critical review of available instruments. Dev Med Child Neurol 2006. 48(1): p. 64-73.

14. Mall V, Heinen F, Kirschner J, et al. Evaluation of botulinum toxin A therapy in children with adductor spasm by gross motor function measure. J Child Neurol 2000. 15(4): p. 214-7.

15. Stinson JN, Kavanagh T, Yamada J, et al. Systematic review of the psychometric properties, interpretability and feasibility of self-report pain intensity measures for use in clinical trials in children and adolescents. Pain 2006. 125(1-2): p. 143-57.

16. Ade-Hall RA and Moore AP. Botulinum toxin type A in the treatment of lower limb spasticity in cerebral palsy. Cochrane Database Syst Rev 2000(2): p. CD001408.

17. Love SC, Valentine JP, Blair EM, et al. The effect of botulinum toxin type A on the functional ability of the child with spastic hemiplegia a randomized controlled trial. Eur J Neurol 2001. 8 Suppl 5: p. 50-8.

18. Reddihough DS, King JA, Coleman GJ, et al. Functional outcome of botulinum toxin A injections to the lower limbs in cerebral palsy. Dev Med Child Neurol 2002. 44(12): p. 820-7.

19. Shakespeare DT, Boggild M, and Young C. Anti-spasticity agents for multiple sclerosis. Cochrane Database Syst Rev 2003(4): p. CD001332.

20. Gregson JM, Leathley M, Moore AP, et al. Reliability of the Tone Assessment Scale and the modified Ashworth scale as clinical tools for assessing poststroke spasticity. Arch Phys Med Rehabil 1999. 80(9): p. 1013-6.

21. Fosang AL, Galea MP, McCoy AT, et al. Measures of muscle and joint performance in the lower limb of children with cerebral palsy. Dev Med Child Neurol 2003. 45(10): p. 664-70.

22. Kilgour G, McNair P, and Stott NS. Intrarater reliability of lower limb sagittal range-of-motion measures in children with spastic diplegia. Dev Med Child Neurol 2003. 45(6): p. 391-9.

23. Aitken RC. Measurement of feelings using visual analogue scales. Proc R Soc Med 1969. 62(10): p. 989-93.

24. Guyatt GH, Townsend M, Berman LB, et al. A comparison of Likert and visual analogue scales for measuring change in function. J Chronic Dis 1987. 40(12): p. 1129-33. 
25. Jaeschke R, Singer J, and Guyatt GH. A comparison of seven-point and visual analogue scales. Data from a randomized trial. Control Clin Trials 1990. 11(1): p. 43-51.

26. Singer AJ and Thode HC, Jr. Determination of the minimal clinically significant difference on a patient visual analog satisfaction scale. Acad Emerg Med 1998. 5(10): p. 1007-11.

27. Hunt O, Burden D, Hepper P, et al. Parent reports of the psychosocial functioning of children with cleft lip and/or palate. Cleft Palate Craniofac J 2007. 44(3): p. 304-11.

28. Sherman SA, Eisen S, Burwinkle TM, et al. The PedsQL Present Functioning Visual Analogue Scales: preliminary reliability and validity. Health Qual Life Outcomes 2006. 4: p. 75.

29. Iyer LV, Haley SM, Watkins MP, et al. Establishing minimal clinically important differences for scores on the pediatric evaluation of disability inventory for inpatient rehabilitation. Phys Ther 2003. 83(10): p. 888-98.

30. Hanna K and Rodger S. Towards family-centered practice in paediatric occupational therapy: a review of the literature on parent-therapist collaboration. Aust Occup Ther J 2002. 49: p. 4-24.

31. White-Koning M, Arnaud C, Bourdet-Loubere S, et al. Subjective quality of life in children with intellectual impairment--how can it be assessed? Dev Med Child Neurol 2005. 47(4): p. 281-5.

32. Skold C. Spasticity in spinal cord injury: self- and clinically rated intrinsic fluctuations and intervention-induced changes. Arch Phys Med Rehabil 2000. 81(2): p. 144-9.

33. Kiresuk $\mathrm{T}$ and Sherman R. Goal attaining scaling: a general method for evaluating community mental health programs. Community Ment Health 1968. 4: p. 442-453.

34. Cusick A, McIntyre S, Novak I, et al. A comparison of goal attainment scaling and the Canadian Occupational Performance Measure for paediatric rehabilitation research. Pediatr Rehabil 2006. 9(2): p. 149-57.

35. Steenbeek D, Ketelaar M, Galama K, et al. Goal attainment scaling in paediatric rehabilitation: a critical review of the literature. Dev Med Child Neurol 2007. 49(7): p. 550-6. 


\section{CHAPTER VII \\ CONSTIPATION AFTER BOTULINUM TOXIN-A INJECTIONS IN LOWER AND UPPER LIMB MUSCLES: \\ A transitory systemic autonomic adverse effect. Report of three cases.}

Vles GF, Vles JSH, Hermans MC, Faber CG, de Louw A, Martina JD

Journal of Experimental and Clinical Medicine 2009; 26: 47-51. 


\section{ABSTRACT}

We report three patients who developed transient constipation after receiving therapeutic doses of Botulinum Toxin-A (BTX-A) for spasticity of the lower limbs (two cases) and the upper limb (one case). Constipation was observed within the first week after treatment. In all three cases, this symptom resolved completely and almost simultaneously with disappearance of the therapeutic effects of BTX-A. None of the patients had previously received BTX-A injections. Two patients received a second treatment and both presented the same autonomic cholinergic remote symptoms. The third patient refused a second treatment due to the complication noted earlier. Familiarity with this autonomic systemic side-effect of BTX-A is essential for those who treat patients already at risk for gastro-intestinal dysfunction. Because the adverse effects were treatable and transitory, we believe that constipation per se is not an absolute contraindication, if from a therapeutic point of view, BTX-A is indicated. 


\section{INTRODUCTION}

In the past 20 years, Botulinum Toxin-A (BTX-A) has been used for a wide spectrum of therapeutic and cosmetic indications, whether or not approved by the Food and Drug Administration (FDA)..$^{1}$ One of such indications not approved by the FDA, but widely studied and reported in the medical literature, is spasticity due to cerebral palsy $(\mathrm{CP})^{2-4}$ or due to acquired brain injury. ${ }^{5-7}$

BTX-A prevents presynaptic release of acetylcholine at the neuromuscular junction and as a result chemodenervation develops in the injected muscle., 9 The toxin, in therapeutic doses, is considered to be effective and safe. Remote adverse effects are rare and include flu-like symptoms, anaphylactic reactions, and excessive fatigue. ${ }^{10}$ Nevertheless, treatment of spasticity due to $\mathrm{CP}$ with BTX-A can be limited by the escape of the toxin from the muscle causing local and distant side-effects.

We report three cases of patients suffering from severe spasticity, who repeatedly experienced a period of constipation as an important and disabling systemic autonomic cholinergic side-effect after BTX-A treatment for spasticity.

\section{Case 1}

An eleven-year old boy, suffering from spasticity and epilepsy due to $\mathrm{CP}$, was referred to the outpatient clinic because of impaired mobility and nursing problems. Clinical examination showed a severely mentally handicapped boy, who was able to assist while being transferred from bed to wheelchair and even to make some steps if supported. Furthermore, body hygiene and dressing were hindered by hip adductor spasms. The possibility of treating the patient with BTX-A injections was discussed with his parents, and the following treatment goals were defined: to facilitate nursing and to improve mobility.

We determined the muscles to be injected by clinical examination. Spastic hypertonia of a specific muscle leading to functional limitations was the criterion to inject.

Therapy was initiated with informed consent of the parents. The child received BTX-A injections under general anaesthesia in the day-care department (JV). The target muscles were identified by muscular electrical stimulation. Dysport ${ }^{\circledR}$ from Ipsen was used according to the recommended maximum dosage: $23 \mathrm{IU} / \mathrm{kg}$ bodyweight, limited to no more than 400 units per limb, within an overall maximum dose of $1200 \mathrm{IU}$ per session, with a dilution of 500 units in 2 $\mathrm{ml} \mathrm{NaCl} 0.9 \%$. The child's bodyweight was $25 \mathrm{~kg}$. The adductor longus, semitendinosus, semimembranosus, and soleus muscles were injected with $50 \mathrm{IU}$ of Dysport ${ }^{\circledR}$ each, and the gastrocnemius muscles with 100 IU (total dose 600 IU).

The patient was seen at our outpatient clinic at 6 and 12 weeks after the intervention. We evaluated the effects and side-effects by means of a standardised questionnaire. Caregivers had to fill out a list with all side-effects possible. The 
Visual Analogue Scale (VAS), an ordinal scale that ranges from $0-10$ with 0 being the optimal situation and 10 the worst situation, was also used to evaluate the intervention. ${ }^{12}$ During follow-up, the mother observed an improvement on mobility (pre-treatment VAS: 5, post-treatment VAS: 1.3 ) and on facilitation in nursing (pre-treatment VAS: 4, post-treatment VAS: 2.2). However, as a remarkable side-effect she reported severe constipation, starting 4 days after the treatment, for which medication (macrogolum) was necessary.

The positive effects on mobility and nursing facilities lasted for more than 3 months and with lessening of these positive effects, the gastro-intestinal dysfunction wore off. After 4,5 months the clinical therapeutic effect was no longer detectable and at the same time macrogolum could be withdrawn.

One year after the first intervention there was a new request for repeated treatment because of increasing nursing and mobility problems. After a careful examination and discussing the systemic side-effect of constipation observed the first time, a decision was made to repeat the initial treatment. Under the same conditions and with a bodyweight of $30 \mathrm{~kg}$, the same muscles were injected with the same dose. The defined goals were reached but the same systemic gastro-intestinal side-effect of constipation was observed. Again, as the positive effects on mobility and nursing diminished, the side-effect faded away.

\section{Case 2}

This 19-year-old male was admitted to the rehabilitation department four months after a severe head trauma with diffuse axonal injury leading to impairments of his cognitive functions, speech, and locomotion. At admission the patient presented a tetraplegia with generalized spasticity (Modified Ashworth Scale - MAS - 2 and 3) of upper and lower limbs, accompanied by a severe diminished range of motion of the knee and ankle joints bilaterally. Orthotic treatment was initiated. The patient was unable to stand and walk and was dependent for all transfers. During the rehabilitation program he eventually developed painful spasms in both legs. Oral spasmolytic medication (Baclofen and Tizanidine) at maximal therapeutic doses was insufficient. Treatment with BTX-A was then discussed and the patient and his parents gave informed consent. He had never been treated with BTX-A before.

One month after admission, the patient received his first BTX-A injection (Botox ${ }^{\circledR}$ from Allergan). The semitendinosus, the semimembranosus, and the biceps femoris muscles of the left leg were treated with 100 units of Botox ${ }^{\circledR}$ each; 300 units in total (maximum recommended doses by the manufacturer: 600 units) in a dilution of 100 units in $5 \mathrm{ml} \mathrm{NaCl} \mathrm{0.9 \% .} \mathrm{Approximately} 6$ days after the injections a significant reduction of the muscle tone of the left leg was observed. The painful spasms disappeared. About 10 days after the treatment the patient reported severe constipation accompanied by abdominal pain. Treatment with laxatives (Bisacodyl and lactulose) was necessary. After two 
months, the intestinal function improved and at the same time the therapeutic effect of BTX-A diminished, although the range of motion could be maintained with orthotic support.

Four months after the first treatment a second treatment with BTX-A was given, aiming to reduce the severe hypertonia of the calf muscles of the right leg. The following therapeutic scheme was used, with the same dilution as before: gastrocnemius muscle: 140 units and soleus muscle: 60 units. Within one week after BTX-A treatment the muscle tone of the right lower leg decreased substantially and a corrective orthosis for the ankle joint could be fitted. Almost simultaneously with the reduction of the muscle tone in the leg the patient again complained about constipation. He also reported tiredness and difficulty with swallowing. Treatment with laxatives was started again. After one month the constipation wore off and the medication could be withdrawn. This time the reduction of muscle tone lasted for six weeks after BTX-A therapy.

Electromyography of distant muscles of the upper limbs could not be performed due to the severe spasticity.

In view of the generalized character of the spasticity it was decided to treat this patient with intrathecal Baclofen (ITB). After a successful therapeutic trial one year ago a Synchromed ${ }^{\circledR}$ infusion system was implanted. At the time of this report the spasticity remains under control (MAS 1) and so far no systemic complaints have been reported.

\section{Case 3}

A 19-year-old woman sustained severe brain injury after a ten meters fall. The Glasgow Coma Score at admission to the Intensive Care Unit was 6. Magnetic resonance imaging of the brain showed diffuse contusional lesions and oedema. Furthermore, she presented a lesion of the third cranial nerve and multiple fractures of the pelvis, left clavicle, acromion, and several ribs. A splenectomy had to be performed due to a spleen rupture. The hospital stay was complicated by a pulmonary embolism and a deep venous thrombosis. She also developed heterotopic ossification at the left hip and the right knee. Half a year later, the patient was referred to the rehabilitation centre for further treatment. At admission the patient presented a hypertonic tetraplegia, with limited range of motion of the left elbow and both knees. She was not able to stand without support and was unable to walk even with walking aids or manual assistance. She was otherwise incontinent for urine and completely dependent for all daily activities, including eating and personal hygiene.

The MAS was 2 for the right arm, and 1 for the left arm and both legs. However, the spasticity of the left arm increased during the following months to a MAS 3, but patient's mother refused pharmacological treatment either with systemic spasmolytic medication or local neuromuscular blocks. Intensive physical therapy and orthotic management for the elbow and knee contractures re- 
sulted in a slight improvement of the range of motion of the right arm and the knees. Nevertheless, the muscle tone of the left arm increased further, causing painful spasms of the arm. Eventually, one year after trauma, patient's mother gave her consent for treatment of the left arm with BTX-A injections. Dysport ${ }^{\circledR}$ (Ipsen) was used in a volume of $2.5 \mathrm{ml}$ per vial of 500 units. The left biceps muscle was injected at two sites with 150 units of Dysport ${ }^{\circledR}$ each and the brachioradial muscle with 200 units; 500 units in total.

The patient was evaluated two weeks after the injections. A remarkable reduction of the spasticity of the left arm flexors was seen (MAS 1). She was able to dissociate flexor and extensor movements selectively. However, the mother reported that three days after BTX-A treatment her daughter was hindered by severe constipation and was feeling more tired than usual. She also noticed that speech articulation and swallowing had become more difficult. At first, the constipation responded positively to treatment with Bisacodyl. However, the patient decided on her own to withdraw the medication and the constipation appeared again. After resuming the Bisacodyl one week later, the constipation wore off. These symptoms persisted during three months. The therapeutic effect on the left arm lasted for five months after the initial BTX-A treatment. Because of the aforementioned complication, the patient and her mother refused a second injection. At the last control visit, two years after trauma, the range of motion of the left arm was maintained with orthotic support and the elbow flexors showed a MAS of 2 . She reported no gastrointestinal nor swallowing complaints.

\section{DISCUSSION}

Although the therapeutic goals were reached in all three patients, they repeatedly showed severe constipation as an autonomic side-effect after treatment sessions with BTX-A injections. As the colon is not in close proximity to the injection sites, this symptom is likely related to a systemic effect of BTX-A. We have performed this treatment in over 50 children and over 200 adults. After each intervention, a list with all possible side-effects had to be filled out by the patient or by the caregiver. All these data were entered into a database. Although in 10 patients side-effects occurred, only in these three patients constipation was reported during evaluation.

The action of BTX-A appears to be limited to cholinergic terminals where BTX-A inhibits release of acetylcholine and co-transmitters in both somatic and cholinergic autonomic terminals. ${ }^{8,9}$ In the first patient described a slow repetitive stimulation of a motor nerve (RNS) was performed in order to investigate the presumed systemic reaction on BTX-A (figure 7.1). Electromyographic recordings were made from the hypothenar while stimulating the ulnar nerve at the wrist. The amplitude of the initial response was normal, but after prolonged $3 \mathrm{~Hz}$ stimulation a slight decrementing response occurred. An average of $11 \%$ 
decrement in amplitude was visible from sixth to eighth compound muscle action potentials. This indicates that fewer muscle fibers responded to nerve stimulation during a train of stimuli, due to generalized blockage of acetylcholine release in nerve terminals. The patient did not show generalized weakness.

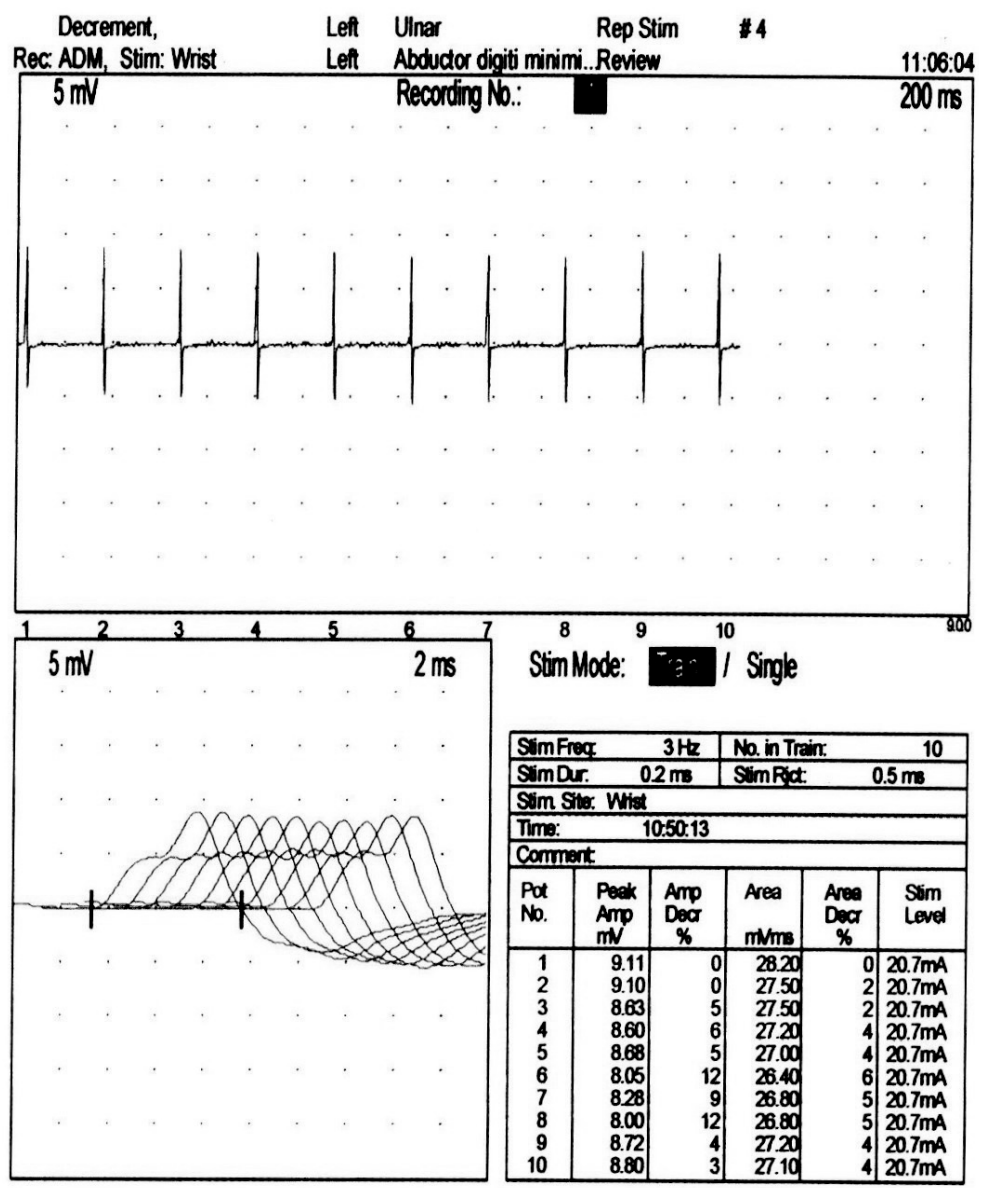

Figure 7.1 In the first patient described a slow repetitive stimulation of a motor nerve (RNS) was performed in order to investigate the presumed systemic reaction on BTX-A. EMG recordings were made from the hypothenar while stimulating the ulnar nerve at the wrist. The amplitude of the initial response was normal, but after prolonged $3 \mathrm{~Hz}$ stimulation a slight decrementing response occurred. An average of $11 \%$ decrement in amplitude was visible from sixth to eighth compound muscle action potentials. This indicates that fewer muscle fibers responded to nerve stimulation during a train of stimuli, due to generalized blockage of acetylcholine release in nerve terminals. The patient did not show generalized weakness.

The efficacy of BTX-A in children with adductor spasticity was demonstrated in a randomized controlled trial by Mall et al. using the Goal Attainment Scale. ${ }^{3}$ The safety profile of BTX-A (Dysport ${ }^{\circledR}$ ) in patients with muscle hypertonia was ret- 
rospectively studied by Bakheit et al. and they reported adverse events in only $7 \%$ of treatment. ${ }^{13}$ Incidence of adverse effects was related to the total dose rather than the dose calculated on basis of body weight. The highest incidence of adverse events was observed in patients who received more than 1000 IU of BTX-A per treatment session. Constipation as a remote autonomic side-effect was not reported in this publication.

Autonomic function as a measure of side-effects using Dysport ${ }^{\circledR}$ in a range of doses $(18-44 \mathrm{IU} / \mathrm{kg})$ was studied by Robertshaw et al. ${ }^{14}$ Their hypothesis was that BTX-A might reduce parasympathetic activity and, therefore, cardiac variability. They conclude that BTX-A is safe using the standard dosage. Only 1 out of 30 children had distant side-effects, which lasted for 6 weeks. Constipation was not mentioned as a side-effect.

Autonomic side-effects occur far more often after Botulinum Toxin-B (BTXB). ${ }^{15}$ In a group of 30 patients (24 cervical dystonia; 6 hyperhidrosis) constipation was observed as a remote side-effect in 3 patients.

In a double blind randomized trial, autonomic function after BTX-A or B was studied in patients with cervical dystonia. ${ }^{16}$ More patients treated with BTX-B showed constipation as compared to those treated with BTX-A (3/9 vs $0 / 11)$.

In a retrospective study, constipation as a side-effect of BTX-A (Botox ${ }^{\circledR}$ ) treatment on upper limb impairment and function was observed in 1 of 18 patients (aged 2-17 years). ${ }^{17}$ Furthermore, severe dysphagia has been reported as a remote side-effect of BTX-B treatment of the lower limbs and lumbar paraspinal muscles in a 29-year-old woman. ${ }^{18}$

Our patients repeatedly showed constipation as an adverse remote effect in response to BTX-A interventions. An explanation for this individual sensitivity is difficult. Probably it is in line with the observed interpersonal variability in autonomic ratio (AR) as described by Robertshaw et al. studying the effects of BTX-A on ECG parameters. ${ }^{14}$ This study reported that the child suffering from distal side-effects for 6 weeks, had the lowest AR.

Dysfunction observed in the gastro-intestinal tract is not uncommon in neurologically handicapped patients. The enteric nervous system contains more neurons than the spinal cord. ${ }^{19}$ Therefore, it is not surprising that generalized insults to the central nervous system (i.e. asphyxia or ischemia) may result in significant neural dysfunction in the gastro-intestinal tract as is shown for the spinal cord. ${ }^{20}$ On the other hand, feeding and intake problems may result from various (motor)problems other than the increased muscle tone observed in these patients. However, from a clinical point of view there is a strong indication that the gastro-intestinal problems in these 3 patients appeared in connection with the BTX-A treatment. 


\section{CONCLUSION}

We conclude that severe constipation may be an autonomic systemic side-effect of BTX-A treatment due to blockade of autonomic neurons via systemic spread. Knowledge of this possible side-effect is important for those who treat patients already at risk for gastro-intestinal dysfunction. A carefully taken clinical history during the treatment period makes prevention and management possible. Because the adverse effects were treatable and transitory, we believe that constipation per se is not an absolute contra-indication if, from a therapeutic view point of view, BTX-A treatment is indicated. 


\section{REFERENCES}

1. Cote TR, Mohan AK, Polder JA, et al. Botulinum toxin type A injections: adverse events reported to the US Food and Drug Administration in therapeutic and cosmetic cases. J Am Acad Dermatol 2005. 53(3): p. 407-15.

2. Dursun N, Dursun E, and Alican D. The role of botulinum toxin a in the management of lower limb spasticity in patients with cerebral palsy. Int J Clin Pract 2002. 56(8): p. 564-7.

3. Mall V, Heinen F, Siebel A, et al. Treatment of adductor spasticity with BTX-A in children with CP: a randomized, double-blind, placebo-controlled study. Dev Med Child Neurol 2006. 48(1): p. $10-$ 3.

4. Polak F, Morton R, Ward C, et al. Double-blind comparison study of two doses of botulinum toxin A injected into calf muscles in children with hemiplegic cerebral palsy. Dev Med Child Neurol 2002. 44(8): p. 551-5.

5. Autti-Ramo I, Larsen A, Taimo A, et al. Management of the upper limb with botulinum toxin type $\mathrm{A}$ in children with spastic type cerebral palsy and acquired brain injury: clinical implications. Eur J Neurol 2001. 8 Suppl 5: p. 136-44.

6. Bergfeldt U, Borg K, Kullander K, et al. Focal spasticity therapy with botulinum toxin: effects on function, activities of daily living and pain in 100 adult patients. J Rehabil Med 2006. 38(3): p. 166-71.

7. van Rhijn J, Molenaers G, and Ceulemans B. Botulinum toxin type A in the treatment of children and adolescents with an acquired brain injury. Brain Inj 2005. 19(5): p. 331-5.

8. Garner CG, Straube A, Witt TN, et al. Time course of distant effects of local injections of botulinum toxin. Mov Disord 1993. 8(1): p. 33-7.

9. Olney RK, Aminoff MJ, Gelb DJ, et al. Neuromuscular effects distant from the site of botulinum neurotoxin injection. Neurology 1988. 38(11): p. 1780-3.

10. Lange DJ, Brin MF, Fahn S, et al. Distant effects of locally injected botulinum toxin: incidence and course. Adv Neurol 1988. 50: p. 609-13.

11. Patti F, Pappalardo A, Lo Fermo S, et al. Life-threatening constipation induced by intrathecal baclofen therapy. Eur Neurol 2008. 60(2): p. 95-6.

12. Vles GF, de Louw AJ, Speth LA, et al. Visual Analogue Scale to score the effects of Botulinum Toxin A treatment in children with cerebral palsy in daily clinical practice. Eur J Paediatr Neurol 2008. 12(3): p. 231-8.

13. Bakheit AM, Severa S, Cosgrove A, et al. Safety profile and efficacy of botulinum toxin A (Dysport) in children with muscle spasticity. Dev Med Child Neurol 2001. 43(4): p. 234-8.

14. Robertshaw K, Watson L, Parkin T, et al. Botulinum toxin A dosage: autonomic function as a measure of side effects. Dev Med Child Neurol 2005. 47(11): p. 792.

15. Dressler D and Benecke R. Autonomic side effects of botulinum toxin type B treatment of cervical dystonia and hyperhidrosis. Eur Neurol 2003. 49(1): p. 34-8.

16. Tintner R, Gross R, Winzer UF, et al. Autonomic function after botulinum toxin type A or B: a double-blind, randomized trial. Neurology 2005. 65(5): p. 765-7.

17. Satila H, Kotamaki A, Koivikko M, et al. Low- and high-dose botulinum toxin A treatment: a retrospective analysis. Pediatr Neurol 2006. 34(4): p. 285-90.

18. Rossi RP, Strax TE, and Di Rocco A. Severe Dysphagia after botulinum toxin B injection to the lower limbs and lumbar paraspinal muscles. Am J Phys Med Rehabil 2006. 85(12): p. 1011-3.

19. Menkes JH and Ament ME. Neurologic disorders of gastroesophageal function. Adv Neurol 1988. 49: p. 409-16.

20. de Louw AJ, de Vente J, Steinbusch HP, et al. Apoptosis in the rat spinal cord during postnatal development; the effect of perinatal asphyxia on programmed cell death. Neuroscience 2002. 112(4): p. 751-8. 
CHAPTER VIII

\section{LONG-TERM FOLLOW-UP ON INTRATHECAL BACLOFEN THERAPY IN NON-AMBULANT CHILDREN WITH INTRACTABLE SPASTIC CEREBRAL PALSY}

Vles GF, Soudant DL, Hoving MA, Vermeulen RJ, Bonouvrié LA, Vles JSH In preparation 


\section{ABSTRACT}

\section{Background}

A couple of years ago, Hoving et al performed methodologically well-designed studies on ITB therapy in 17 children with intractable spastic CP. Follow-up showed positive effects on pain, ease of care, and mental health to be present 1 year after pump implantation.

Long-term results of ITB therapy in children with intractable spastic CP are limited, especially with regard to outcomes relevant to the patient and his / her caregivers.

\section{Aims}

The aims of this long-term follow-up study were threefold: I: to determine whether or not beneficial effects of ITB therapy are still present 6-9 years after commencement of treatment in the 17 children initially described by Hoving et al, II: to describe the course of these effects over time, and III: to investigate whether or not caregivers would still choose ITB therapy for their child considering the advantages and disadvantages they have experienced.

\section{Methods}

The parents of the 17 children filled out the Child Health Questionnaire (CHQ), current satisfaction on a Visual Analogue Scale regarding previous set treatment goals, a questionnaire concerning functioning of their child, and a self-made questionnaire.

\section{Results}

One parent did not return the CHQ questionnaire. Previous identified beneficial effects were found to still be present 6-9 years after commencement of treatment. Minimal improvement can still be expected 12 months after pumpimplantation, especially for individually defined treatment goals and physical QoL. Ninety-four percent of the care-givers would choose for ITB treatment again.

\section{Conclusion}

This study shows that beneficial effects after ITB are still present 6-9 years after commencement of treatment in non-ambulant children. Minimal improvement can still be expected 12 months after pump-implantation, especially for individually defined treatment goals. Ninety-four percent of the care-givers would choose for ITB treatment again. 


\section{INTRODUCTION}

Intrathecal baclofen (ITB) therapy is the direct administration of Baclofen into the intrathecal space by means of a neurosurgically placed cathether. The catheter is attached to a pump which is implanted subcutaneously or subfacially in the abdomen. This invasive treatment modality has been proven effective for the treatment of intractable spasticity in non-ambulant children with cerebral palsy (CP) $\cdot^{1-4}$ ITB therapy has the large advantage of by-passing the blood-brainbarrier (BBB). Orally administered Baclofen passes the BBB poorly and therefore results in high blood levels (hence side-effects) and almost undetectable cerebrospinal fluid levels of Baclofen (hence low therapeutic effect). When administrating Baclofen intrathecally a hundredth part of the oral dose of Baclofen is sufficient to effectively reduce spasticity. ${ }^{5}$ Therefore the side-effects encountered when Baclofen is administered orally can be prevented.

Between 2006 and 2009, Hoving et al published the results of a Dutch national study in seven articles addressing safety, efficacy, and cost-effectiveness of ITB therapy in a group of 17 carefully selected children with intractable spastic CP. At that time there was a lack of methodologically well-designed studies in this field. Therefore, they used a double blind, randomised, placebo-controlled design for the ITB dose-finding test treatment study and a prospective, randomised design for the open-label pump implantation study. In this Dutch national study, continuous infusion of ITB (CITB) relieved pain, facilitated ease of care, and improved mental health. The majority of children could extend their activities and participation. During a mean follow-up of 18.4 months (12-24), Hoving et al recorded 80 adverse events. Eight adverse events were serious, but none were life-threatening and none of the children needed to be hospitalised. During the last follow-up visit, 15 of the 17 children and/or their parents stated that they were satisfied with CITB and would participate in all ITB related procedures again. Two parents were not sure they would have the pump implanted in their child again, in spite of the achieved individual treatment goals.

Since then several interesting articles and commentaries have been published. Recently, Morton et al found ITB therapy to improve quality of life (QoL; comfort, ease of care) and to reduce muscle tone and spasms in 38 nonambulant children aged 5-16 years with spastic CP over a sustained period of 18 months after pomp implantation. ${ }^{6}$ Minimal effects on function, participation in society, and contracture formation were found. ${ }^{6}$

In a reply to this study Miller made two important remarks. ${ }^{7}$ Firstly, he stated that expecting to observe a functional gain after ITB therapy in non-ambulant children with CP is unrealistic. Most of the times the goal is to improve comfort and facilitate care-giving, which can be reported by care-givers. Secondly, he criticized the short term follow-up on a treatment that is probably going to be continued for 50-60 years. 
Another recently published study is the one by Motta et al in which it was stated that ITB improves Gross Motor Function Measurement scores, Ashworth scale scores, Barry-Albright dystonia scores, and functional ability in 37 patients (18 males, 19 females; GMFCS level 2: $n=9$; level 3: $n=13$; level 4: $n=7$; level 5: $n=8$ ). ${ }^{8}$

In a reply to this study Krach highlighted some methodologically limitations of the study by Motta et al, but also stated that these limitations might be inevitable in children with neurodisability. ${ }^{9}$ She suggested the single-participant experimental design that uses the individual as his / her own comparison as an option for future research. This merits the establishment of sufficient baseline measurements.

Acting upon these remarks made by Miller and Krach we prolonged the well-designed study by Hoving et al 6-9 years after pump implantation., 4, 10 Our aim was to study: I: whether or not beneficial effects of ITB therapy are still present 6-9 years after commencement of treatment, II: the course of effects after ITB treatment over time, and III: whether or not caregivers would still choose this treatment modality for their child again considering the advantages and disadvantages of ITB therapy now known.

\section{METHODS}

\section{Design}

This prospective follow-up study is a continuation of the prospective Dutch national study on the efficacy and safety of CITB in 17 children with intracable spastic CP (figure 1).3, 4, 10 Their parents were informed about the study and all agreed to participate.

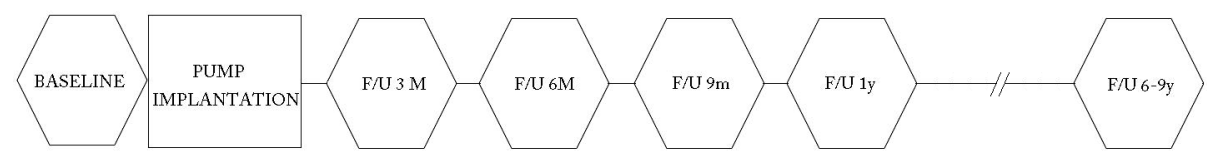

Figure 8.1 Follow-up diagram of the 17 children with intractable spastic CP treated with CITB therapy

This follow-up study was approved by the Medical Ethics Committee of the Maastricht University Medical Centre (MUMC) according to Dutch governmental guidelines.

\section{Participants}

The 17 children with bilateral CP consisted of 9 girls and 8 boys with a mean age of 21.1 years (SD 3.1; 14-25). One boy was GMFCS level 3; 1 boy and 1 girl were 
both GMFCS level 4; 14 children were GMFCS level 5. Mean follow-up on pump implantation was 7.5 years (SD 0.9; 6-9).

\section{Outcome measures}

After all these years we were mainly interested in the QoL and the satisfaction for the initially defined treatment goals of these children. The child health questionnaire (CHQ) and the visual analogue scale (VAS) were chosen as outcome measures as these instruments have shown to be capable of detecting improvements. ${ }^{3,4,10}$

The CHQ is a generic QoL instrument which measures 14 unique physical and psychosocial concepts. ${ }^{11}$ In this present study the 50 -item, parent-form was used (CHQ-PF50). All domains are scored on a 0-100 scale with higher scores reflecting better QoL. Physical and psychosocial summary scores can be derived from the separate CHQ profile scores which have a mean of 50 and an SD of 10 in the general population.

To measure satisfaction the VAS was used. This is a straight $10-\mathrm{cm}$ horizontal line with the anchor points "very satisfied" (score 10) and "very dissatisfied" (score 0 ). This is opposite to how the VAS is commonly used, but in line with the previous studies by Hoving et al. Although, the parents were reminded of the three treatment goals defined before pump-implantation, they were not informed about the previous scores. They scored their current satisfaction with regard to these goals on the VAS. The mean of these 3 VAS scores was used for statistical analysis (individual VAS). VAS scores for improvement of ease of care and relief of pain were analyzed separately as these were the most frequently formulated treatment goals.

Additionally, we wanted to know whether or not caregivers would still choose ITB therapy for their child at present considering the advantages and disadvantages encountered over the last 6-9 years. As caregivers might not be aware of changes detected by the CHQ questionnaire and the VAS, we used a questionnaire which addresses improvement / worsening of functioning of their child by means of 40 questions. Questions are scored on a 5-point Likert scale ("A lot worse" - "Slightly better" - "The same" - "Slightly better" - "A lot better"). This questionnaire was developed by Staal et al who used it to identify areas of positive improvement after ITB therapy in 49 individuals. ${ }^{12}$ It has also been used by Krach et al in order to evaluate satisfaction regarding ITB therapy in 100 patients / caregivers. ${ }^{13}$ This questionnaire was carefully translated into Dutch.

Furthermore, parents answered questions with regard to pain caused by the ITB pump, side-effects at present time, hospitalizations, and surgeries since ITB pump implantation, and finally whether or not they would choose ITB therapy for their child again. 


\section{Statistical analysis}

PASW statistics 18 was used for statistical analysis. The non-parametric Wilcoxon Signed Rank Test was used to compare present CHQ and VAS scores to baseline and 1 year post-implantation CHQ and VAS scores.

\section{RESULTS}

The caregivers of all 17 children participated in the study. Only one caregiver did not return the CHQ questionnaire due to an ongoing divorce. All other data were available.

\section{Beneficial effects of ITB therapy 6-9 years after commencement of treatment}

In table 1 the means and standard deviations of CHQ and VAS scores of the 17 children at 4 different moments in time can be found: before pump implantation (baseline), at 6 months post-implantation, at 12 months post-implantation, and at present (6-9 years after pump-implantation). Furthermore, present CHQ and VAS were compared to scores at baseline and scores at 12 months postimplantation. It can be seen that there are no statistically significant differences between present scores and scores at 12 months post-implantation. The positive effects on pain, ease of care, and mental health are still present. Moreover, additional benefits have appeared i.e. significantly improved scores on the Parent Impact - Emotional subscale, Parent Impact - Time subscale, and the Physical Summary. 


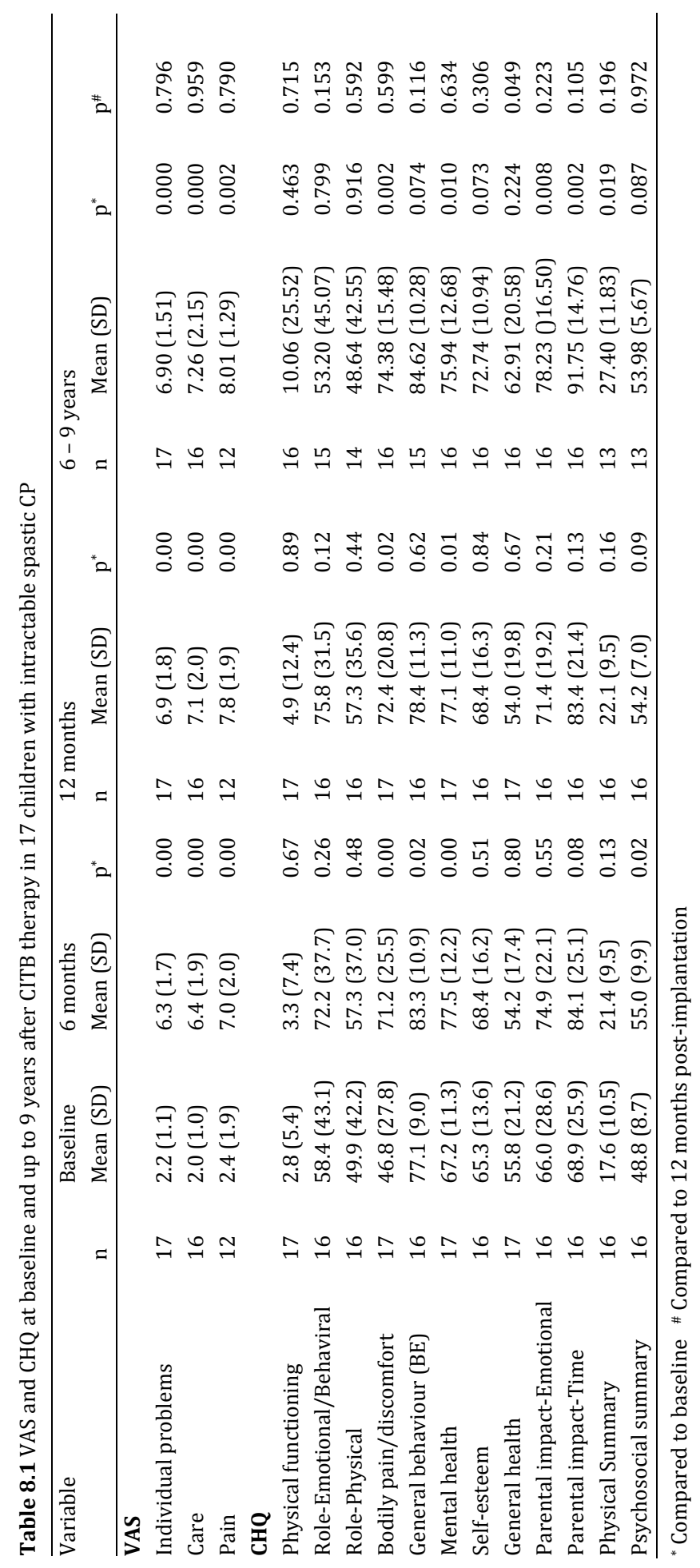




\section{The course of effects of ITB therapy over time}

Figure 2 shows the course of 4 outcome measures over time: the physical (PhS) and psychosocial summary scores (PsS) of the CHQ questionnaire, and the VAS scores for improvement of pain and ease of care. It is evident that treatment effects are still present 6-9 years after commencement of treatment. Although it seems that the effect stabilizes, minimal improvement can still be expected 12 months after pump-implantation, especially for individually defined treatment goals. Furthermore, it appears that improvements in terms of physical QoL (CHQ $\mathrm{PhS}$ ) need more time to become evident. At 12 months post-implantation there was no statistically significant difference compared to baseline $(\mathrm{p}=0.16)$; however, at 6-9 years post-implantation there is $(\mathrm{p}=0.02)$.
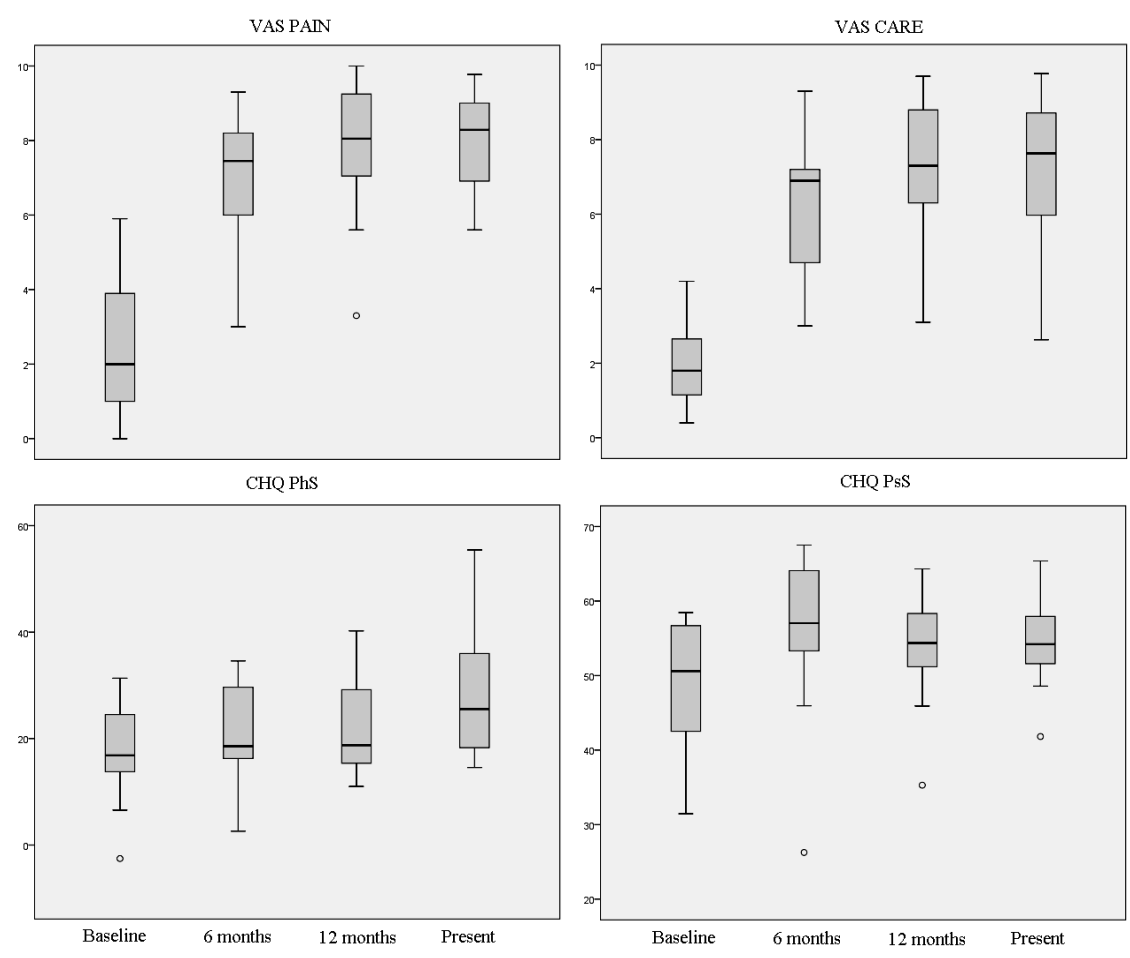

Figure 8.2 Box and whisker plots of 2 VAS scores (pain and ease of care) and 2 CHQ summary scores (PhS and PsS)

\section{Caregivers chosing ITB therapy for their child again}

The advantages as measured by means of the CHQ and the VAS have already been described (figure 2). In addition, parents rated improvement / worsening for 40 domains of functioning on a 5-point Likert scale (figure 3). It can be seen that improvements were more frequent than worsening for all questions, except 
for questions 6 (drooling) and 19 (bladder control). Improvements were most frequently noted for questions 1 (ability to transfer), 27 (startle movements, sudden jerks), and 29 (sleeping at night).
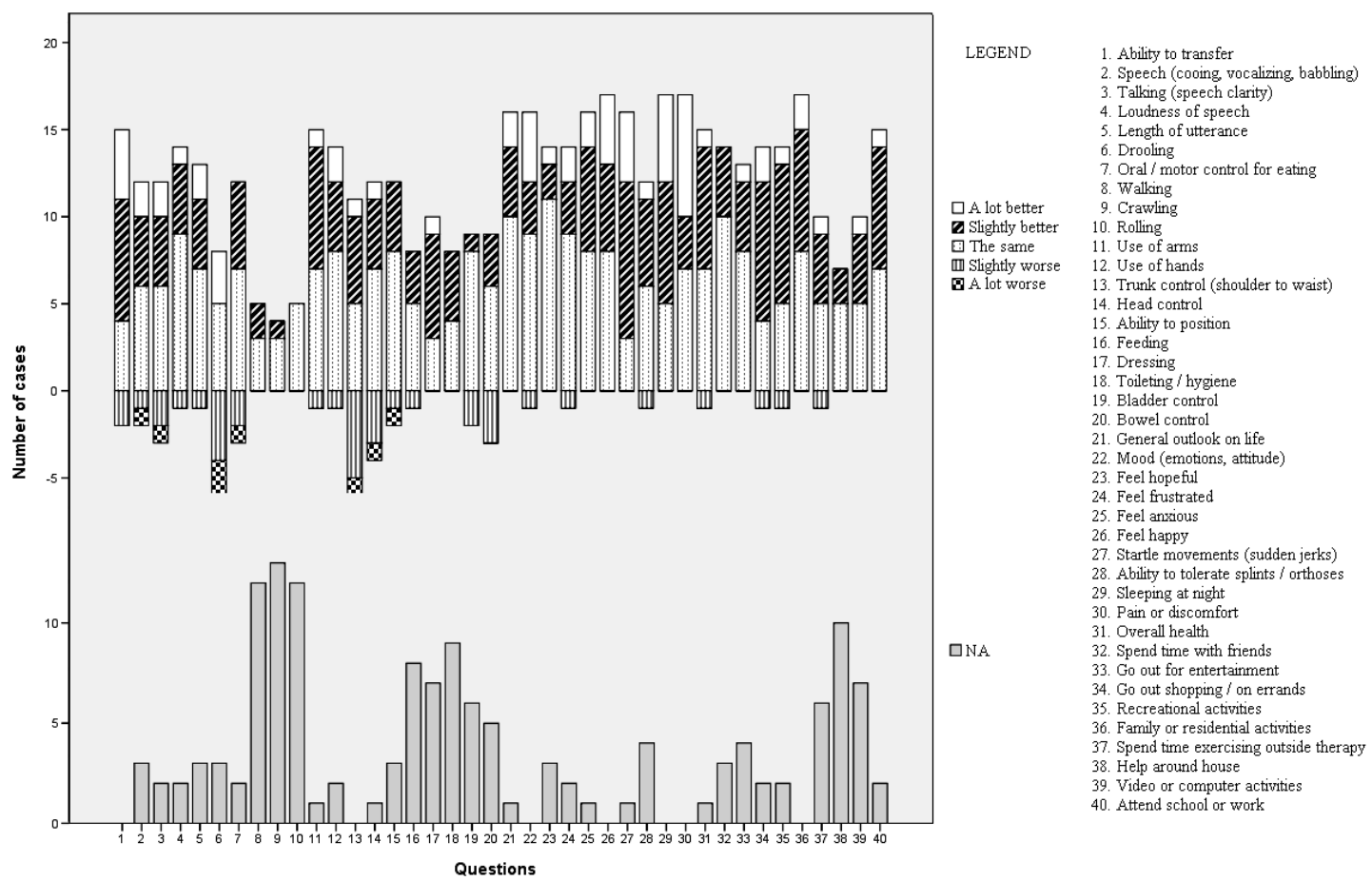

Figure 8.3 Caregivers responses to 40 questions with regard to improvement / worsening of functioning after 6-9 years of CITB treatment

The disadvantages were measured in terms of pain caused by the pump, device related problems, number of hospitalizations, number of surgeries, and sideeffects at present time. Two out of seventeen children were reported to experience pain caused by the pump. During these 6-9 years of follow-up 11 devicerelated problems were encountered: 2 pump-related problem (failure of the pump; subsidence of the pump), 6 drain-related problems (drain too high: 2; drain too low: 1; drain too superficial: 1; drain obstructed: 2), and 3 refillrelated problems. Every child was hospitalized at least once since pumpimplantation (28 hospitalizations in total; range 1-4). Most of these were ITBrelated (18/28), but mainly involved substitution of the pump (15/18). Three out of 17 children underwent orthopedic surgery (all scoliosis). Forty-three side-effects at present were reported for 17 children.

If given the choice, sixteen parents (94\%) would choose ITB therapy for their child again, and 1 parent was not sure. 


\section{DISCUSSION}

Previous studies have addressed the long-term effects of ITB therapy in children with CP. However, most of them were retrospective, had a broad range of follow-up months, did not include QoL and other subjective outcome measures, did not perform sufficient baseline measurements, included both ambulant and non-ambulant children, had large numbers of drop-outs, and / or included (adult) patients with spasticity not due to CP. ${ }^{14-19}$ In our opinion, the present study is unique because of the systematical evaluation of the 17 ITB treated children over a long period of time. At baseline and at 3, 6, 9, and 12 months after pump-implantation a comprehensive set of outcome measures was used and the outcome measures showing benefits were also used in this present study 6-9 years after pump implantation.

It was shown that the previous identified positive effects on pain, ease of care, and mental health are still present 6-9 years post-implantation. Moreover, additional benefits have appeared, e.g. significantly improved scores on the Parent Impact - Emotional subscale, and the Parent Impact - Time subscale. According to the CHQ manual this means that care-givers experience fewer feelings of emotional worry / concern and fewer limitations in time available for personal needs due to the child's physical and / or psychosocial health. ${ }^{11}$ It is difficult to tell whether this is a direct result of ITB therapy or whether this would also occur in parents of children with CP not receiving ITB therapy. An ever growing amount of experience in caring for their children could explain the decrease in worries and concern and the increase in time for personal needs of the care-givers.

Another additional benefit was present 6-9 years after pump implantation, i.e. significantly improved scores on $\mathrm{CHQ} \mathrm{PhS}$. The subscales that contribute most profoundly to the $\mathrm{PhS}$ are physical functioning, role/social limitations (physical), bodily pain/discomfort, and general health. ${ }^{11}$ It appears that improvements in CHQ PhS need more than 12 months to become evident (figure 2). A possible explanation for this observation is that improvements in terms of CHQ PhS require more than a reduction in spasticity alone. New possibilities have to be explored and practiced, which takes some time. On the other hand, a reduction in spasticity will cause an immediate effect on pain and ease of care (figure 2).

Although it seems that the improvements reach somewhat of a plateau 12 months after pump-implantation, minimal improvement can still be expected at that time, especially for individually defined treatment goals. This is important information for children and care-givers (who consider ITB therapy).

Regardless of the side-effects, the complications, and the necessity of eventually substituting the pump, $94 \%$ of the care-givers would choose ITB therapy for their child again. This is a common finding in literature, highlighting the high satisfaction with ITB therapy. $2,13,20-22$ 
Although this study is one of the first with such an extensive follow-up on ITB therapy in children with intractable spastic $\mathrm{CP}$, this is only the beginning. Large groups of children receiving ITB therapy should be measured by means of multiple outcome measures at baseline and systematically up until 50-60 years after pump implantation. Using both objective and subjective outcome measures in both quantitative and qualitative designed studies are needed to determine the very long-term effects of ITB therapy.

\section{Limitations}

This study has several limitations.

Firstly, the questionnaires were filled out by the care-givers and not the patients themselves. However, in this present study self-reports would have been extremely difficult to obtain and interpret given the severity of disability of the majority of the children with CP. In this case, parents / caregivers are the most logical source of information as they are assumed to have intimate knowledge of the child.

Secondly, the questionnaire developed by Staal et al has not been validated. ${ }^{12}$ The development of a well-constructed, validated, and easy to administer long-term outcome measure specific for ITB treatment would be highly useful. This should include both beneficial effects of ITB therapy on all domains of the ICF and detrimental effects in terms of side-effects, complications, hospitalizations, and surgeries.

Finally, we did not search for correlations with other factors that might influence outcome such as major life events, additional treatments, and aging.

\section{CONCLUSION}

This study shows that beneficial effects after ITB are still present 6-9 years after commencement of treatment in non-ambulant children. Minimal improvement can still be expected 12 months after pump-implantation, especially for individually defined treatment goals. Ninety-four percent of the care-givers would choose for ITB treatment again. This information is very useful for physicians and can be used to inform patients and their care-givers who are considering ITB therapy. Future studies should aim at measuring large groups of children receiving ITB therapy by means of multiple outcome measures at baseline and systematically up until 50-60 years after pump implantation. 


\section{REFERENCES}

1. Butler, C. and Campbell, S. Evidence of the effects of intrathecal baclofen for spastic and dystonic cerebral palsy. AACPDM Treatment Outcomes Committee Review Panel. Dev Med Child Neurol, 2000. 42(9): p. 634-45.

2. Campbell, W.M., et al., Long-term safety and efficacy of continuous intrathecal baclofen. Dev Med Child Neurol, 2002. 44(10): p. 660-5.

3. Hoving, M.A., et al., Efficacy of intrathecal baclofen therapy in children with intractable spastic cerebral palsy: a randomised controlled trial. Eur J Paediatr Neurol, 2009. 13(3): p. 240-6.

4. Hoving, M.A., et al., Intrathecal baclofen in children with spastic cerebral palsy: a double-blind, randomized, placebo-controlled, dose-finding study. Dev Med Child Neurol, 2007. 49(9): p. 6549.

5. Kroin, J.S., Intrathecal drug administration. Present use and future trends. Clin Pharmacokinet, 1992. 22(5): p. 319-26.

6. Morton, R.E., N. Gray, and M. Vloeberghs, Controlled study of the effects of continuous intrathecal baclofen infusion in non-ambulant children with cerebral palsy. Dev Med Child Neurol, 2011. 53(8): p. 736-41.

7. Miller, F., The effects of continuous intrathecal baclofen infusion in non-ambulant children with cerebral palsy. Dev Med Child Neurol, 2011. 53(8): p. 679-80.

8. Motta, F., C.E. Antonello, and C. Stignani, Intrathecal baclofen and motor function in cerebral palsy. Dev Med Child Neurol, 2011. 53(5): p. 443-8.

9. Krach, L., Intrathecal baclofen and motor function in cerebral palsy. Dev Med Child Neurol, 2011. 53(5): p. 391.

10. Hoving, M.A., et al., Safety and one-year efficacy of intrathecal baclofen therapy in children with intractable spastic cerebral palsy. Eur J Paediatr Neurol, 2009. 13(3): p. 247-56.

11. Landgraf, J., L. Abetz, and J. Ware, The CHQ User's Manual. Second printing ed. 1999, Boston, MA: Health act.

12. Staal, C., A. Arends, and S. Ho, A self-report of quality of life of patients receiving intrathecal baclofen therapy. Rehabil Nurs, 2003. 28(5): p. 159-63.

13. Krach, L.E., A. Nettleton, and B. Klempka, Satisfaction of individuals treated long-term with continuous infusion of intrathecal baclofen by implanted programmable pump. Pediatr Rehabil, 2006. 9(3): p. 210-8.

14. Albright, A.L., et al., Long-term intrathecal baclofen therapy for severe spasticity of cerebral origin. J Neurosurg, 2003. 98(2): p. 291-5.

15. Azouvi, P., et al., Intrathecal baclofen administration for control of severe spinal spasticity: functional improvement and long-term follow-up. Arch Phys Med Rehabil, 1996. 77(1): p. 35-9.

16. Brochard, S., et al., Intrathecal baclofen infusion for ambulant children with cerebral palsy. Pediatr Neurol, 2009. 40(4): p. 265-70.

17. Plassat, R., et al., Treatment of spasticity with intrathecal Baclofen administration: long-term follow-up, review of 40 patients. Spinal Cord, 2004. 42(12): p. 686-93.

18. Rawicki, B., Treatment of cerebral origin spasticity with continuous intrathecal baclofen delivered via an implantable pump: long-term follow-up review of 18 patients. J Neurosurg, 1999. 91(5): p. 733-6.

19. Ucar, T., et al., Outcomes of intrathecal baclofen (ITB) therapy in spacticity. Turk Neurosurg, 2011. 21(1): p. 59-65.

20. Borowski, A., et al., Complications of intrathecal baclofen pump therapy in pediatric patients. J Pediatr Orthop, 2010. 30(1): p. 76-81.

21. Zdolsek, H.A., et al., Intrathecal baclofen therapy: benefits and complications. J Intellect Dev Disabil, 2011. 36(3): p. 207-13.

22. Bonouvrie, L.A., et al., Satisfaction with intrathecal baclofen treatment in paediatric patients with progressive neurological disease. Dev Med Child Neurol, 2008. 50(8): p. 636-8. 


\section{CHAPTER IX \\ QUALITY OF LIFE OF CHILDREN WITH CEREBRAL PALSY:}

\section{A cross-sectional KIDSCREEN study in the Southern part of the Netherlands}

Vles GF, Hendriksen RGF, Hendriksen JGM, van Raak EPM, Vles JSH

Submitted 


\section{ABSTRACT}

\section{Objective}

To compare the quality of life (QoL) of 8-18 year old children with cerebral palsy (CP) in the Southern part of the Netherlands to a sample of European children from the general population and to investigate factors associated with possible differences.

\section{Design}

A cross-sectional KIDSCREEN-52 (by-proxy version) study.

\section{Subjects / patients}

The parents of 80 out of 81 children (mean age 13.4 years, SD 2.98; 49 boys, 31 girls; Gross Motor Function Classification System (GMFCS) level 1: 21, 2: 5. 3: 16, 4: 18, 5:20) agreed to participate.

\section{Methods}

Two-sample T-tests were used to compare domain scores between groups. Regression analysis was used to identify factors associated with deviant QoL scores.

\section{Results}

Significantly higher QoL compared to the reference population was reported for the parent relation \& home life and school environment domains. Significantly lower QoL was reported for the physical well-being, social support \& peers, and social acceptance domains. Lower cognitive levels, less communication skills, and higher GMFCS levels were associated with some of the above mentioned domains of QoL.

\section{Conclusion}

This study exposed and provided possible explanations for problem domains of QoL in children with CP living in the Southern part of the Netherlands. This information can be used to inform caregivers and service-providers. 


\section{INTRODUCTION}

In recent years there has been increasing interest in the Quality of Life (QoL) of children with Cerebral Palsy (CP) (figure 9.1: pubmed search; MeSH terms: "Quality of life" AND "Cerebral Palsy"). The World Health Organization (WHO) defines QoL as "an individual's perception of their position in life in the context of culture and value systems in which they live, and in relation to their goals, expectations, standards, and concerns". ${ }^{1}$ Technically speaking QoL is not a definition; it is a concept, an invention of the human mind to construct a model of the world. ${ }^{2}$ As with all human inventions, it is not perfect and therefore QoL does not represent one single truth. Nevertheless, attempts should be made to capture and analyse this QoL in the best way possible as it may expose problem areas in chronically ill children and could lead to treatment opportunities.

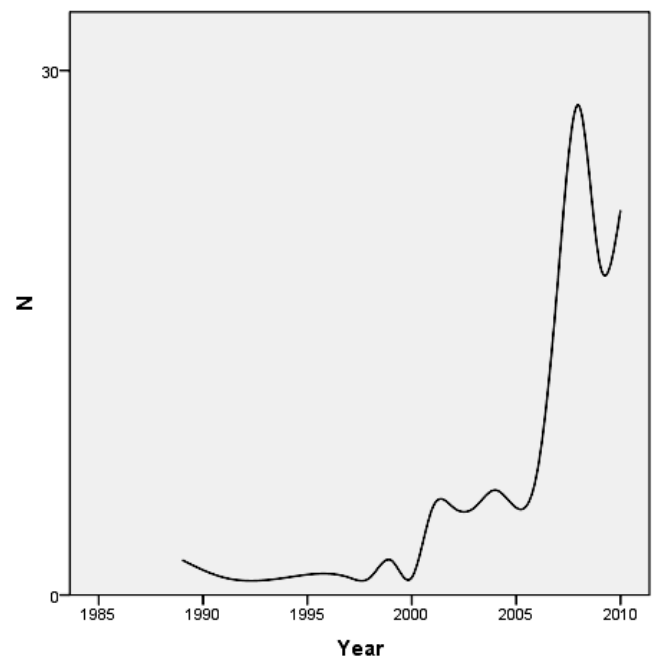

Figure 9.1 Number of publications on QoL of patients with CP (pubmed; MeSH terms: "Quality of life" AND "Cerebral Palsy")

There are several instruments claiming to be able to assess QoL of children with CP, e.g. the Pediatric QoL Questionnaire CP Module (PedsQL), the Child Health Questionnaire (CHQ), the CP QoL questionnaire for children (CP QoL-Child), and the KIDSCREEN. As all these different QoL instruments make it more and more difficult for researchers and clinicians to interpret and compare data found, studies have been conducted to identify the most appropriate QoL questionnaire for their purpose..$^{3-5}$ Although clearly the most commonly used instrument internationally ${ }^{5-7}$, the CHQ was outperformed conceptually and psychometrically by the KIDSCREEN in a study by Davis et al with 204 primary caregivers of children with CP. ${ }^{3}$ The KIDSCREEN is a modern, generic QoL instrument, which uses questions based on focus-groups with children and adolescents all over Europe $^{8-10}$ It focuses entirely on subjective perceptions, has shown to possess excellent psychometric properties, can be used for both disabled and non- 
disabled children, and can be reported by both the children themselves and their caregivers. ${ }^{8-11}$

Previous studies have assessed QoL of children with CP. Several smaller studies found contradicting results.6, 7, 12, 13 The largest study so far (Study of Participation of Children with CP Living in Europe (SPARCLE), 7 European countries, KIDSCREEN-52) found that QoL of children with CP aged 8-12 years is, on average, similar to that of children in the general population on practically all domains. ${ }^{14}$ This study provided clues that children with CP have a slightly better school environment, but experience lower autonomy. Specific factors were found to be associated with lower QoL in certain domains, e.g. pain is associated with less QoL in the physical and psychological well-being and self-perception domains. ${ }^{15}$ Greater limitations, on the other hand, led to higher or lower QoL depending on the domain. However, impairment and pain could only explain a small amount of variance in QoL, which is therefore likely to be largely determined by social and environmental factors.

Given that social and environmental factors can differ significantly between countries and even regions and since the Netherlands did not participate in the SPARCLE study, a study was performed to describe the QoL of the entire population of children with CP in the Southern part of the Netherlands by means of the by-proxy version of the KIDSCREEN-52. As a first step the QoL profile of these children will be displayed. Next, a comparison is made to the QoL of a European sample of children (including Dutch children) from the general population ${ }^{9}$ in order to determine problem domains in Dutch children with CP. Finally, factors associated with problem domains of QoL are investigated.

\section{METHODS}

\section{Design}

The parents of all 81 children with $\mathrm{CP}$ aged 8-18 years seen at the outpatient clinic of the Maastricht University Medical Centre (MUMC), were informed about the study and were asked whether they were willing to participate. All except one agreed to participate. After permission was obtained, parents were sent the by-proxy version of the KIDSCREEN-52 and a questionnaire concerning basic characteristics (table 9.1).

This cross-sectional study was approved by the Medical Ethics Committee (MEC) of the MUMC according to Dutch governmental guidelines. 
Table 9.1 Characteristics of the children with CP living in the Southern part of the Netherlands

\begin{tabular}{|c|c|c|c|}
\hline & $\begin{array}{l}\text { Mean (range) } \\
\text { Frequency (\%) }\end{array}$ & & $\begin{array}{l}\text { Mean (range) } \\
\text { Frequency }(\%)\end{array}$ \\
\hline$\overline{\mathbf{N}}$ & 80 & Age (years) & $13.4(8-18)$ \\
\hline Sex & & Sensory disability & \\
\hline M & $49(61 \%)$ & Visual & $14(18 \%)$ \\
\hline $\mathrm{F}$ & $31(39 \%)$ & Auditory & $2(3 \%)$ \\
\hline Type CP & & Feeding & \\
\hline Spastic unilateral & $26(33 \%)$ & I: Without difficulties & $64(80 \%)$ \\
\hline Spastic bilateral & $52(65 \%)$ & II: Significant Difficulties & $9(11 \%)$ \\
\hline Dyskinetic & $1(1 \%)$ & III: Stoma & $6(8 \%)$ \\
\hline Ataxic & $1(1 \%)$ & Missing & $1(1 \%)$ \\
\hline Cognitive level & & Pain / discomfort & \\
\hline$<50$ & $22(28 \%)$ & None & $50(63 \%)$ \\
\hline $50-70$ & $22(28 \%)$ & Some - severe & $28(35 \%)$ \\
\hline$>70$ & $36(45 \%)$ & Missing & $2(3 \%)$ \\
\hline GMFCS & & Communication Skills & \\
\hline I & $21(26 \%)$ & I: Normal & $47(59 \%)$ \\
\hline II & $5(6 \%)$ & II: Problems & $17(21 \%)$ \\
\hline III & $16(20 \%)$ & III: Alternatives & 7 (9\%) \\
\hline IV & $18(23 \%)$ & IV: None & $8(10 \%)$ \\
\hline $\mathrm{V}$ & $20(25 \%)$ & Missing & $1(1 \%)$ \\
\hline Wheelchair dependent & & Level of hand functioning & \\
\hline Yes & $38(48 \%)$ & I: No limitations & $15(19 \%)$ \\
\hline No & $42(53 \%)$ & $\begin{array}{l}\text { II: Limitations with fine motor task in } \\
\text { both hands }\end{array}$ & $22(28 \%)$ \\
\hline Family composition & & $\begin{array}{l}\text { III: Needs assistance in performing } \\
\text { tasks }\end{array}$ & $18(23 \%)$ \\
\hline Two parents family & $73(91 \%)$ & $\begin{array}{l}\text { IV: Needs assistance and makes use of } \\
\text { adaptive equipment }\end{array}$ & $5(6 \%)$ \\
\hline One parent family & $3(4 \%)$ & V: Requires assistance in everything & $18(23 \%)$ \\
\hline Missing & $4(5 \%)$ & Missing & $2(3 \%)$ \\
\hline Epilepsy & & Occupation parents & \\
\hline None the last year & $62(78 \%)$ & $\geq 1$ parent works fulltime & $53(66 \%)$ \\
\hline$<1$ / month last year & $13(16 \%)$ & Other situation & $24(30 \%)$ \\
\hline$>1$ / month last year & $5(6 \%)$ & Missing & $3(4 \%)$ \\
\hline Schooltype & & Parental qualification & \\
\hline Normal education & $27(34 \%)$ & None & $4(5 \%)$ \\
\hline Special education & $50(63 \%)$ & Below university & $67(86 \%)$ \\
\hline Missing & $3(4 \%)$ & University degree & $7(9 \%)$ \\
\hline Living area & & Missing & $2(3 \%)$ \\
\hline Urban & $40(50 \%)$ & & \\
\hline Countryside & $38(48 \%)$ & & \\
\hline Missing & $2(3 \%)$ & & \\
\hline
\end{tabular}




\section{Participants}

The 80 children with CP consisted of 49 boys and 31 girls with a mean age of 13.4 years (SD 2.98). Forty-eight per cent of the CP children were wheelchair dependent and 55\% had cognitive levels below 70. The major patient and sociodemographic characteristics are displayed in table 9.1.

\section{Outcome measures}

The KIDSCREEN-52 is a generic QoL instrument for children aged 8-18 years and was validated psychometrically with 22110 European children from the general population all over Europe.9, 10 It consists of 52 items assessing QoL in ten domains (table 9.2). Items are scored on a 5-point Likert-scale ("never-seldomsometimes-often-always" / "not at all-slightly-moderately-very-extremely"). Missing values are to be replaced by the mean of the other items belonging to the same domain if no more than 1 item is missing for that domain.

Table 9.2 Explanation of the KIDSCREEN domains ${ }^{9,14}$

\begin{tabular}{ll}
\hline Domain & Aspects measured \\
\hline Physical Well-being & Physical activity, energy, and fitness \\
Psychological Well-being & Positive emotions and satisfaction with life \\
Moods \& Emotions & Negative moods, boredom, and stress \\
Self-Perception & Self, bodily appearance, and body image \\
Autonomy & Freedom of choice and self-determination in leisure time \\
Parent Relation \& Home Life & Interactions and relationships with parents and the socioemo- \\
& tional atmosphere at home \\
Financial Resources & Adequacy of pocket money relative to peers \\
Social Support \& Peers & Social support available from friends and peers \\
School Environment & Learning and feelings about school and teachers \\
Social acceptance & Social acceptance or rejection by peers, including bullying \\
\hline
\end{tabular}

Two ways of calculating domain scores are used in literature. First, item responses can be summed for each domain and are then rescaled to a 0-100 scale (sum-scores), with higher scores indicating better QoL. These sum-scores are used when describing the QoL profile of a population. ${ }^{15,16}$ Second, Rasch Person Parameters can be computed for each dimension, which are then transformed into T-scores with a mean of 50 and an SD of 10 . Higher T-scores indicate higher QoL. T-scores are used when comparing QoL between populations. ${ }^{14}$

In this study, both sum-scores and T-scores will be used to describe the QoL profile of the population of children with CP living in the Southern part of the Netherlands. This will enable future studies to compare their results to Dutch children with CP. 
T-scores will be used to compare the QoL of children with CP living in the Southern part of the Netherlands to a sample of European children (aged 8-18 years) from the general population. Unfortunately, as parent-reported T-scores are not available for the European population of children with $\mathrm{CP}$, no comparison can be made to this group of children. ${ }^{15}$

\section{Statistical analysis}

After all the parents returned the questionnaires all data were entered into SPSS 18.0 for statistical analysis (RH). Afterwards, data entry was randomly checked and found correct by another researcher $(\mathrm{JH})$.

The SPSS syntax provided by the KIDSCREEN group Europe was used to calculate Rasch Person Parameters and T-scores for each of the ten domains. ${ }^{17}$ Furthermore, item responses were summed and rescaled to a 0-100 score (sum-scores). Floor and ceiling effects were considered to be present if the proportions of respondents with the maximal resp. minimal scores for each domain were $>15 \%{ }^{18}$ Stata/ES 9.0 was used to perform two-sample T tests in order to compare the T-scores of the children with CP living in the Southern part of the Netherlands to the general population of European children.9, 15 Given the number of hypotheses tested, an alpha of 0.01 was considered significant.

Regression models were used to investigate the association between patient and sociodemographic characteristics and T-scores of domains in which children with CP living in the Southern part of the Netherlands score significantly different compared to the sample of European children from the general population. Linear regression analysis was used which meant that logistic transformation of the social acceptance and parent relation \& home life domains had to be performed, as scores in these domains were not distributed normally. All factors identified using univariate (SPSS 18.0, dummy variables, $\mathrm{p}<0.1$ ) model testing were used for the subsequent multivariate model testing.

\section{RESULTS}

\section{QoL profile of Dutch children with CP}

In figure 9.2 box and whisker plots of the sum-scores of the 10 KIDSCREEN-52 domains of the 80 children with CP living in the Southern part of the Netherlands can be found. It is clear that the studied population scores relatively low in the physical well-being and social support \& peers domains compared to the other domains of QoL. In table 9.3 the exact sum-scores (mean, SD, median, interquartile range, floor and ceiling effect) can be found. For the parent relation \& home life, financial resources, and social acceptance domains ceiling effects were observed. No floor effects were observed. 


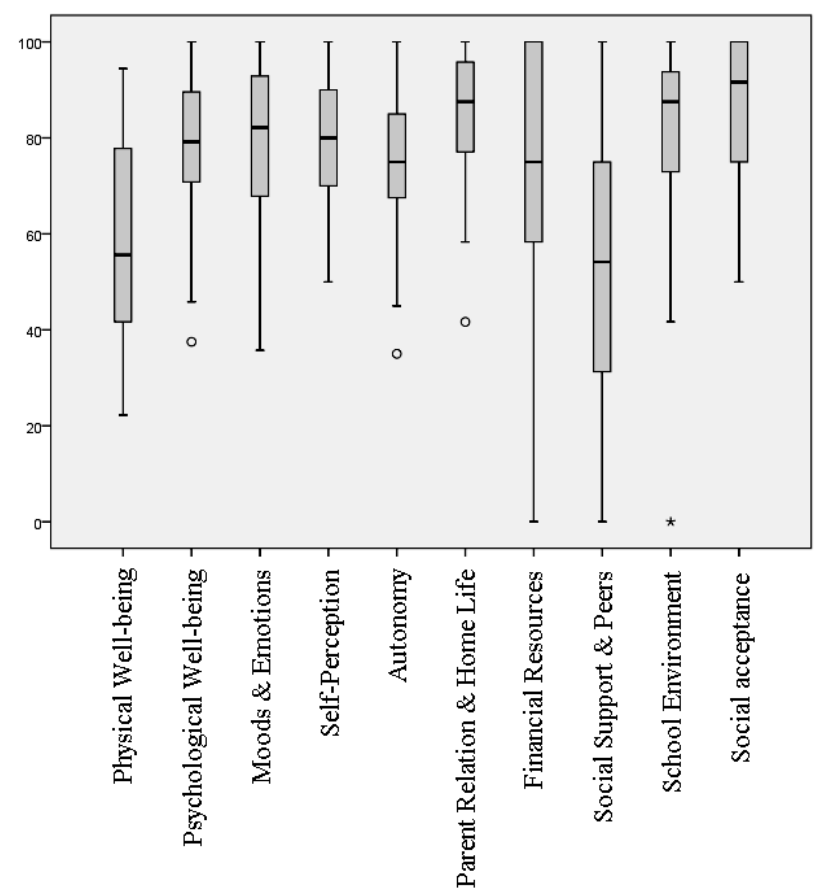

Figure 9.2 Box and whisker plots of the KIDSCREEN sum-scores for 80 children with CP living in the South of the Netherlands

Table 9.3 Sum-scores of 80 children with CP living in the Southern part of the Netherlands

\begin{tabular}{|c|c|c|c|c|c|c|c|}
\hline \multirow[t]{2}{*}{ Domains } & \multirow[t]{2}{*}{$\begin{array}{l}\text { No. of } \\
\text { items }\end{array}$} & \multicolumn{4}{|c|}{$\begin{array}{l}\text { CP - Southern part of the Netherlands } \\
\text { Sum-scores }\end{array}$} & \multirow[b]{2}{*}{ Floor effect $\%$} & \multirow[b]{2}{*}{ Ceiling effect $\%$} \\
\hline & & Mean & SD & Median & IQR & & \\
\hline Physical Well-being & 5 & 58.0 & 21.5 & 55.6 & $38.9-77.8$ & 0.0 & 2.5 \\
\hline Psychological Well-being & 6 & 77.5 & 14.9 & 75.0 & $66.8-87.5$ & 0.0 & 10.0 \\
\hline Moods \& Emotions & 7 & 78.8 & 16.1 & 82.1 & $67.9-92.9$ & 0.0 & 6.3 \\
\hline Self-Perception & 5 & 78.0 & 15.1 & 80.0 & $68.8-90.0$ & 0.0 & 10.0 \\
\hline Autonomy & 5 & 72.1 & 15.3 & 75.0 & $60.0-80.0$ & 0.0 & 6.3 \\
\hline Parent Relation \& Home Life & 6 & 84.3 & 13.9 & 87.5 & $75.0-95.8$ & 1.3 & 18.8 \\
\hline Financial Resources & 3 & 73.2 & 26.0 & 75.0 & $58.3-100.0$ & 3.8 & 23.8 \\
\hline Social Support \& Peers & 6 & 49.2 & 27.6 & 54.2 & $25.0-75.0$ & 5.0 & 2.5 \\
\hline School Environment & 6 & 80.3 & 17.9 & 83.3 & $70.8-95.8$ & 1.3 & 8.8 \\
\hline Social acceptance & 3 & 83.3 & 19.0 & 91.7 & $75.0-100.0$ & 1.3 & 35.0 \\
\hline
\end{tabular}




\section{Comparison to a sample of European children from the general population}

T-scores (mean, SD, comparison to a sample of European children from the general population) can be found in table 9.4. Again, low scores for the physical well-being and social support \& peers domains are reported. Also, the children are reported to have low QoL in the social acceptance domain compared to the sample of European children from the general population. In contrast, significantly higher QoL is reported for parent relation and home life and the school environment domains.

Table 9.4 T-scores of 80 children with CP living in the Southern part of the Netherlands compared to a sample of European children from the general population

\begin{tabular}{llllrl}
\hline Domains & No. of items & & & \\
& & N & Mean & \multicolumn{1}{c}{ SD } & $\mathrm{p}^{*}$ \\
\hline Physical well-being & 5 & $74 / 80$ & 41.1 & 9.7 & 0.00 \\
Psychological well-being & 6 & $77 / 80$ & 51.7 & 10.3 & 0.13 \\
Moods \& emotions & 7 & $76 / 80$ & 48.7 & 11.5 & 0.27 \\
Self-perception & 5 & $74 / 80$ & 50.7 & 9.9 & 0.57 \\
Autonomy & 5 & $71 / 80$ & 48.0 & 8.4 & 0.09 \\
Parent relation \& home Life & 6 & $74 / 80$ & 54.8 & 10.3 & 0.00 \\
Financial resources & 3 & $60 / 80$ & 52.7 & 10.9 & 0.04 \\
Social support \& peers & 6 & $65 / 80$ & 40.0 & 15.4 & 0.00 \\
School environment & 6 & $71 / 80$ & 56.4 & 11.1 & 0.00 \\
Social acceptance & 3 & $78 / 80$ & 46.9 & 11.7 & 0.01 \\
\hline
\end{tabular}

${ }^{*}$ Significance compared to the general population of European children $(\mathrm{N}=15485-15897$; Mean $\approx$ 50.00 ; $\mathrm{SD} \approx 10.00$, depending on the domain $)^{9}$

\section{Factors associated with domains of significantly different QoL in Dutch children with $\mathrm{CP}$}

Patient characteristics and sociodemographic factors (table 9.1) were investigated to see whether they were significantly associated with the physical wellbeing, parent relation \& home life, social support \& peer relations, school environment, and social acceptance domains (table 9.5). For the physical well-being domain it was found that higher GMFCS level was associated with lower Tscores. Less communication skills and lower cognitive levels were associated with lower T-scores in the social support \& peers and school environment domains. Furthermore, parents with no educational qualification rated their childs QoL in the parent relation \& home life domain higher. For the social acceptance domain no associated factors could be identified. 
Table 9.5 Factors associated with low QoL domains (T-scores) in Dutch children with CP (multivariate analysis)

\begin{tabular}{|c|c|c|c|}
\hline Domain & Independent variable & $\mathrm{B}$ & $\mathrm{p}$ \\
\hline \multirow[t]{6}{*}{ Physical well-being } & GMFCS & & \\
\hline & Level 1 & 0.0 & NA \\
\hline & Level 2 & -11.5 & 0.00 \\
\hline & Level 3 & -10.6 & 0.00 \\
\hline & Level 4 & -14.8 & 0.00 \\
\hline & Level 5 & -16.5 & 0.00 \\
\hline \multirow[t]{4}{*}{ Parent relation \& home life } & Parental qualification & & \\
\hline & No qualification & 0.0 & NA \\
\hline & Below university & -1.1 & 0.00 \\
\hline & University degree & -1.0 & 0.00 \\
\hline \multirow[t]{9}{*}{ Social support \& peers } & Communication skills & & \\
\hline & I: normal & 0.0 & NA \\
\hline & II: Problems & -10.5 & 0.04 \\
\hline & III: Alternatives & -2.6 & 0.71 \\
\hline & IV: none & -15.7 & 0.02 \\
\hline & Cognitive level & & \\
\hline & $>70$ & 0.0 & NA \\
\hline & $50-70$ & -1.0 & 0.82 \\
\hline & $<50$ & -13.5 & 0.01 \\
\hline \multirow[t]{9}{*}{ School environment } & Communication skills & & \\
\hline & I: normal & 0.0 & NA \\
\hline & II: Problems & 3.6 & 0.06 \\
\hline & III: Alternatives & 4.7 & 0.01 \\
\hline & IV: none & 5.3 & 0.00 \\
\hline & Cognitive level & & \\
\hline & $>70$ & 0.0 & NA \\
\hline & $50-70$ & 3.1 & 0.04 \\
\hline & $<50$ & 3.7 & 0.00 \\
\hline Social acceptance & No factor identified & & \\
\hline
\end{tabular}

NA = not applicable

\section{DISCUSSION}

To the best of our knowledge this is the first study to investigate QoL of Dutch children with CP by means of the KIDSCREEN-52. The main strength of this study is that $99 \%$ of the parents of all children with CP seen at the outpatient clinic of the MUMC participated. The overall QoL profile of children with CP living in the Southern part of the Netherlands seems to be quite similar to the 
QoL profile of children with CP as found in the SPARCLE study. ${ }^{14,15}$ For example, relatively high scores on the school environment domain and relatively low scores on the autonomy domain were found, which is in accordance with the study by Dickinson et al. ${ }^{14}$ These findings confirm the usefulness of the KIDSCREEN-52 across national borders. In this present study it was found that children with CP living in the Southern part of the Netherlands are reported to have low QoL on three KIDSCREEN-52 domains compared to a sample of European children from the general population, i.e. the physical well-being, social support \& peers, and social acceptance domains.

\section{Less physical well-being}

According to the KIDSCREEN group Europe low scores in the physical wellbeing domain mean that more children than usual feel physically exhausted, unwell, and unfit. ${ }^{9}$ In this present study it was found that higher GMFCS levels were associated with lower QoL in this domain. This is a logical finding and is in accordance with the studies by Dickinson et al and Arnaud et al. ${ }^{14,15}$ However, both Arnaud et al and Dickinson et al found pain to be associated with lower QoL scores. This was not the case in the present study. This discrepancy between our findings and literature may be due to the fact that dichotomous pain data were used. Furthermore, it could be that the relationship between QoL and pain is not as obvious as we expect it to be. For example, in a study by Engel et al it was shown that in adults with $\mathrm{CP}$ it is not the pain itself that influences psychological functioning, but the coping strategies in reaction to the pain. ${ }^{19}$

\section{More family, less friends?}

It is intriguing to see that these Dutch children with $\mathrm{CP}$ are reported to have significantly higher QoL in the school environment and parent relation \& home life domains and significantly lower QoL in the social support \& peers and social acceptance domains compared to a sample of European children from the general population. This is a pattern not observed in the European population of children with $\mathrm{CP}$. We came up with two possible, non-exclusive explanations: one based on quantitative research, the other on qualitative research.

With regard to the first, in a large, cross-sectional survey study using the KIDSCREEN-52 among 16.210 children in children and adolescents 8-18 years old in 11 European countries, Analitis et al found that living in the Netherlands holds the highest odds ratio (1.68) of being bullied. ${ }^{20}$ These results could explain why more Dutch children with CP than usual feel tormented, bullied, and rejected by peers. The observed pattern leads to the assumption that Dutch people committed to these children (parents, family, teachers, etc) have a significant positive contribution to their QoL, while non-committed others (peers) might bully and negatively influence their QoL. 
The second explanation is based on qualitative research by Parkinson et al who investigated the extent of agreement between children with CP and their caregivers concerning their views on what contributed to the children QoL. ${ }^{21}$ They conducted qualitative interviews with 26 children with $\mathrm{CP}$ and 35 caregivers and came to the conclusion that there is considerable overlap but also some divergence. For example, children reported enjoying being on their own from time to time. Caregivers do not appreciate these attitudes and put substantial effort into creating opportunities for their child to be included socially. The interviewers found them very concerned about their child's experiences of being isolated or bullied by other children, often emphasizing this more than the children themselves. In other words, it is very well possible that low QoL on the social support \& peers and social acceptance domains is due to concerns of the caregivers rather than what the children experience themselves. This is in accordance with our PARS-III study in which it was shown that children with CP psychosocially adjust to their motor and accompanying problems by withdrawal, without establishing sufficient and comprehensive peer relations. The question remains: who is right? Is it acceptable for children with $\mathrm{CP}$ to withdraw and enjoy time spent on their own, or are the caregivers right by stating that the children underestimate the risk and consequences of being socially isolated and that effort has to be put into engineering opportunities for their child to be included socially?

\section{Comparison to the QoL of other patient populations in the Netherlands}

Several other studies have investigated the QoL profile of specific patient populations in the Netherlands by means of the KIDSCREEN. For example, van Dijk et al found 65 child and adolescent retinoblastoma survivors to report good QoL compared to the reference population, with even significantly higher QoL for the moods \& emotions and autonomy domains. ${ }^{22}$ Smets et al found no significant difference in QoL between 35 children with a positive carrier status for inherited cardiovascular diseases and the reference population. ${ }^{23}$ The same was observed by Michielsen et al in 56 children and adolescents with congenital lower limb deficiency (LLD). ${ }^{24}$ Therefore, we can state the QoL profile of Dutch children with CP to be unique as significant lower QoL was reported for three domains. As single physical (LLD) or psychological (fear of sudden cardiac death or recurrence of cancer) factors do not seem to influence QoL, one could argue that it is the interaction of multiple impairments met by Dutch children with CP which causes the decrease in QoL in certain domains.

\section{Limitations of this study}

An important limitation of this study is the sole reliance on proxy reports. The literature on the best source to evaluate QoL is inconsistent at best. The WHO 
recommends that children should report their own QoL.25 Furthermore, a recent study has shown that, especially in children with chronic neurological disorders, parent-children agreement is suboptimal and that parents under-report subjective aspects of well-being. ${ }^{26}$ However Le Coq et al found 8 to 11 year old pediatric asthma patients to be less responsive and less reliable reporters on a QoL measure compared to their parents. ${ }^{27}$ It is now becoming more and more accepted that there is no one single truth concerning QoL and therefore selfreports and proxy-reports are complementary. ${ }^{28}$ With regard to the present study, self-reports would have been extremely difficult to obtain and interpret given the severity of disability of the majority of the population of the children with CP. This problem is omnipresent which is probably best illustrated by the SPARCLE study itself in which 318 out of the 818 selected children with CP could not self-report. ${ }^{14}$ In this case, proxy-reports are the only way to evaluate QoL with their parents / caregivers being the most logical source of information as they are assumed to have intimate knowledge of the child. This inevitably means that parents have to judge how their children experience life.

Furthermore, no data on parental stress was collected. Arnaud et al have shown that parents with higher levels of stress were more likely to report poor QoL on all domains.15

Finally, it was not possible to compare parent-reported T-scores of Dutch children with CP to parent-reported T-scores of an European sample of children with $\mathrm{CP}$ as these are not reported in literature. ${ }^{15}$ The authors suggest publication of these T-scores in order to let future studies be able to compare the QoL of their population of children with CP to an European standard.

\section{CONCLUSION}

This study describes the QoL profile of 80 children with CP living in the Southern part of the Netherlands as measured by means of the by-proxy version of the KIDSCREEN-52. The children studied are reported to have relatively low QoL in the physical well-being, social support \& peers, and social acceptance domains, but relatively high QoL in the parent relation \& home life and the school environment domains. These findings provide a better understanding of the QoL of Dutch children with CP. They can be used to inform caregivers and service-providers and to focus health programs aiming to increase QoL in this group of children towards identified problem domains. 


\section{REFERENCES}

1. The World Health Organization Quality of Life assessment (WHOQOL): position paper from the World Health Organization. Soc Sci Med 1995. 41(10): p. 1403-9.

2. Sowa JF. Conceptual structures: Information processing in mind and machine. 1983: AddisonWesley Pub.,Reading, MA. Medium: X; Size: Pages: 300.

3. Davis E, Shelly A, Waters E, et al. Measuring the quality of life of children with cerebral palsy: comparing the conceptual differences and psychometric properties of three instruments. Dev Med Child Neurol 2010. 52(2): p. 174-80.

4. McCarthy ML, Silberstein CE, Atkins EA, et al. Comparing reliability and validity of pediatric instruments for measuring health and well-being of children with spastic cerebral palsy. Dev Med Child Neurol 2002. 44(7): p. 468-76.

5. Schneider JW, Gurucharri LM, Gutierrez AL, et al. Health-related quality of life and functional outcome measures for children with cerebral palsy. Dev Med Child Neurol 2001. 43(9): p. 6018.

6. Liptak GS, O'Donnell M, Conaway M, et al. Health status of children with moderate to severe cerebral palsy. Dev Med Child Neurol 2001. 43(6): p. 364-70.

7. Vargus-Adams J. Health-related quality of life in childhood cerebral palsy. Arch Phys Med Rehabil 2005. 86(5): p. 940-5.

8. Detmar SB, Bruil J, Ravens-Sieberer U, et al. The use of focus groups in the development of the KIDSCREEN HRQL questionnaire. Qual Life Res 2006. 15(8): p. 1345-53.

9. KIDSCREEB Group Europe. The KIDSCREEN questionnaires. Quality of life questionnaires for children and adolescents - handbook, ed. Lengerich. 2006: Pabst Science Publisher.

10. Ravens-Sieberer U, Gosch A, Rajmil L, et al. KIDSCREEN-52 quality-of-life measure for children and adolescents. Expert Rev Pharmacoecon Outcomes Res 2005. 5(3): p. 353-64.

11. Robitail S, Simeoni MC, Ravens-Sieberer U, et al. Children proxies' quality-of-life agreement depended on the country using the European KIDSCREEN-52 questionnaire. J Clin Epidemiol 2007. 60(5): p. 469-78.

12. Varni JW, Burwinkle TM, Sherman SA, et al. Health-related quality of life of children and adolescents with cerebral palsy: hearing the voices of the children. Dev Med Child Neurol 2005. 47(9): p. 592-7.

13. Kennes J, Rosenbaum P, Hanna SE, et al. Health status of school-aged children with cerebral palsy: information from a population-based sample. Dev Med Child Neurol 2002. 44(4): p. 2407.

14. Dickinson HO, Parkinson KN, Ravens-Sieberer U, et al. Self-reported quality of life of 8-12-yearold children with cerebral palsy: a cross-sectional European study. Lancet 2007. 369(9580): p. 2171-8.

15. Arnaud C, White-Koning M, Michelsen SI, et al. Parent-reported quality of life of children with cerebral palsy in Europe. Pediatrics 2008. 121(1): p. 54-64.

16. Mc Manus V, Corcoran P, and Perry IJ. Participation in everyday activities and quality of life in pre-teenage children living with cerebral palsy in South West Ireland. BMC Pediatr 2008. 8: p. 50.

17. Tesio L. Measuring behaviours and perceptions: Rasch analysis as a tool for rehabilitation research. J Rehabil Med 2003. 35(3): p. 105-15.

18. Assessing health status and quality-of-life instruments: attributes and review criteria. Qual Life Res 2002. 11(3): p. 193-205.

19. Engel JM, Jensen MP, and Schwartz L. Coping with chronic pain associated with cerebral palsy. Occup Ther Int 2006. 13(4): p. 224-33.

20. Analitis F, Velderman MK, Ravens-Sieberer U, et al. Being bullied: associated factors in children and adolescents 8 to 18 years old in 11 European countries. Pediatrics 2009.123(2): p. 569-77.

21. Parkinson KN, Rice H, and Young B. Incorporating children's and their parents' perspectives into condition-specific quality-of-life instruments for children with cerebral palsy: a qualitative study. Value Health 2011.14(5): p. 705-11. 
22. van Dijk J, Huisman J, Moll AC, et al. Health-related quality of life of child and adolescent retinoblastoma survivors in the Netherlands. Health Qual Life Outcomes 2007. 5: p. 65.

23. Smets EM, Stam MM, Meulenkamp TM, et al. Health-related quality of life of children with a positive carrier status for inherited cardiovascular diseases. Am J Med Genet A 2008. 146A(6): p. 700-7.

24. Michielsen A, van Wijk I, and Ketelaar M. Participation and health-related quality of life of Dutch children and adolescents with congenital lower limb deficiencies. J Rehabil Med 2011. 43(7): p. 584-9.

25. Organization WH, Measurement of Quality of Life in children, W.H. Organization, Editor. 1993, World Health Organization: Geneva, Switzerland.

26. Morrow AM, Hayen A, Quine S, et al. A comparison of doctors', parents' and children's reports of health states and health-related quality of life in children with chronic conditions. Child Care Health Dev.

27. le Coq EM, Boeke AJ, Bezemer PD, et al. Which source should we use to measure quality of life in children with asthma: the children themselves or their parents? Qual Life Res 2000. 9(6): p. 625-36.

28. Eiser C and Morse R. Can parents rate their child's health-related quality of life? Results of a systematic review. Qual Life Res 2001. 10(4): p. 347-57. 

CHAPTER X

GENERAL DISCUSSION AND CONCLUSION 


\section{GENERAL DISCUSSION}

Topic specific discussions can be found at the end of each chapter. This general discussion will focus on three issues encountered repeatedly while writing this thesis. The first issue is the problems and dilemmas associated with measuring concepts. The second issue is the rationale of evaluating your outpatient clinic. The third and final issue is the surplus value of qualitative research.

\section{MEASURING CONCEPTS}

During this thesis attempts have been made to measure several concepts, i.e. QoL and psychosocial adjustment. Concepts are inventions of the human mind to construct a model of the world. ${ }^{1}$ They are abstract and cannot be touched, felt, or seen. Nevertheless, the significance of concepts like QoL and psychosocial adjustment is widely recognized. Therefore, these abstract and unobservable concepts have to be translated into something concrete and measurable. This process is called operationalisation and requires several criteria with regard to validity, consistency, stability, and reliability to be met. ${ }^{2}$ Fortunately, the KIDSCREEN group Europe and Stein \& Jessop have already done this and provided the clinician / researcher with valid and reliable tools to measure QoL (KIDSCREEN) and psychosocial adjustment (PARS-III) respectively.3, 4 However, results found still have to be interpreted with caution and considerable knowhow. Let us take the concept of QoL. QoL is defined as "an individual's perception of their position in life in the context of culture and value systems in which they live, and in relation to their goals, expectations, standards, and concerns". ${ }^{5}$ In a very large, comprehensive, multi-centre study published in the Lancet it was concluded that the QoL of children with CP is similar to that of other children on all domains. ${ }^{6}$ The authors stated that pity and sorrow are therefore not in place. Another study investigated QoL of child and adolescent retinoblastoma survivors and found that their QoL is comparable to the general population with even significantly higher QoL on the moods \& emotions and the autonomy domains. ${ }^{7}$ Does this mean that the QoL of a child with CP fighting has spastic movements in his wheelchair is similar to that of his brother outside playing soccer and that we should wish for everybody to get retinoblastoma? Probably not. It most likely means that determinants of QoL have shifted in children with CP and that surviving retinoblastoma makes people more aware of certain domains of QoL when approached by a researcher interested in their QoL. Furthermore, admitting that your or your child's QoL is below average is a hard thing to do. The psychological effects when asked to judge your own or your child's QoL have not yet been studied. However, indirect evidence for a biased representation of one's own QoL comes from studies on self-presentation 
and narcissism on facebook, the planets largest social networking platform today. It is repeatedly found that people tend to self-promote and over-represent their lives. ${ }^{8-11}$

In my opinion two aspects of concepts like QoL and psychosocial adjustment are the most useful and the most interpretable: 1) the profile expressed in different domains; 2) the development over time.

Studying the domains of QoL in a population of patients may expose problem areas which could lead to treatment options. In our KIDSCREEN study on the QoL of Dutch children with CP (chapter IX) we found that these children are reported to have significantly higher QoL on the school environment and parent relation \& home life domains and significantly lower QoL on the social support \& peers and social acceptance domains. This observation leads to the assumption that Dutch people committed to these children (parents, family, teachers) have a significant positive contribution to their QoL, while non-committed others (peers) might negatively influence their QoL. These results are in accordance with the results obtained in our PARS-III study on psychosocial adjustment in Dutch children with CP (chapter III) in which we found low scores on the peer relations domain of psychosocial adjustment. It therefore makes sense to focus future health programs aiming to raise QoL in children with CP towards improving peer relations and social acceptance of these chronically impaired children.

The development of QoL over time was also studied in this thesis. This was done in children with CP who received an ITB pump in order to treat intractable spasticity (chapter VIII). It was shown that the positive effects on pain, ease of care, and mental health identified in the first year after commencement of treatment are still present today. Moreover, additional benefits have appeared, e.g. significantly improved scores on the Parent Impact - Emotional and the Parent Impact - Time subscales of the CHQ. According to the CHQ manual this means that care-givers experience fewer feelings of emotional worry / concern and fewer limitations in time available for personal needs due to the child's physical and / or psychosocial health. ${ }^{12}$ It is difficult to tell whether this is a direct result of ITB therapy or whether this would also occur in parents with children not receiving ITB therapy. An ever growing amount of experience in caring for their children could explain the decrease in worries and concern and the increase in time for personal needs of the care-givers.

Another additional benefit was present 6-9 years after pump implantation, i.e. significantly improved scores on CHQ PhS. The subscales that contribute most profoundly to the $\mathrm{PhS}$ are physical functioning, role/social limitations (physical), bodily pain/discomfort, and general health. ${ }^{12}$ It appears that improvements in CHQ PhS need more than 12 months to become evident (figure 8.2). A possible explanation for this observation is that improvements in terms of CHQ PhS require more than a reduction in spasticity alone. New possibilities have to be explored and practiced, which takes some time. On the other hand, a 
reduction in spasticity will cause an immediate effect on pain and ease of care (figure 8.2).

\section{EVALUATING YOUR OUTPATIENT CLINIC}

Part of this thesis could be interpreted as a so-called audit. An audit measures clinical practice against current standards. It is a slightly odd type of research. In stead of searching for the right thing to do, it is checked whether or not the right thing is being done. In the United Kingdom it is standard practice for young doctors to perform an audit while in their foundation years. ${ }^{13}$ An audit serves multiple purposes. A cochrane review concluded that an audit can improve the practice of health care professionals. ${ }^{14}$ Furthermore, in these times where there is both an increasing demand on clinicians to implement evidence based medicine and optimize health care interventions routinely as an increasing pressure to rationalize treatment costs, evaluating your outpatient clinic seems a logical thing to do. The main problem, especially when treating severely handicapped children, is the lack of a quick, simple, and meaningful outcome measure. For example, it is not reasonable to expect clinicians to evaluate all children with $\mathrm{CP}$ receiving BTX-A injections by means of the PEDI, which takes over 1 hour per session.

During this thesis a VAS was used multiple times for different purposes. It was, along with other more sophisticated and time-consuming instruments, used to evaluate the effects of BTX-A treatment, ITB treatment, and RF-DRG treatment in children with $\mathrm{CP}$. In chapter VI we showed that a VAS was able to measure effect of BTX-A treatment and that overall correlations with standard evaluation instruments were in the expected direction. Besides being a quick and easy method for evaluating treatment in a busy outpatient setting, the VAS is a subjective measure of the effects that treatment has on individually chosen goals. We would like to argue that it is this subjective nature of the VAS that makes it very suitable to evaluate treatment effects in children with $C P$ at the severe end of the spectrum. Expecting to measure functional gain after treatment is not realistic in these children and most of the times is not the desired treatment goal set by the child and his caregivers. Usually the child and his caregivers are the best judges of the impact that the treatment has had on the daily life of the child. Furthermore, it is known that caregivers of children with profound impairments note changes in function far more accurately than staff workers. Small changes, noticed by caregivers but not picked up by conventional outcome measures, can add significant improvement to lives of children with CP and their caregivers.

Using this subjective VAS and other more objective and time-consuming instruments (Tardieux, MAS, CHQ, KIDSCREEN) we found evidence supporting the use of BTX-A, ITB, and RF-DRG treatment in the population of children with CP 
seen at the outpatient clinic of the MUMC. These results verify the methods used to treat children in this university hospital. Furthermore, caregivers and children with CP can now be informed about the anticipated effects of several treatments not only based on data reported in literature but also based on results obtained by the local multidisciplinary $\mathrm{CP}$ working group.

\section{QUALITATIVE RESEARCH}

Traditionally, research in medicine has been quantitative by nature. These studies consist of identifying a problem, formulating a hypothesis, conducting an experiment, followed by supporting or dismissing the hypothesis. This is considered true research by many.

However, over the last decade there has been increasing interest for qualitative research. Boyd described qualitative research as broadly stated questions about human experiences and realities studied through sustained contact with persons in their natural environment, and producing rich, descriptive data that aid in understanding those person's experiences. ${ }^{15}$

Although qualitative studies have not been performed as part of this thesis, they have been very useful in the interpretation of data found. This was particularly true for the KIDSCREEN study (chapter IX). In this study we assessed the QoL of all children with CP living in the Southern part of the Netherlands. Bearing in mind the severity of $\mathrm{CP}$ in these children, we were forced to use the byproxy version of the KIDSCREEN-52. Using this generic QoL instrument it was found that children with CP living in the Southern part of the Netherlands are reported to have significant lower QoL on three domains: physical well-being, social support \& peers, and social acceptance. Less QoL on the physical wellbeing domain makes sense considering the GMFCS levels, the frequency of reported pain, and the accompanying impairments in these children. However, interpreting the results on the social support \& peers and social acceptance domains posed somewhat of a problem, especially since these data were reported by care-givers. In other words, a QoL problem was identified however possible explanations for this observation were lacking. We came up with two possible, non-exclusive explanations: one based on quantitative research, the other on qualitative research. With regard to the first, in a large, cross-sectional survey study using the KIDSCREEN-52 among 16.210 children in children and adolescents 8-18 years of age in 11 European countries, Analitis et al found that living in the Netherlands holds the highest odds ratio (1.68) of being bullied. ${ }^{16}$ These results could explain why more Dutch children with CP than usual feel tormented, bullied, and rejected by peers. The second explanation is based on qualitative research by Parkinson et al who investigated the extent of agreement between children with $\mathrm{CP}$ and their caregivers concerning their views on what contributed to the children's QoL. ${ }^{17}$ They conducted qualitative interviews with 
26 children with $\mathrm{CP}$ and 35 caregivers and came to the conclusion that there is considerable overlap but also some divergence. For example, children reported enjoying being on their own from time to time, while caregivers tended not to value these attitudes and put considerable effort into engineering opportunities for their child to be included socially. The interviewers found them very concerned about their child's experiences of being isolated or bullied by other children, often emphasizing this more than the children themselves. In other words, it is very well possible that low QoL on the social support \& peers and social acceptance domains is due to concerns of the caregivers rather than what the children experience themselves. This is in accordance with our PARS-III study (chapter III) in which it was shown that children with CP psychosocially adjust to their motor and accompanying problems by withdrawal, without establishing sufficient and comprehensive peer relations. The question remains: who is right? Is it acceptable for children with $\mathrm{CP}$ to withdraw and enjoy time spent on their own, or are the caregivers right by stating that the children underestimate the risk and consequences of being socially isolated and that effort has to be put into engineering opportunities for their child to be included socially? Again, this highlights the necessity of measuring concepts like QoL and psychosocial adjustment through time as this would show the long-term consequences of withdrawal and the lack of social support in these children.

Another surplus value of qualitative research will be discussed. As already stated before, measuring treatment effect in children with $\mathrm{CP}$ poses somewhat of a challenge. Expecting large improvement in severely impaired children is unfortunately most often not realistic. However, small improvements, no matter how little, can make a huge difference. Against this background the following example is discussed.

In our long-term follow-up study on the effects of ITB treatment on intractable spasticity in children with CP (chapter VIII), multiple evaluation instruments were used. Among others, these included the CHQ, the KIDSCREEN, three self-made questionnaires (pain, function, complications, surgeries, hospitalizations, outpatient clinic visits), the Lifestyle Assessment Questionnaire for CP (LAQ-CP), the PARS-III, the CBCL and the SEV (manuscript in preparation). For one child treated with ITB only minimal improvements on all of these instruments were reported by the caregivers. However, when asked if they would choose for ITB treatment for their child again, considering the advantages (effects) and disadvantages (surgeries, complications, outpatient visits, and hospitalizations) experienced over all those years, they were absolutely positive. They stated that the slight increase in the range of leg abduction, improved ease of care and dressing dramatically. Thus, in this case a qualitative interview shed an entirely different light on results obtained by quantitative research. 


\section{CONCLUSION}

In this thesis several clinical and therapeutic aspects of $\mathrm{CP}$ have been studied. The psychosocial adjustment (chapter I) and QoL (chapter IX) of children with $\mathrm{CP}$ seen at the outpatient clinic of the MUMC were investigated. Conventional treatments, like BTX-A (chapter IV) and ITB (chapter VI), and their complications (chapter V) have been evaluated and their effectiveness was confirmed. Furthermore, new treatments, like RF-DRG (chapter II) and Levetiracetam (chapter III), have been researched and found promising. The main message of this thesis is the following. When treating children with $\mathrm{CP}$ it is essential to understand their way of coping with their often severe disabilities and limitations and how this influences their QoL. Subsequently, treatment goals have to be set that are both obtainable and desired by both the child and his caregivers. Not only does one have to select the right treatment option, but also the right evaluation method. 


\section{REFERENCES}

1. Sowa JF. Conceptual structures: Information processing in mind and machine. 1983: AddisonWesley Pub.,Reading, MA. Medium: X; Size: Pages: 300.

2. Greenstein T, Methods of family research. 2006, Sage publications. p. 51-62.

3. KIDSCREEN GROUP EUROPE. The KIDSCREEN questionnaires. Quality of life questionnaires for children and adolescents - handbook, ed. Lengerich. 2006: Pabst Science Publisher.

4. Stein REK, Jessop D, Manual for Personal Adjustment and Role Skills Scale III (PARS III). 1990: Bronx, New York.

5. The World Health Organization Quality of Life assessment (WHOQOL): position paper from the World Health Organization. Soc Sci Med 1995. 41(10): p. 1403-9.

6. Dickinson HO, Parkinson KN, Ravens-Sieberer U, et al. Self-reported quality of life of 8-12-yearold children with cerebral palsy: a cross-sectional European study. Lancet 2007. 369(9580): p. 2171-8.

7. van Dijk J, Imhof SM, Moll AC, et al. Quality of life of adult retinoblastoma survivors in the Netherlands. Health Qual Life Outcomes 2007. 5: p. 30.

8. Goel S, Mason W, and Watts DJ. Real and perceived attitude agreement in social networks. J Pers Soc Psychol 2010. 99(4): p. 611-21.

9. Kim J and Lee JE. The Facebook paths to happiness: effects of the number of Facebook friends and self-presentation on subjective well-being. Cyberpsychol Behav Soc Netw 2011. 14(6): p. 359-64.

10. Mehdizadeh S. Self-presentation 2.0: narcissism and self-esteem on Facebook. Cyberpsychol Behav Soc Netw 2010. 13(4): p. 357-64.

11. Tucker JH. Status update: "I'm so glamorous". A study of facebook users shows how narcissism and low self-esteem can be interrelated. Sci Am 2010. 303(5): p. 32.

12. Landgraf J, Abetz L, and Ware J. The CHQ User's Manual. Second printing ed. 1999, Boston, MA: Health act.

13. Benjamin A. Audit: how to do it in practice. BMJ 2008. 336(7655): p. 1241-5.

14. Jamtvedt G, Young JM, Kristoffersen DT, et al. Audit and feedback: effects on professional practice and health care outcomes. Cochrane Database Syst Rev 2006(2): p. CD000259.

15. Boyd CO and Munhall PL. Qualitative research proposals and reports. NLN Publ 1993(19-2535): p. 424-53.

16. Analitis F, Velderman MK, Ravens-Sieberer U, et al. Being bullied: associated factors in children and adolescents 8 to 18 years old in 11 European countries. Pediatrics 2009. 123(2): p. 569-77.

17. Parkinson KN, Rice H, and Young B. Incorporating children's and their parents' perspectives into condition-specific quality-of-life instruments for children with cerebral palsy: a qualitative study. Value Health 2011.14(5): p. 705-11. 
ENGLISH SUMMARY 
ENGLISH SUMMARY 
This thesis addressed clinical and therapeutic aspects of cerebral palsy (CP). Several aspects of overall assessment, treatment, and its evaluation were studied in the population of children with CP seen at the outpatient clinic of the Maastricht University Medical Centre (MUMC).

$\mathrm{CP}$ is a major health problem as it affects 1 in 400 children making it the most common developmental disorder associated with lifelong disability. It is defined as a static, but often changing disorder of movement and posture due to a defect or lesion to the developing fetal or infant brain. In addition to their motor problems, children with CP often have impairments of learning, hearing, vision, and communication and frequently have seizure disorders. As a first step of this thesis a study was performed to see how these children adjust to their often severe disabilities and limitations. Therefore, in chapter III the psychosocial adjustment of children with $\mathrm{CP}$ is described. The main problem in this research area is that there are few standardized instruments specifically developed to assess psychosocial adjustment in children with a chronic illness. One very suitable instrument but not previously used in children with CP is the Psychosocial Adjustment and Role Skills Scale - III (PARS-III). The parents of all 94 children with CP (aged 4-18 years) seen at the outpatient clinic of the MUMC were informed about the study and asked to participate. All except one agreed and were sent the PARS-III questionnaire. The 93 children with CP consisted of 59 boys and 34 girls with a mean age of 12.3 years (SD 3.8; 4-18). Forty-four per cent of the children with $\mathrm{CP}$ were wheelchair dependent and $52 \%$ had a cognitive level below 70. Ninety-five healthy children and 63 boys with Duchenne Muscular Dystrophy (DMD) were used as reference groups. As the PARS-III had never before been applied to children with CP, its use had to be justified first. Results showed good internal consistency for the total PARS-III score: an alpha of 0.89 . Confirmatory Factor Analysis confirmed the six domains of psychosocial functioning on the PARS-III questionnaire in children with CP. Based on these results the PARS-III scores of children with CP were investigated. It was found that they achieve significantly lower psychosocial adjustment scores when compared to healthy children $(p=0.00)$, especially on the domains peer relations $(p=0.00)$, anxiety/depression $(\mathrm{p}=0.00)$, withdrawal $(\mathrm{p}=0.00)$, and productivity $(\mathrm{p}=$ 0.02). Overall, they did not differ significantly from boys with DMD ( $p=0.93)$, however, they scored significantly lower on the domain peer relations $(\mathrm{p}=$ $0.03)$.

It was found that the patient characteristics most predictive for lower PARSIII domain and total scores were less gross motor function, a lower level of hand function, less communication skills, and bilateral spastic CP. Put together in a model, these four patient characteristics could explain a significant proportion (36\%) of the variation in PARS-III total scores.

It was concluded that the PARS-III questionnaire for parents can be used in children with $\mathrm{CP}$. Using this questionnaire, it was found that children with $\mathrm{CP}$ 
achieve lower psychosocial adjustment scores when compared to healthy children, especially in the domains peer relations, anxiety/depression, withdrawal, and productivity. It was suggested that a better understanding of why and when children with CP develop psychosocial maladjustment could lead to opportunities to alter the course of coping and therefore improve their quality of life (QoL).

The most common motor problem in children with $\mathrm{CP}$ is spasticity. Besides intrathecal Baclofen (ITB), selective dorsal rhizotomy (SDR) is one of the most commonly performed neurosurgical procedures. As multi-level laminectomies at the L1-S1 level are often required, the procedure is invasive and can lead to complications as transient urinary incontinence, chronic low back pain, and spinal deformity. Furthermore, considerable cooperation of the patient is required to successfully complete the postoperative rehabilitation program. We hypothesized a percutaneous radiofrequency lesion of the dorsal root ganglion (RF-DRG) to be a simple and safe alternative treatment. In chapter IV the pilot study undertaken to test this hypothesize is reported. The RF-DRG treatment was considered by the multi-disciplinary spasticity management team of the MUMC in children with severe hip flexor / adductor spasms accompanied by pain and / or care giving difficulties. During this pilot study a total of 19 RF-DRG procedures were performed in 17 children.

The first six children were systematically evaluated at baseline, and 1 month and 6 months after treatment by means of the Modified Ashworth Scale (MAS), the Gross Motor Function Measure (GMFM), and a caregiver's questionnaire. An improvement in muscle tone after RF-DRG was identified on both the short (1 month) and long ( 6 months) term using the MAS. No functional improvement on the GMFM could be detected. Using the caregiver's questionnaire, improvements in ease and quality of care and pain were found.

The following 11 children were evaluated at 6 weeks and 3 months after intervention using a Visual Analogue Scale (VAS), which was used to measure change on individually formulated treatment goals. We changed the evaluation methods, as we were not able to detect the kind of change that the caregivers unanimously did notice. Furthermore, studies were being published that showed that the MAS and the GMFM are not suitable to measure changes in these severely handicapped children. The VAS scores showed improvement on most of the defined treatment goals in most children. Most parents reported that the positive effects of the RF-DRG lasted at least 6-9 months.

It was concluded that RF-DRG is a promising new treatment option for severe spasticity in children with $\mathrm{CP}$. The main advantages are its less invasive character compared to the SDR with the potential benefit of a shorter hospitalization period, and its clear pain-reducing effect. We suggested a randomized controlled trial to define its definitive effectiveness. 
Less common than the spastic subtype of $\mathrm{CP}$ is the dyskinetic subtype. Its pathophysiology is not fully elucidated, but existing evidence suggests that dysfunction of the basal ganglia (BG) plays a role in this entity. As with most diseases in which the causes are not yet fully understood, the symptomatic treatment of this movement disorder remains very difficult. Several anticonvulsants seem to be efficacious for the treatment of (paroxysmal) involuntary movement disorders. On the basis of a recent report about Levetiracetam (LEV) efficacy in the treatment of movement disorders, we started LEV in two female patients (aged 5 and 8 years) with dyskinetic CP unresponsive to conventional drugs mostly used in such cases. These 2 cases are described in chapter V. Both patients experienced severe perinatal asphyxia and subsequently developed dyskinetic $\mathrm{CP}$, clinically characterized by choreoathetosis. Neuropsychological testing of these children showed a low average developmental quotient and no attentional deficits. Monotherapy with LEV was initiated to improve balance control and fine motor skills. Treatment was evaluated by use of video analysis and VAS. In both children an impressive improvement of balance control and fine motor skills was observed. No side-effects occurred. Furthermore, both patients showed more interest for and pleasure during activities according to their parents. During multidisciplinary evaluations of the initiated therapy, the parents, the therapist, and the rehabilitation doctor all confirmed that the effect initially observed was still present at 14 respectively 26 months after commencement of therapy. This is the first report suggesting that LEV may be used as an alternative to treat unmanageable choreoathetosis of a non-progressive kind, e.g. in children with dyskinetic CP. This is important because choreoathetosis appears to be a very severe and disabling condition which is difficult to treat. This could partly be due to the differences in pathophysiology between the two aspects of the condition, i.e. athetosis can be treated by increasing dopaminergic activity in the BG, while chorea can be treated by decreasing dopaminergic activity. These findings and our results suggest that LEV might reduce choreoathetosis by means of another pathway. So far, the synaptic vesicle protein SV2A has been identified as the binding site for LEV, but the molecular action of SV2A is still unknown.

Further and larger studies are needed to confirm the positive effects of LEV on choreoathetosis in patients with a non-progressive, non-paroxysmal, dyskinetic movement disorder.

When treating children with $\mathrm{CP}$, evaluation of treatment is essential. Furthermore, there is an increasing need for clinicians to evaluate their daily clinical practice. One of the most commonly performed treatments in children with $\mathrm{CP}$ is Botulinum toxin A (BTX-A) injections to reduce spasticity. The main problem is that there is no simple, quick, and useful outcome measure available to evaluate these kinds of treatments. In spite of its clear limitations, the standard clinical scale for measuring spasticity remains the Ashworth Scale. However, the Ashworth Scale does not measure spasticity exclusively, it has low inter-rater reliability, and it lacks precision and sensitivity for measuring smaller changes 
in spasticity. Although the GMFM is widely accepted as the best available quantitative measure for gross motor function in $\mathrm{CP}$, it is of limited value when assessing functional benefits in severely affected children. In chapter VI we hypothesized that a simple VAS could be a quick and useful tool to evaluate the effects of BTX-A injections on spasticity in daily clinical practice. Therefore, we prospectively collected data on 55 children with CP (25 males; 30 females) with a mean age of 8.3 years (SD 3.3) who were carefully selected by a multi-disciplinary team of specialists to be treated with BTX-A injections. Goals for BTX-A treatment were defined in close consultation with the parents / caregivers and the children themselves. Treatment goals were improvement of pain, problems with nursing, sitting position, standing, and walking. On the day of the intervention, the caregivers were asked to score the present situation for the selected treatment goals on a VAS ( $0=$ very satisfied; $10=$ very dissatisfied). VAS scores and side-effects were assessed at follow-up 6 and 12 weeks after treatment. Furthermore, for children who where able to walk three clinical examinations of tone (passive range of motion (PROM), angle of catch (AOC), and the Modified Tardieu) were performed for the hamstrings and gastrocnemius muscles.

Seventy-four interventions were performed in 55 children. The most frequently formulated goal was improvement of walking (56 times), followed by improvement of nursing (24 times) and improvement of standing (15 times). A statistically significant effect was found for improvement of care $(\mathrm{p} \leq 0.00)$, standing $(\mathrm{p} \leq 0.00)$, and walking $(\mathrm{p} \leq 0.00)$. No statistically significant effect was found for pain ( $\mathrm{p}=0.18)$, probably because of small numbers. The VAS was positively but not significantly correlated to the PROM for both muscle groups and to the AOC for the hamstrings. There was a negative but not significant correlation between the VAS and the AOC of the gastrocnemius. The Modified Tardieu was positively correlated to the VAS for all muscles investigated and significant for the left gastrocnemius. In 36 of the 74 (48.6\%) interventions a positive effect was observed for more than 12 weeks.

We concluded that a VAS was able to measure treatment effect and that overall correlations with standard evaluation instruments were in the expected direction. Evaluating spasticity treatment with the use of the VAS has several important advantages. Firstly $\backslash$, it is a quick and easy method for evaluating treatment in an outpatient setting, in which time-consuming evaluations are not an option and where there is a need for these kinds of instruments. Secondly, it is a subjective measure of the effects that BTX-A treatment has had on individually chosen goals. Usually the patient and his/her caregiver(s) are the best judges of the severity of the spasticity, as they are the only people who can assess its impact on the daily life of the patient.

Besides evaluating the effect of BTX-A treatment on spasticity, the clinician has to be aware of possible side-effects. In the group of 55 children described in chapter VI side-effects were observed 7 times in five children treated with BTX- 
A injections. One of those side-effects was constipation. Chapter VII describes this up until now unknown side-effect of BTX-A treatment in this and two other patients treated with BTX-A injections. Constipation was observed within the first week of BTX-A treatment. In all three cases, this symptom resolved completely and almost simultaneously with disappearance of the therapeutic effects of BTX-A. Two patients received a second treatment and both presented the same autonomic cholinergic remote symptoms. The third patient refused a second treatment due to the side-effect noted earlier.

As the colon is not in close proximity to the injection sites, the constipation is most likely caused by a systemic effect of BTX-A. This presumption was made even more likely after electromyography (EMG) of the hypothenar muscles while stimulating the ulnar nerve at the wrist in 1 patient. The amplitude of the initial response was normal, but after prolonged $3 \mathrm{~Hz}$ stimulation a slight decrementing response occurred. An average of $11 \%$ decrement in amplitude was visible from sixth to eighth compound muscle action potentials. This indicates that fewer muscle fibers than normal responded to nerve stimulation during a train of stimuli, i.e. due to generalized blockage of acetylcholine release in nerve terminals.

We concluded that familiarity with this autonomic systemic side-effect of BTX-A is essential for clinicians treating patients already at risk for gastrointestinal dysfunction. Because the adverse effects were treatable and transitory, we suggested that constipation per se is not an absolute contra-indication, if from a therapeutic point of view, BTX-A is indicated.

Another, not yet discussed treatment option in the management of spastic CP is ITB therapy. A couple of years ago, Hoving et al performed methodologically well-designed studies on ITB therapy in 17 children with intractable spastic CP. Follow-up showed positive effects on pain, ease of care, and mental health to be present 1 year after pump implantation.

However, long-term results of ITB therapy in children with intractable spastic $\mathrm{CP}$ are still limited, especially with regard to outcomes relevant to the patient and his / her caregivers. Therefore, we re-evaluated these 17 patients 6-9 years (mean 7.5 years, SD 0.9) after commencement of treatment. The results can be found in chapter VIII.

The parents of these 17 children ( 9 girls, 8 boys; mean age 21.1 years, SD 3.1, 14-25; GMFCS level 3: $n=1$, level 4: $n=2$, level 5: $n=14$ ) filled out the Child Health Questionnaire (CHQ), current satisfaction on the VAS regarding previous set treatment goals, a questionnaire concerning functioning of their child, and a self-made questionnaire.

It was found that the CHQ and VAS scores had not changed significantly since 12 months post-implantation. The positive effects on pain, ease of care, and mental health were still present. Moreover, additional benefits had ap- 
peared i.e. significantly improved scores on the Parent Impact - Emotional subscale, Parent Impact - Time subscale, and the Physical Summary.

Although it seems that the effects eventually stabilize, minimal improvement can still be expected 12 months after pump-implantation, especially for individually defined treatment goals. Furthermore, it appears that improvements in terms of physical QoL (CHQ PhS) need more time to become evident. At 12 months post-implantation there was no statistically significant difference compared to baseline $(p=0.16)$; however, at present there is $(p=0.02)$.

Regardless of the side-effects, the complications, and the necessity of eventually substituting the pump, $94 \%$ of the care-givers would choose ITB therapy for their child again.

We concluded that this study confirmed the long-term beneficial effects of ITB-therapy in children with intractable spastic CP and should be considered as a first step towards studies with even longer and more extensive follow-up.

So far the emphasis of this thesis has been on the treatment and its evaluation of motor problems in children with CP. However, children with CP are often faced with a broad spectrum of accompanying problems, e.g. impairments of learning, hearing, vision, communication, sleep, sexual functioning, and seizure disorders. There is increasing interest in the consequences of the combination of motor problems and these accompanying problems on the QoL of these children with CP. Therefore, in chapter IX the QoL of all children with CP aged 8-18 years seen at the outpatient clinic is described.

Acting upon the largest study on QoL of children with CP so far (Study of Participation of Children with CP Living in Europe (SPARCLE), 7 European countries), we used the same QoL instrument, i.e. the KIDSCREEN-52. This is a modern, generic QoL instrument, which uses questions based on focus-groups with children and adolescents all over Europe. The KIDSCREEN-52 focuses entirely on subjective perceptions, has shown to possess excellent psychometric properties, can be used for both disabled and non-disabled children, and can be reported by both the children themselves and their caregivers.

The parents of all 81 children with CP aged 8-18 years seen at the outpatient clinic of the MUMC, were informed about the study and the parents of 80 children (31 girls, 49 boys; mean age 13.4 years, SD 2.98; 44\% wheelchair dependent; $55 \%$ cognitive levels below 70 ) were willing to participate. T-scores were used to compare the QoL of Dutch children with CP to the QoL of over 15.000 children from the general European population. It was found that Dutch children with CP are reported to have relatively low QoL in the physical wellbeing, social support \& peers, and social acceptance domains, but relatively high QoL in the parent relation \& home life and the school environment domains. For the physical well-being domain it was found that higher GMFCS level was associated with lower T-scores. Less communication skills and lower cognitive levels were associated with lower T-scores in the social support \& peers and school 
environment domains. Furthermore, parents with no educational qualification rated their childs QoL in the parent relation \& home life higher. For the social acceptance domain no associated factors could be identified.

We found it intriguing to see that these Dutch children with CP are reported to have significantly higher QoL in the school environment and parent relation \& home life domains and significantly lower QoL in the social support \& peers and social acceptance domains compared to a sample of European children from the general population. We came up with two possible, non-exclusive explanations for this pattern not observed in the European population of children with CP. First of all, living in the Netherlands holds the highest odds ratio of being bullied and this could explain why more Dutch children with CP than usual feel tormented, bullied, and rejected by peers. Secondly, qualitative research has shown that children with CP enjoy being on their own from time to time. This is in accordance with our PARS-III study (chapter III) in which it was shown that children with CP psychosocially adjust to their motor and accompanying problems by withdrawal, without establishing sufficient and comprehensive peer relations. Caregivers do not appreciate these attitudes and put substantial effort into creating opportunities for their child to be included socially. In other words, it is very well possible that low QoL on the social support \& peers and social acceptance domains is due to concerns of the caregivers rather than what the children experience themselves.

We concluded that these findings provide a better understanding of the QoL of Dutch children with CP and that they can be used to inform caregivers and service-providers, and to focus health programs aiming to increase QoL in this group of children towards identified problem domains. 

NEDERLANDSE SAMENVATTING 
NEDERLANDSE SAMENVATTING 
Dit proefschrift beschrijft klinische en therapeutische aspecten van cerebrale parese (CP). Verschillende aspecten van behandeling en evaluatie werden bestudeerd in de populatie kinderen met $\mathrm{CP}$ die gezien wordt op de polikliniek van het Maastricht University Medical Centre (MUMC).

$\mathrm{CP}$ is een groot gezondheidsprobleem. Het wordt gezien bij 1 op de 400 nieuwgeborenen waardoor het de meest voorkomende ontwikkelingsstoornis is die gepaard gaat met levenslange handicaps. De definitie van CP stelt dat het een niet-progressieve bewegings- en houdingsstoornis is t.g.v. schade aan het zich ontwikkelende brein van de foetus of het jonge kind. Naast motorische problemen ontwikkelen kinderen met CP vaak leerstoornissen, epileptische stoornissen en problemen ten aanzien van het gehoor, visus of communicatie.

Als eerste onderdeel van dit proefschrift werd gekeken hoe deze kinderen omgaan met hun vaak ernstige handicaps en beperkingen. In hoofdstuk III wordt de psychosociale aanpassing van kinderen met CP beschreven. Het grootste probleem in dit onderzoeksgebied is dat er maar weinig gestandaardiseerde instrumenten zijn die specifiek ontwikkeld zijn om psychosociale aanpassing bij kinderen met een chronische aandoening te onderzoeken. Een zeer geschikte, maar nog niet eerder voor kinderen met CP gebruikte vragenlijst is de Psychosocial Adjustment and Role Skills Scale III (PARS-III). De ouders van alle 94 kinderen (4-18 jaar oud) die gezien worden op de polikliniek van het MUMC werden gevraagd om deel te nemen aan de studie. Op één na gaven alle ouders toestemming en kregen de PARS-III vragenlijst toegestuurd. De groep van 93 kinderen bestond uit 59 jongens en 34 meisjes. De gemiddelde leeftijd bedroeg 12.3 jaar (SD 3.8; 4-18). Vierenveertig procent van de kinderen was rolstoelgebonden en $52 \%$ had een cognitief niveau onder de 70 . Als referentie werd de psychosociale aanpassingsdata van 95 gezonde kinderen en 63 jongen met Duchenne's Musculaire Dystrofie (DMD) gebruikt. Omdat de PARS-III vragenlijst niet eerder gebruikt werd voor kinderen met $\mathrm{CP}$, moest in eerste instantie het gebruik ervan gerechtvaardigd worden. Testen lieten een goede interne consistentie zien: een Cronbach's alfa van 0.89. Confirmatory Factor Analysis bevestigde de 6 domeinstructuur van de PARS-III vragenlijst wanneer deze gebruikt wordt voor kinderen met CP. Vervolgens konden de PARS-III scores van kinderen met $\mathrm{CP}$ bestudeerd worden. Er werd gevonden dat ze lager scoorden qua psychosociale aanpassing dan gezonde kinderen $(p=0.00)$, m.n. op de domeinen "peer relations" ( $p=0.00)$, "anxiety/depression" ( $p=0.00)$, "withdrawal" ( $p$ $=0.00)$ en "productivity" $(p=0.02)$. Over het algemeen verschilden de kinderen met CP niet van jongens met DMD ( $p=0.93)$. Echter, wanneer men kijkt naar de verschillende domeinen van psychosociale aanpassing, scoorden de kinderen met CP significant lager dan jongens met DMD op het domein "peer relations" ( $\mathrm{p}$ $=0.03$ ). Middels univariate en multivariate (forward entry, dummy variables) regressie analyse werd gevonden dat grove motorische functie, mate van hand- 
functie, communicatie kunde en bilaterale $\mathrm{CP}$ de patiëntkarakteristieken waren met de grootste associatie met PARS-III scores. Wanneer men deze 4 patiëntkarakteristieken samen in een regressiemodel zet, kan een significant gedeelte (36\%) van de variatie in PARS-III scores verklaard worden.

De conclusie luidde dat de PARS-III vragenlijst voor ouders bruikbaar is voor het meten van psychosociale aanpassing in kinderen met CP. Middels deze vragenlijst toonden wij aan dat kinderen met $\mathrm{CP}$ lager scoorden qua psychosociale aanpassing dan gezonde kinderen, m.n. op de domeinen "peer relations", "anxiety/depression", "withdrawal" en "productivity". Een beter begrip van onjuiste psychosociale aanpassing kan mogelijkheden bieden tot het optimaliseren van copingsmechanismen bij deze kinderen met een chronische aandoening. Dit kan vervolgens bijdragen aan een betere kwaliteit van leven (QoL).

Het meest voorkomende motorische probleem bij kinderen met CP is spasticiteit. Indien er sprake is van ernstige spasticiteit, kan neurochirurgisch ingrijpen noodzakelijk zijn. Naast intrathecale Baclofen (ITB) behandeling, is selectieve dorsale rhizotomie (SDR) één van de meest uitgevoerde neurochirurgische procedures. Hierbij zijn vaak laminectomieën op meerdere niveaus van L1-S1 nodig en tevens bestaat er een aanzienlijk risico op tijdelijke urine incontinentie, chronische lage rugpijn en spinale deformiteiten. Verder is er een aanzienlijke medewerking van de patiënt nodig om het intensieve post-operatieve revalidatietraject succesvol te doorlopen. Wij veronderstelden dat een percutane radiofrequente laesie van het achterste wortel ganglion (RF-DRG) een simpel en veilig alternatief zou kunnen vormen voor SDR. In hoofdstuk IV wordt deze hypothese getoetst middels een pilot studie. Een RF-DRG behandeling werd door de multi-disciplinaire spasticiteitswerkgroep van het MUMC overwogen bij kinderen met ernstige heup flexor / adductor spasmes die gepaard gingen met pijn of moeilijkheden rondom de verzorging. Uiteindelijk werden gedurende deze pilot studie bij 17 kinderen 19 RF-DRG behandelingen uitgevoerd. De eerste 6 kinderen werden systematisch geëvalueerd vlak voor de start van behandeling en 1 en 6 maanden na behandeling. Evaluatie geschiedde middels de Modified Ashworth Scale (MAS), de Gross Motor Function Measure (GMFM) en een zelfde gemaakte vragenlijst voor verzorgers. De MAS liet een verbetering van spiertonus na RF-DRG behandeling zien op zowel de korte (1 maand) als de lange (6 maanden) termijn. Op het gebied van functie kon geen verbetering worden gevonden middels de GMFM. De zelfgemaakte vragenlijst voor verzorgers liet een verbetering zien in het gemak en de kwaliteit van verzorging en een vermindering van pijn.

De volgende 11 kinderen werden geëvalueerd middels een Visual Analogue Scale (VAS). Deze werd voor aanvang van de behandeling en vervolgens 6 weken en 3 maanden na behandeling gescoord voor individueel gestelde behandeldoelen. Wij achtten deze verandering van evaluatiemethode noodzakelijk daar we met behulp van de gebruikte evaluatie instrumenten niet in staat waren 
de effecten van behandeling te detecteren die de verzorgers van deze kinderen unaniem wel aangaven. Daarbij kwam dat er in de literatuur studies verschenen die lieten zien dat de MAS en de GMFM niet geschikt waren om effect van behandeling te evalueren bij deze groep van ernstig gehandicapte kinderen. De VAS scores lieten verbetering zien bij de meeste van de van tevoren vastgestelde doelen. Volgens het merendeel van de ouders waren de effecten de RF-DRG behandeling 6 tot 9 maanden later nog steeds aanwezig.

De conclusie naar aanleiding van deze pilot studie luidde dat RF-DRG een veelbelovende mogelijkheid is voor de behandeling van ernstige spasticiteit bij kinderen met CP. De grote voordelen zijn het minder invasieve karakter van RFDRG t.o.v. SDR, een mogelijk kortere opnameduur en een duidelijk pijnverminderend effect. Een RCT is nodig om de definitieve plaats van RF-DRG bij de behandeling van spastische $\mathrm{CP}$ te bepalen.

Een subtype van CP dat minder vaak voorkomt dan spastische CP is dyskinetische CP. De pathofysiologie van dyskinetische CP is vooralsnog niet geheel opgehelderd. Huidige literatuur suggereert een dysfunctioneren van de basale ganglia (BG) als oorzaak voor de klinische symptomen. Net zoals als geldt voor andere ziektes waarbij de oorzaak onduidelijk blijft, is de symptomatische behandeling van deze bewegingsstoornis vaak erg moeilijk. Enkele anti-epileptica lijken werkzaam in de behandeling van (paroxysmale) onvrijwillige bewegingsstoornissen. Naar aanleiding van een recent case report over de werkzaamheid van Levetiracetam (LEV) bij bewegingsstoornissen, startten wij LEV bij twee meisjes ( 5 en 8 jaar oud) die niet reageerden op de conventionele medicatie voor dit type aandoening. Deze twee casussen worden beschreven in hoofdstuk V. Beide meisjes maakten perinataal ernstige asfyxie door en ontwikkelden vervolgens dyskinetische CP die klinisch gekenmerkt werd door choreoathetosis. Neuropsychologisch onderzoek van deze kinderen wees uit dat er sprake was van een laagnormaal ontwikkelingsniveau zonder aandachtsstoornissen. Monotherapie met LEV werd gestart om balans en fijne motoriek te verbeteren. Effect van behandeling werd geëvalueerd aan de hand van videoanalyse en VAS scores. Bij beide kinderen werd een indrukwekkende verbetering geconstateerd op het gebied van balans en fijne motoriek. Er traden geen bijwerkingen op. Verder gaven de ouders aan dat de kinderen meer interesse hadden gekregen voor activiteiten en hiervan ook meer plezier ondervonden. Tijdens een recente multidisciplinaire evaluatie van de therapie, 14 en 26 maanden na start van de medicatie, waren de ouders, de artsen en de fysiotherapeuten het met elkaar eens dat het effect van behandeling nog steeds aanwezig was.

Dit zijn de eerste twee casussen die suggereren dat LEV mogelijk een alternatieve behandelmogelijkheid is voor non-progressieve choreoathetosis, zoals die bij kinderen met dyskinetische CP. Dit is belangrijk daar choreathetosis een sterk invaliderende en moeilijk te behandelen aandoening is. Dit is mogelijk terug te voeren op de verschillen in pathologie tussen de twee aspecten van het 
ziektebeeld. Athetosis kan namelijk verminderd worden door dopaminerge activiteit in de BG te verhogen, terwijl chorea verminderd kan worden door dopaminerge activiteit in de BG juist te verlagen. Deze bevindingen en de door ons beschreven casussen suggereren dat LEV choreoathetosis mogelijk middels een andere pathway vermindert. Men heeft de bindingsplaats voor LEV inmiddels achterhaald (synaptic vesicle protein SV2A), echter het moleculaire werkingsmechanisme van dit eiwit is vooralsnog onbekend.

Toekomstige, goed opgezette studies zijn nodig om het positieve effect van LEV op choreo-athetosis bij patiënten met een non-progressieve, nonparoxysmale, dyskinetische bewegingsstoornis te bevestigen.

Wanneer men kinderen met CP behandelt, is evaluatie van deze behandeling essentieel. Hier bovenop komt dat er tegenwoordig onder dokters een grote behoefte aan het evalueren van hun dagelijkse klinische praktijk bestaat. Een van de meest uitgevoerde behandelingen bij kinderen met $\mathrm{CP}$ is het injecteren van Botulinum toxine A (BTX-A) met als doel spasticiteit te verminderen. Het grootste probleem is echter dat er geen simpele, snelle en zinvolle methode beschikbaar is om dit type behandelingen te evalueren. Ondanks zijn duidelijke beperkingen, wordt de Ashworth Scale voor dit doeleinde nog steeds het meest gebruikt. Echter, de Ashworth Scale meet niet enkel spasticiteit, heeft een lage inter-rater betrouwbaarheid en is niet in staat om kleine veranderingen in spasticiteit op te pikken. Ondanks dat de GMFM wereldwijd als beste kwantitatieve instrument wordt beschouwd voor het meten van grof motorisch functioneren, heeft deze maar beperkte waarde wanneer het gaat om ernstig beperkte kinderen. In hoofdstuk VI veronderstelden wij dat een simpele VAS een eenvoudig, snel en zinvol instrument zou kunnen zijn om de effecten van BTX-A behandeling van spasticiteit te evalueren. $\mathrm{Om}$ dit te onderzoeken verzamelden we prospectief data van 55 kinderen met CP (25 jongens; 30 meisjes) met een gemiddelde leeftijd van 8.3 jaar (SD 3.3) die zorgvuldig geselecteerd werden door een multi-disciplinaire spasticiteitswerkgroep om behandeling middels BTX-A injecties te ondergaan. Doelstellingen van behandeling werden samen met de ouders / verzorgers en de kinderen vastgesteld. De categorieën waarop verbetering werd nagestreefd betroffen pijn, verzorging, zitten, staan en lopen. Op de dag van behandeling werd aan de ouders / verzorgers gevraagd om op een VAS de huidige situatie per categorie te scoren. Hierbij betekende een score van 0 op de VAS dat de huidige situatie totaal niet problematisch was en een score van 10 dat de huidige situatie problematischer kon zijn. Zes en 12 weken na start van behandeling werden wederom VAS scores bepaald en werd er gekeken of er bijwerkingen waren opgetreden. Verder werd er voor kinderen die konden lopen 3 klinische onderzoeken van tonus verricht (passive range of motion (PROM), angle of catch (AOC) en Modified Tardieu) voor de hamstrings en de gastrocnemius spieren. 
Bij 55 kinderen werden uiteindelijk 74 interventies verricht. Bij sommige kinderen werd van tevoren meer dan één doel gesteld. De meest geformuleerde doelstelling was het verbeteren van lopen (56 keer), gevolgd door het verbeteren van verzorging ( 24 keer) en verbeteren van staan ( 15 keer). Een statistisch significant effect van behandeling werd gevonden voor verbetering van verzorging $(p \leq 0.00)$, staan $(p \leq 0.00)$ en lopen $(p \leq 0.00)$. Waarschijnlijk t.g.v. het kleine aantal patiënten bij wie vermindering van pijn werd nagestreefd, werd er geen significant effect voor deze doelstelling gevonden $(p=0.18)$. De VAS liet een positieve, maar statistisch geen significante correlatie zien met de PROM voor de twee spiergroepen en met de AOC voor de hamstrings. Er was sprake van een negatieve, maar statistisch geen significante correlatie tussen de VAS en de AOC voor de gastrocnemius. De Modified Tardieu was positief gecorreleerd aan de VAS voor de onderzochte spiergroepen en significant m.b.t. de linker gastrocnemius. In 36 van de 74 (48.6\%) interventies werd geconstateerd dat het positieve effect van behandeling langer dan 12 weken aanhield.

We concludeerden dat een simpele VAS in staat was om effect van behandeling te meten en dat de correlaties met de conventionele evaluatie methoden in de te verwachten richting waren. Het evalueren van spasticiteit met gebruik van een VAS heeft een aantal belangrijke voordelen. Ten eerste is het een snelle en eenvoudige methode voor het evalueren van behandeling tijdens een poliklinisch spreekuur, waar ingewikkelde en tijdrovende evaluatiemethoden nu eenmaal geen optie zijn. Ten tweede meet een VAS op een subjectieve manier het effect van behandeling op vooraf gestelde doelen. Het is bekend dat de patiënt en zijn of haar ouders / verzorgers de beste beoordelaars zijn van de spasticiteit, daar zij de enige zijn die in staat zijn om de impact op het dagelijks leven in te schatten.

Naast het evalueren van het effect van BTX-A behandeling, moet de behandelend arts ook aandacht hebben voor mogelijke bijwerkingen. In de groep van 55 kinderen die beschreven wordt in hoofdstuk VI werden bij 5 kinderen in totaal 7 bijwerkingen geconstateerd na behandeling met BTX-A injecties. Bij één kind trad constipatie op als bijwerking. In hoofdstuk VII wordt deze vooralsnog onbekende bijwerking van BTX-A behandeling beschreven bij dit kind en nog 2 andere jongvolwassenen die ook behandeld werden met BTX-A.

Constipatie werd in alle 3 de gevallen binnen 1 week na behandeling geconstateerd. Deze bijwerking verdween uiteindelijk volledig en dit ging samen met het verdwijnen van de gunstige effecten van de BTX-A injecties. Twee patiënten ondergingen een tweede serie van BTX-A injecties en weer traden dezelfde autonome cholinerge bijwerkingen op. De derde patiënt weigerde een vervolgbehandeling i.v.m. de destijds opgetreden constipatie.

Het colon is niet nabij de injectieplaatsen gelegen en daarom is de constipatie het beste te verklaren als een systemische bijwerking van de BTX-A behandeling. Deze aanname werd nog waarschijnlijker gemaakt door het verrichten van 
een EMG studie in 1 patiënt. Er werd een EMG gemaakt van de hypothenaire spieren terwijl de nervus ulnaris t.h.v. de pols gestimuleerd werd. De amplitudo van het initiële signaal was normaal, maar na langer durende stimulatie $(3 \mathrm{~Hz})$ trad een licht decrement in amplitudo op. Een gemiddelde van $11 \%$ decrement in amplitudo was zichtbaar van de zesde tot de achtste compound van actiepotentialen. Dit duidt erop dat minder spiervezels dan normaal reageren op een zenuwprikkel tijdens een reeks van stimuli. Oorzaak hiervoor is een algehele blokkade van acetycholine vrijkomst in de zenuwuiteinden.

We concludeerden dat kennis van deze autonome en systemische bijwerking van BTX-A behandeling belangrijk is voor behandelaars van deze kinderen die sowieso al een grotere kans op gastro-intestinaal disfunctioneren hebben. Omdat de bijwerkingen goed te behandelen waren en van voorbijgaande aard bleken, stelden we voor dat constipatie an sich niet als absolute contra-indicatie beschouwd dient te worden in geval BTX-injecties therapeutisch geïndiceerd zijn.

Een andere, tot dusver niet besproken behandeloptie van spasticiteit bij kinderen met CP is ITB behandeling. Een aantal jaar geleden, verrichtten Hoving et al methodologisch zeer goed opgezette studies naar ITB behandeling bij 17 kinderen met CP met moeilijk behandelbare spasticiteit. Follow-up liet zien dat positieve effecten op pijn, verzorgingsgemak, and "mental health" nog steeds aanwezig waren 1 jaar na pomp-implantatie.

Echter, lange termijnsresultaten van ITB behandeling bij kinderen met CP met moeilijk behandelbare spasticiteit ontbreken vooralsnog. Daarom herevalueerden wij de 17 patiënten beschreven door Hoving et al 6-9 jaar (gemiddeld 7.5 jaar, SD 0.9) na start van behandeling. De resultaten staan beschreven in hoofdstuk VIII.

Aan de ouders van deze 17 kinderen ( 9 meisjes, 8 jongens, gemiddelde leeftijd 21.1 jaar, SD 3.1, 14-25; GMFCS level 3: $n=1$, level 4: $n=2$, level 5: $n=14$ ) werd gevraagd verschillende vragenlijsten in te vullen, te weten de Child Health Questionnaire (CHQ), een functioneringsvragenlijst, een zelf gemaakte vragenlijst en hun huidige tevredenheid op een VAS m.b.t. de doelen gesteld voor aanvang van behandeling.

Eén ouder stuurde de CHQ niet terug. Alle overige data waren beschikbaar voor analyse.

Analyse liet dat CHQ en VAS scores niet significant veranderd waren t.o.v. de laatste evaluatie 12 maanden na pomp plaatsing. De positieve effecten op pijn, verzorgingsgemak en "mental health" waren nog steeds aanwezig. Bovendien waren er ook op andere schalen significante verbeteringen duidelijk geworden: de Parent Impact - Emotional subschaal, Parent Impact - Time subschaal en de Physical Summary. 
Alhoewel het lijkt dat het behandeleffect na verloop van tijd stabiliseert, mag men toch ook nog 12 maanden na pomp plaatsing kleine verbeteringen verwachten, m.n. m.b.t. de individueel gestelde behandeldoelen.

Verder lijkt het erop dat verbetering op de Physical Summary meer tijd nodig had om tot stand te komen. Twaalf maanden na pomp plaatsing was er namelijk nog geen statistisch significant effect zichtbaar ( $p=0.16)$, maar inmiddels wel $(\mathrm{p}=0.02)$.

Ondanks de bijwerkingen, de complicaties, en de noodzaak om uiteindelijk de pomp te vervangen, zou $94 \%$ van de ouders / verzorgers opnieuw voor ITB behandeling voor hun kind kiezen.

Wij concludeerden dat deze studie de positieve effecten van ITB behandeling van kinderen met CP op de lange termijn bevestigt. Deze studie moet gezien worden als een eerste stap richting nog langere en uitgebreide follow-up studies.

Tot dusver heeft dit proefschrift zich gericht op de behandeling van motorisch problemen bij kinderen met $\mathrm{CP}$ en de evaluatie hiervan. Echter, kinderen met $\mathrm{CP}$ worden geconfronteerd met meer dan enkel motorische problematiek. Leerstoornissen, epileptische stoornissen, problemen met het gehoor, zicht of communicatie, slaapproblemen en sexuele problematiek zijn aan de orde van de dag. $\mathrm{Er}$ is de laatste jaren in de literatuur in toenemende mate belangstelling voor de gevolgen die deze combinatie van motorische en bijkomende problematiek heeft op de QoL van deze kinderen. Daarom wordt in hoofdstuk IX de QoL van alle kinderen met CP die gezien worden op de poli van het MUMC beschreven.

In navolging van de tot nu toe grootste studie naar de QoL van kinderen met CP (Study of Participation of Children with CP Living in Europe (SPARCLE), 7 Europese landen), gebruikten ook wij de KIDSCREEN-52 vragenlijst om QoL te meten. Dit is een moderne, generieke QoL vragenlijst die gebruik maakt van vragen die ontwikkeld zijn in focus-groups met Europese kinderen en jongvolwassen. De KIDSCREEN-52 richt zich volledig op subjectieve percepties, heeft uitstekende psychometrische eigenschappen, kan gebruikt worden voor zowel geïnvalideerde als gezonde kinderen en kan door zowel kinderen zelf als door hun ouders ingevuld worden.

De ouders van alle 81 8-18 jarige kinderen met $\mathrm{CP}$ die gezien worden op de polikliniek van het MUMC werden geïnformeerd over de studie en de ouders van 80 kinderen (31 meisjes, 49 jongens; gemiddelde leeftijd 13.4 jaar, SD 2.98; $44 \%$ rolstoelgebonden; 55\% cognitieve niveau onder de 70) waren bereid mee te doen. Er werd gebruik gemaakt van T-scores om de QoL van Nederlandse kinderen met CP te vergelijken met de QoL van meer dan 15.000 Europese kinderen van de algemene populatie. Het bleek dat volgens hun ouders Nederlandse kinderen met CP relatief laag scoorden op de domeinen "physical well-being", "social support \& peers" en "social acceptance", terwijl ze juist hoog scoorden op de domeinen "parent relation \& home life" en "school environment". 
Hogere GMFCS levels waren geassocieerd met lagere T-scores op het domein "physical well-being". Minder communicatievaardigheden en een lager cognitief niveau waren geassocieerd met lagere T-scores op de domeinen "social support \& peers" en "school environment". Verder bleek dat ouders zonder vervolgopleiding hogere scores rapporteerden op het domein "parent relation \& home life". Geen van de onderzochte factoren waren geassocieerd met het domein "social acceptance".

Het fascineerde ons om te zien dat, in vergelijking met de Europese kinderen van de algemene populatie, deze Nederlandse kinderen met $\mathrm{CP}$ volgens hun ouders significant hogere QoL hadden op de domeinen "school environment" en "parent relation \& home life", maar significant lagere QoL hadden op de domeinen "social support \& peers" en "social acceptance". Twee mogelijke, elkaar niet uitsluitende verklaringen werden voor deze observatie aangedragen. Ten eerste, uit onderzoek is gebleken dat men in Nederland de hoogste odds ratio kent om gepest te worden, wat zou kunnen verklaren dat meer Nederlandse kinderen met CP dan gebruikelijk zich gepest, gekweld en afgewezen voelen.

Ten tweede, kwalitatief onderzoek heeft laten zien dat kinderen met CP van tijd tot tijd graag op zich zelf willen zijn. Dit is in overeenstemming met onze PARS-III studie waarin we vonden dat kinderen met CP zich psychosociaal aanpassen aan hun motorische en bijkomende problemen door zich terug te trekken en hierdoor ook weinig vriendschappen ontwikkelen. Ouders / verzorgers maken zich zorgen over dit terugtrekgedrag en stoppen veel moeite in het creeren van mogelijkheden voor hun kind om sociaal betrokken te worden. Met andere woorden, het is zeer wel mogelijk dat de lage QoL scores op de domeinen "social support \& peers" en "social acceptance" eerder te danken is aan de zorgen van de ouders / verzorgers dan aan ervaringen van kinderen zelf.

Wij concludeerden dat bovenstaande onderzoeksresultaten bijdragen aan een beter begrip van de QoL van Nederlandse kinderen met CP en dat deze informatie gebruikt kan worden om ouders en behandeld artsen te informeren. Verder kunnen hierdoor ook gezondheidsprogramma die beogen QoL in deze groep van kinderen te verbeteren, gericht worden op geïdentificeerd probleem domeinen. 


\section{DANKWOORD}


DAN KWOORD 
Dit proefschrift is tot stand gekomen vanuit een gezamenlijke inspanning door een aantal mensen van zeer verschillende disciplines.

Allereerst wil ik bedanken mijn vader. Hij stimuleerde mij al vroeg tijdens mijn studie geneeskunde om onderzoek te gaan doen. Iets waar ik hem eigenlijk nu pas voor het eerst voor bedank. Samen met je vader onderzoek doen, is iets waar velen over kunnen spreken, maar slechts enkelen over mee kunnen praten. Ik zal eerlijk zijn, het is een hele beproeving geweest. Veelvuldig heb ik mijn vader vervloekt als hij weer aan kwam zetten met een nieuwe deadline, een te bouwen database of de zoveelste stapel uitgeprinte artikelen. En dit niet alleen tijdens werkuren, maar ook thuis, vlak voor het voetballen of tijdens het houthakken. Achteraf gezien was dit een perfecte infrastructuur voor een jonge, onervaren onderzoeker.

Lieve pap, bedankt voor alles. Je was altijd bereid mijn artikelen te lezen en van commentaar te voorzien. Je bracht me in contact met neurologen, neurochirurgen, orthopeden, revalidatie-artsen, bewegingswetenschappers, fysiotherapeuten, statistici, etc. Je zorgde ervoor dat ik de moed erin hield als ik het even allemaal niet meer zag zitten en voor elk probleem had jij zo een oplossing. Jij excelleert als arts, wetenschapper, docent, mentor en bovendien als vader. Jij bent de promotor van mijn leven. Ik ben trots op jou.

Professor doctor Beuls, Emile, u bent vanaf het begin af aan bij mijn promotie betrokken geweest. Uw kritische blik is een enorme meerwaarde geweest. Van alle keren dat ik bij $\mathrm{u}$ thuis in Lanaken kwam, kan ik mij niet herinneren dat $\mathrm{u}$ ooit niet zat te studeren. Uw oneindige nieuwsgierigheid en leergierigheid werken aanstekelijk.

Professor doctor Van Oostenbrugge, Robert, u raakte pas in een later stadium bij mijn promotie betrokken en dat terwijl u vroeger al op mij als baby hebt gepast. U gaf mij de kans om als arts-onderzoeker binnen uw vakgroep mijn proefschrift af te ronden. Bedankt voor het geschonken vertrouwen.

Doctor Hendriksen, Jos, jij hielp mij op alle mogelijke gebieden. Met het opzetten van een studie, met de statistiek, met het interpreteren van resultaten, met het schrijven van een artikel en met het verwerken van commentaar. Wat je ook aan je hoofd had, je maakte altijd tijd voor me. Ontzettend bedankt voor de begeleiding op alle fronten.

Ruben, vriend, wat hebben wij lopen stoeien met die databasen en vragenlijsten, op jouw of mijn kamer, op het ziekenhuis en in Kempenhaeghe. Met jouw toewijding, je punctualiteit en het gemak waarmee je schrijft, zal jouw promotie niet lang op zich laten wachten. De databasen doen we niet meer, de biertjes wel.

Doctor de Louw, Anton, jij was de begeleider van mijn eerste artikel. Ik weet nog goed de woensdagen dat ik naar Wahlwiller reed om op jullie prachtige hoeve aan ons manuscript te werken. Jij leerde mij een artikel schrijven. 
Yvonne, jij introduceerde mij op het ganglab en bracht mij als eerste in contact met kinderen met CP. Jouw uitgebreide databasen zijn van onschatbare waarde geweest.

Dokter Kessels, Fons, met veel plezier kwam ik langs op jouw kamer met een statistische vraag. Je beantwoordde mijn vraag en zadelde mij vervolgens op met vele andere vragen over statistiek, onderzoek, de geneeskunde en het leven. Je stimuleerde mij om kritisch te denken.

Lisette, telkens weer kwam ik jou lastig vallen met kleine problemen en telkens weer nam jij de tijd om mij uit de brand te helpen. Jouw punctualiteit en taalgevoel maken elk artikel af. Ook ben ik je erg dankbaar voor een bepaald gesprek dat we ooit hadden.

Dan, bedankt voor alle hulp bij het verzamelen van de data. Jouw goede patiëntcontacten hebben zeker bijgedragen aan onze hoge participatie ratio's.

Leden van de leescommissie, bedankt voor het beoordelen en goedkeuren van mijn proefschrift.

Desiree, bedankt voor alle administratieve hulp bij mijn promotie.

De mensen van Datawyse, bedankt voor de hulp bij de omslag, de lay-out en het drukken van dit proefschrift.

Mijn moeder, mam, ik kan altijd op je rekenen. Je bent de meest zorgzame, geduldige, flexibele, warme en oprechte persoon die ik ken. Zowel pap als ik moeten regelmatig ons (tegenstrijdige) verhaal bij jou kwijt en jij weet dit telkens weer in goede banen te lijden. Jouw kookkunsten maken elke dag weer goed.

David, mijn broertje, zo vaak hielp jij mij uit de problemen als mijn computer weer eens kuren had. Ondanks dat ik de oudste ben, kijk ik op tegen jouw rust en jouw logische redeneerkunst. Je bent een topbroer.

Sophie en Annabel, trouwe viervoeters, zonder dat jullie het weten waren jullie van essentieel belang bij het tot stand komen van dit proefschrift. Zonder de uren die ik met jullie gevoetbald heb in de tuin had ik mijn statistiek nooit af kunnen krijgen.

Brenda, mijn mooie en lieve vriendin, jij bent er altijd voor me. Ontzettend lief dat je het feest wilde organiseren. 


\section{LIST OF PUBLICATIONS}


LIST OF PUBLICATIONS

152 
Vles GF, Soudant DL, Honving MA, Vermeulen RJ, Bonouvrié LA, Vles JSH. Longterm follow-up on intrathecal Baclofen therapy in non-ambulant children with intractable spastic CP. 2012. In preparation.

Vles GF, Hendriksen RGF, Hendriksen JGM, van Rak EPM, Vles JSH. Quality of life of children with Cerebral Palsy: A cross-sectional KIDSCREEN study in the Southern part of the Netherlands. 2012. Submitted.

Vles GF, Teernstra OP, Soudant DL. Intrathecal baclofen for progressive neurological disease in childhood. Eur J Paediatr Neurol. 2012 Feb 24.

Vles GF, Hendriksen RG, Vles JS, Kessels AG, Hendriksen JG. Psychosocial adjustment in a Dutch sample of children with CP. Eur J Paediatr Neurol. 2011

Vles GF, Vles JSH, van Kleef M, van Zundert J, Staal HM, Weber WEM, van Rhijn LW, Soudant D, Graham HK, de Louw AJ. Percutaneous radiofrequency lesions adjacent to the dorsal root ganglion alleviate spasticity and pain in children with cerebral palsy: pilot study in 17 patients. BMC Neurol. 2010: 22; 10:52.

Vles GF, Vles JSH. Constipation as an adverse event after Botulinum Toxin A treatment in children with Cerebral Palsy. Letter to the editor. Accepted for publication in Dev Med Child Neurol 2010. Dev Med Child Neurol. 2010: 52(10): 972

Vles GF, Vles JSH, Hermans MC, Faber CG, de Louw AJ, Martina JD. Constipation after Botulinum Toxin-A injection in lower and upper limb muscles: A transitory systemic autonomic adverse effect. Report of three cases. Journal of Experimental and Clinical Medicine 2009; 26: 47-51.

Vles GF, Hendriksen JG, Visschers A, Speth L, Nicolai J, Vles JS. Levetiracetam therapy for treatment of choreoathetosis in dyskinetic cerebral palsy. Dev Med Child Neurol. 2009 Jun;51(6):487-90.

Vles GF, de Louw AJ, Speth LA, van Rhijn LW, Janssen-Potten YJ, Hendriksen JG, Vles JS. Visual Analogue Scale to score the effects of Botulinum Toxin A treatment in children with cerebral palsy in daily clinical practice. Eur J Paediatr Neurol. 2008 May;12(3):231-8. 

CURRICULUM VITAE 
CURRICULUM VITAE 
Georges (Joris) Vles werd op 11 november 1986 geboren te Maastricht. Na het voltooien van zijn VWO aan het Jeanne d'Arc College, startte hij met de opleiding geneeskunde aan de Universiteit van Maastricht. In de zomer tussen zijn eerste en tweede jaar werd hij door zijn vader, hoogleraar kinderneurologie, gevraagd om onderzoeksgegevens in te voeren. De interesse voor het doen van onderzoek was gewekt en 2 jaar later publiceerde hij zijn eerste artikel. Tijdens de rest van zijn studie geneeskunde bleef onderzoek een belangrijke nevenactiviteit en groeide uiteindelijk uit tot een promotietraject onder leiding van Professior Beuls en later Professor van Oostenbrugge. Het laatste jaar van zijn studie spendeerde hij aan orthopedische chirurgie in het Atrium Medisch Centrum onder leiding van Dr. Heyligers. Na het afronden van zijn studie vertrok hij naar Seattle, Washington, om daar onder leiding van Prof. Conrad een stage kinderorthopedie en orthopedische oncologie te doen. Dit werd gevolgd door een kortdurend traject als arts-onderzoeker bij de vakgroep neurologie van het Academisch Ziekenhuis Maastricht ter voltooiing van zijn proefschrift. Per 1 januari 2012 startte Georges als assistent op de intensive care in het Atrium Medisch Centrum, het ziekenhuis waar hij een half jaar later zijn opleiding tot orthopedisch chirurg zal beginnen. 